\title{
ARTICLES
}

\section{VIEWPOINT DIVERSITY AND MEDIA CONSOLIDATION: AN EMPIRICAL STUDY}

\author{
Daniel E. Ho* \& Kevin M. Quinn**
}

One of the central predicates of legal regulation of media ownership is that ownership consolidation reduces substantive viewpoint diversity. Appellate

* Assistant Professor of Law \& Robert E. Paradise Faculty Fellow for Excellence in Teaching and Research, Stanford Law School, 559 Nathan Abbott Way, Stanford, CA 94305; Tel: 650-723-9560; Fax: 650-725-0253; Email: dho@law.stanford.edu, URL: http://dho.stanford.edu.

** Associate Professor, Department of Government and Institute for Quantitative Social Science, Harvard University, 1737 Cambridge Street, Cambridge, MA 02138; Tel: 617-495-4134; Fax: 617-496-5149; Email: kevin_quinn@harvard.edu, URL: http://www.people.fas.harvard.edu/ kquinn/.

We thank Patrick Behrer, Esther Cheng, Melissa Suzel Deas, Diana Dinh, Dominique Gracia, Max Haines-Stiles, Pete Mandel, Briggs Matheson, Monica Mleczko, Elizabeth McBride, Katie O'Banion, Dwight Pope, David Schwartz, Denise Sohn, Neal Ubriani, and especially Tim Shapiro for outstanding research assistance. For helpful conversations and comments, we thank David Abrams, Jon Adler, Enrique Armijo, Greg Crawford, Tino Cuéllar, Lee Epstein, Barbara Fried, Stephen Galoob, Seeta Peña Gangadharan, Paul Goldstein, Gillian Hadfield, Jay Hamilton, Deborah Hensler, Matt Hindman, Mark Kelman, Rod Kiewiet, Gary King, Jon Klick, Larry Kramer, David Law, Mark Lemley, Rick Lempert, Jonathan Levy, Kristin Madison, Anup Malani, Mat McCubbins, John McGinnis, Alison Morantz, Mark Nadel, Anne Joseph O'Connell, Gideon Parchomovsky, Nick Parrillo, Bob Rabin, Deborah Rhode, Jane Schachter, Tom Spavins, Matt Spitzer, Jeff Strnad, Mike Tomz, David Weisbach, Robert Weisberg, Abe Wickelgren, Simon Wilkie, Stephen F. Williams, Chris Yoo, and participants at the faculty workshops at Northwestern, Stanford, and University of Southern California Law Schools, the law and economics workshops at the University of Chicago Law School and the University of Pennsylvania Law School, the American Politics and Institutions Project at the University of California, San Diego, the applied statistics workshop at Harvard University, and a seminar at the Federal Communications Commission. Easy-to-use dynamic viewpoint software developed for this project, as well as replication materials, data, and viewpoint measures, will be made available upon publication for free at the author websites. This work was supported by the National Science Foundation (SES 03-50613 and SES 07-51834), the Stanford Law School, the Institute for Quantitative Social Science at Harvard University, and the Center for Advanced Study in the Behavioral Sciences at Stanford University. 
courts and, in turn, the Federal Communications Commission have increasingly demanded evidence for this convergence hypothesis, but extant empirical measures of viewpoint diversity sidestep the problem, ignoring diversity, viewpoints, or both. Our Article develops and offers a finely tuned, time-varying statistical measure of editorial viewpoint diversity, based on a new database of over 1600 editorial positions in twenty-five top newspapers from 1988-2004. Using this new measure, we assess the validity of the convergence hypothesis by examining the evolution of editorial viewpoints over the course of five major mergers and acquisitions. Our data reveal complex patterns that defy extant accounts, showing stability, convergence, and divergence of viewpoints in the face of-and depending on the circumstances of -consolidation. These findings fundamentally challenge extant empirical regulatory assumptions-pointing to the crucial role of editorial policies-and deeply inform the viability of the ownership regulations and the interpretation of the 1996 Telecommunications Act.

INTRODUCTION: THE DIVERSITY INDEX THAT DIDN'T INDEX DIVERSITY .............783

I. THE CONVERGENCE HYPOTHESIS ...............................................................787

A. Viewpoint Diversity and the Empirical Turn in the Law of Media .............789

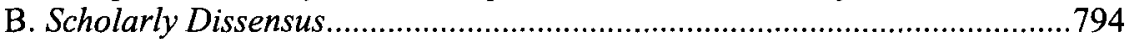

II. LIMITATIONS OF EXISTING MEASUREMENTS OF VIEWPOINT DivERSITY ............798

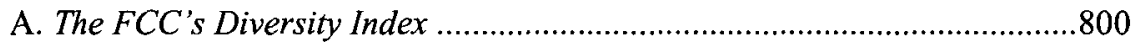

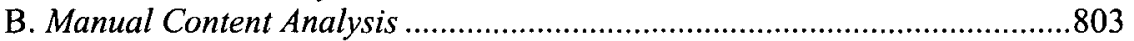

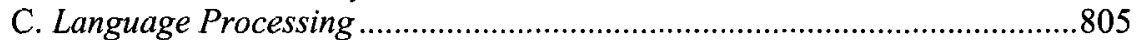

D. Political Endorsements ....................................................................809

III. EMPIRICALly CAPTURING SubSTANTIVE VIEWPOINT Diversity....................810

A. The Data: Supreme Court Editorials, 1988-2004 ..................................813

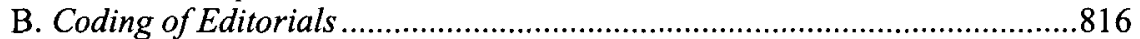

C. Statistical Inference of Viewpoint Diversity ...........................................819

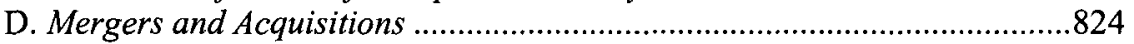

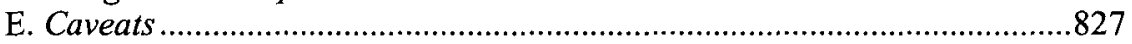

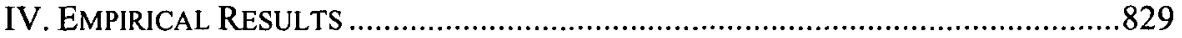

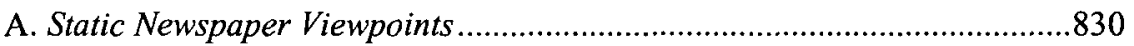

B. Time-Varying Newspaper Viewpoints ..........................................8. 832

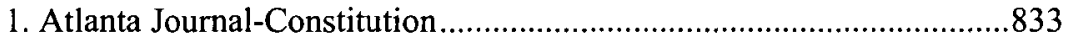

2. New York Times-Boston Globe .................................................837

3. Chicago Tribune-Los Angeles Times ..............................................838

4. Houston Chronicle-San Francisco Chronicle ..................................840

5. USA Today-Arizona Republic .................................................840

V. CONVERGENCE OR MONOPOLY DIVERSIFICATION? AN IN-DEPTH VIEW ...........841

A. Atlanta Journal-Constitution .............................................................843

1. Divergence in the face of common ownership .................................844

2. Viewpoint diversity in the face of convergence .................................850

B. New York Times-Boston Globe........................................................856

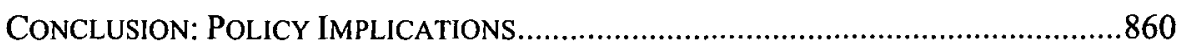

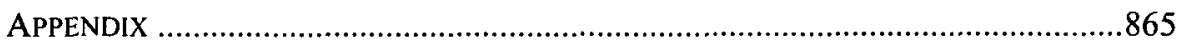

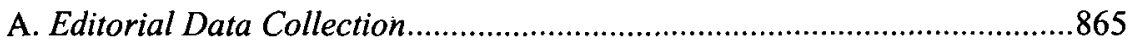

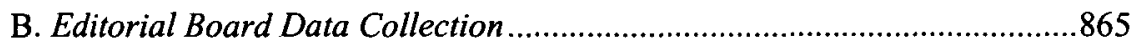

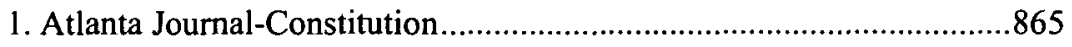


2. Boston Globe 865

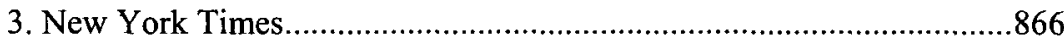

C. Dynamic Item-Response Theoretic Model...................................................866

\section{INDEX OF FIGURES AND TABLES}

Figure 1. Illustration of Diversity Index from Appendix C of Biennial Order ..... 802 Figure 2. Illustration of Word Frequency "Cosine (Dis)similarity" ..................... 807 Figure 3. Halavais Dissimilarity Methods Applied to Supreme Court Editorials

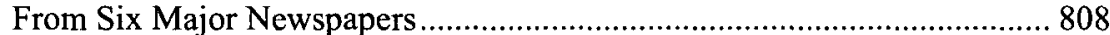

Figure 4. Presidential Endorsements of Major Newspapers, 1992-2004.............. 810

Table 1. Newspapers, Abbreviations, and Supreme Court Terms Covered.......... 814

Figure 5. Supreme Court Editorial Publication Rates by Newspaper and

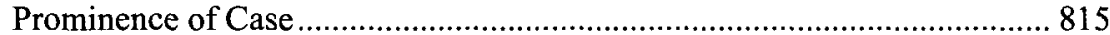

Figure 6. Editorial Coverage of the Supreme Court by Term.............................. 816

Figure 7. Direction Position of Newspapers on the Legal Merits.......................... 818

Figure 8. Fraction of Conservative Decisions on Cases from 1994-2004 Terms for

Justices and Newspapers ........................................................................ 820

Figure 9. Fraction of Conservative Decisions by Term for Selected Justices and

Newspapers, 1994-2004 ....................................................................... 822

Figure 10. Illustration of Model-Based Differential Weighting of Votes with Four

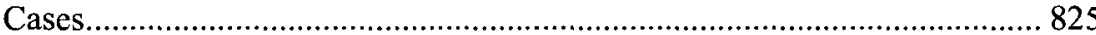

Figure 11. Editorial Viewpoints and Judicial Ideal Points from Pooled Analysis of

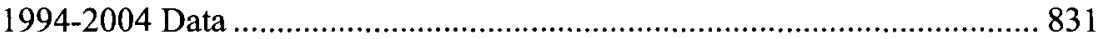

Figure 12. Dynamic Editorial Viewpoint Estimates for 25 Major Newspapers,

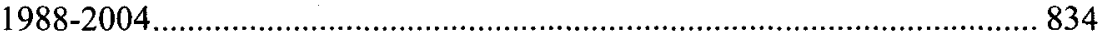

Figure 13. Viewpoint Estimates for the Atlanta Constitution (solid), Atlanta

Journal (overlaid), and the Atlanta Journal-Constitution ............................. 836

Figure 14. Viewpoint Estimates for the Boston Globe (solid) and the New York

Times (overlaid).

Figure 15. Viewpoint Estimates for the Chicago Tribune (solid) and the Los

Angeles Times (overlaid) ........................................................................ 839

Figure 16. Viewpoint Estimates for the Houston Chronicle (solid) and the San

Francisco Chronicle (overlaid) ...

Figure 17. Viewpoint Estimates for the Arizona Republic (solid) and USA Today (overlaid)

Figure 18. Circulation for the Atlanta Journal (top-left), the Atlanta Constitution

(top-middle), and the Atlanta Journal-Constitution (top-right).................... 842

Figure 19. Nationwide Circulation Trends in the Newspaper Industry ................. 844

Figure 20. Median Household Income in Atlanta Journal-Constitution Designated

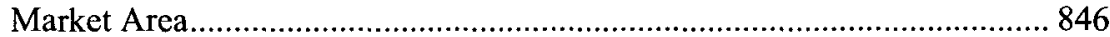

Figure 21. Geographic Readership Distribution of the Journal and Constitution 848

Figure 22. Readership Substitution in Largest Counties ...................................... 849

Figure 23. Editorial Board Composition for the Journal and Constitution ...........851

Table 2. Distribution of Editorial Positions on Supreme Court Cases for All Types

of Opinion Pieces in the Atlanta Journal-Constitution Papers, 1994-2008.. 854

Figure 24. Viewpoint Estimates for Cynthia Tucker and Jim Wooten 
Figure 25. Circulation (in 10,000s) for the New York Times (left) and Boston Globe

(right).

Figure 26. Circulation (in 10,000s) for the Times (black) and Globe (gray) for

Sunday (solid) and Weekday (dashed) Editions

Figure 27. Editorial Board Membership of the Globe 860

Figure 28. Editorial Board Membership for the Times 861

\section{INTRODUCTION: THE DIVERSITY INDEX THAT DIDN’T INDEX DIVERSITY}

It is a rare federal rulemaking that unifies the National Rifle Association, Catholic Conference of Bishops, MoveOn, National Organization for Women, and Common Cause. Together this motley crew rallied its troops, leading to the submission of over 500,000 comments to the Federal Communications Commission's (FCC) review of media ownership regulations in 2002. The large majority of these comments opposed the proposed relaxation of the FCC's ownership regulations, which restrict the number and types of media outlets a single entity can own. FCC Chairman Michael K. Powell wasn't so much moved by the submissions: "You don't govern just by polls and surveys." 1

Yet Powell proceeded to do just that, albeit in an unexpected fashion. Relying on a Nielsen poll to calculate market shares for all media outlets, the former Department of Justice (DOJ) antitrust lawyer adapted a well-known antitrust measure (the Herfindahl index) to index diversity. The so-called "diversity index" would be used to determine whether a merger or acquisition of a media outlet harms viewpoint diversity.

But the diversity index would be short-lived. Consumer groups assailed its validity, and the Third Circuit would have none of it on review. Despite the fact that the index was based on poll and survey data, the court held that the diversity index was unjustified. ${ }^{2}$

The result has left media regulation in a state of quandary. Over the course of the past decade, courts have increasingly demanded empirical justification for the Commission's ownership rules. At heart, these rules rest on what we call the "convergence" assumption that media consolidation reduces viewpoint diversity. By restricting consolidation, the theory goes, ownership regulations preserve diverse and antagonistic viewpoints that broadly further democratic goals. Others counter that media conglomerates do not speak in a single voice. Media consolidation may capitalize on efficiencies, ultimately increasing the quality of the content and viewpoints expressed. Indeed, monopolists might have an incentive to diversify viewpoints in a way that competing outlets would not. The intense disagreement between critics of media consolidation and regulatory critics, as Professor Waldfogel notes, may seem to some as "an

1. Frank Ahrens, FCC Plan to Alter Media Rules Spurs Growing Debate, WASH. PosT, May 28, 2003, at A1.

2. See Prometheus Radio Project v. FCC, 373 F.3d 372, 402-11 (3d Cir. 2004). 
argument between 'the sky is falling' versus 'we have a working missile shield." "3

Our Article contributes to this important legal and policy debate in two principal ways. First, we fill the empirical void by developing a valid statistical measure of editorial viewpoint diversity for twenty-five top newspapers from 1988-2004. The measure - based on an exhaustive and new data collection of over 1600 editorial positions on every nonunanimous Supreme Court case decided during that period-is directly and substantively interpretable as the editorial viewpoint of a newspaper. To our knowledge, it is the first measure that directly quantifies, with valid uncertainty intervals, the political viewpoints of newspaper editorial boards at any given point of time. By capitalizing on modern statistical approaches to measurement and data collection, we address considerable shortcomings of previous approaches, which have ignored viewpoints, diversity, or both. Second, our Article directly assesses the overarching assumption that consolidation should lead to convergence in viewpoint diversity. Using finely tuned statistical methods, we examine the evolution of editorial viewpoints for all five mergers and acquisitions amongst our newspapers from 1988 through 2004: the New York Times Company's acquisition of the Boston Globe, the merger of the Atlanta Journal and Atlanta Constitution into the Atlanta Journal-Constitution, the Chicago Tribune Company's acquisition of the Los Angeles Times, Gannett's purchase of the Arizona Republic, and Hearst's acquisition of the San Francisco Chronicle. For each of these ownership changes, about which a cacophony of commentators have speculated, we provide direct measurements on editorial viewpoints of each paper pre- and postownership change, allowing us to directly test for breakpoints in views. ${ }^{4}$

With these measures and evidence, we are able to speak to a host of fundamental questions in regulation, media, markets, and the First Amendment: When the government intervenes to promote "diverse and antagonistic" voices, ${ }^{5}$ is it successful? Does the empirical record reveal a trade-off between liberalizing media markets and preserving deliberative democratic values? Can we quantify regulatory benefits for diversity in a tangible way? How wellfounded is populist hostility towards media consolidation? Do the media respond in meaningful ways on editorial pages to ownership changes? Can a

3. Joel Waldfogel, Should We Regulate Media Ownership?, in MEDIA DIVERSITY AND LoCAlism: MEANING AND Metrics 3, 3 (Philip M. Napoli ed., 2007) [hereinafter DIVERSITY].

4. While our analyses do not lend themselves to a direct causal interpretation, in this policy area it is arguably the association between ownership changes and viewpoints that matters. An acquisition might cause a paper to change in orientation, or market pressures may simultaneously cause the newspaper to be acquired and to change its outlook. From a policy perspective, the descriptive quantity of convergence in the face of consolidation matters.

5. Associated Press v. United States, 326 U.S. 1, 20 (1945). 
solid foundation for statutory and doctrinal mandates for empirical evidence be built?

Our findings defy extant accounts. First, we show that the convergence assumption that underpins federal regulation receives little support from three of the five of the ownership changes we study. There is no evidence of convergence-i.e., a decrease in the difference of political viewpointsbetween newspapers already owned by the acquiring party and the Los Angeles Times, the Arizona Republic, and the San Francisco Chronicle. Second, for two cases of consolidation, we detect marked shifts in editorial viewpoints that are consistent with convergence and, counterintuitively, divergence. Under common ownership (but with separate editorial boards), the Atlanta Journal and Atlanta Constitution diverged sharply in editorial viewpoints prior to the merger of their editorial boards. This provides some evidence for monopoly diversification. Yet upon merging, the editorial viewpoint of the Atlanta Journal-Constitution fell squarely between the positions of its parent papers, providing strong evidence for convergence. Lastly, while ideologically indistinguishable preacquisition, after consolidation of ownership the New York Times and the Boston Globe separated sharply into liberal and (relatively) centrist newspapers, respectively, suggesting diversification instead of convergence.

To study each of these ownership changes in more detail, we amassed data from several other novel sources to document (to our knowledge, for the first time) editorial board composition and broad-based demographic data for each of these transactions. These data shed substantial light on the puzzling findings: divergence and convergence may be best explained by differences in editorial policies, and seeming convergence in Atlanta may be divergence in fact. Our findings challenge long-held assumptions about viewpoint diversity. The implications for law and policy are considerable, particularly for the FCC's merger review and what we argue to be a sharp tension in the statutory interpretation of the 1996 Telecommunications Act.

While our approach to measuring viewpoint diversity has significant advantages over alternative measurement strategies, it is no panacea. Most importantly, our analysis does not directly speak to the causal impact of modifying the newspaper-broadcast cross-ownership rule (or other ownership rules). Further, because the measure is based on editorial positions of major newspapers, we do not directly capture slant or bias in news reporting or trends in small, locally owned newspapers. We discuss such limitations more fully in Part III.E.

This Article proceeds as follows. Part I discusses the hypothesis that consolidation should lead to convergence in substantive viewpoint diversity. We review how commentators, scholars, courts, and the Commission have grappled with the conceptually muddy convergence hypothesis. Part II demonstrates how existing measures of viewpoints fail-none truly measures viewpoint diversity. Part III sketches our finely tuned statistical measurement 
approach, which we show solves both the conceptual muddiness and measurement challenges. While the technical details of our approach are complex and make use of state-of-the-art developments in applied statistics, the intuition is straightforward: we locate every newspaper editorial that takes an express position on a Supreme Court case and "scale" the newspaper in the same substantively meaningful dimension used to descriptively characterize the Justices. (The technical details of our approach are reserved for Subpart C of the Appendix.) Upon publication, easy-to-use software to estimate dynamic viewpoints will be made publicly available for free. ${ }^{6}$ Part IV presents our empirical results. It first demonstrates that our static measure (pooling time periods) reliably, consistently, and intuitively quantifies editorial viewpoint differences across papers. We then present the dynamic measures (accounting for temporal trends), demonstrating the seeming paradox of stability, divergence, and convergence depending on the newspaper. In Part $\mathrm{V}$, we conduct a detailed study of the most puzzling cases of the Atlanta JournalConstitution and the New York Times / Boston Globe. We contextualize the mergers and acquisitions of interest with new editorial board and demographic data and highlight the fundamental importance of editorial policy and the organizational structure of a board. We conclude with legal and policy implications for communications law. In addition to the primary tension we highlight in the interpretation of the 1996 Act, we suggest that in its waiver review the Commission should scrutinize the organizational structure of editorial boards and newspaper personnel policies, because our study suggests that these play a considerable role in determining editorial viewpoints.

\section{THE CONVERGENCE HYPOTHESIS}

As with most areas of administrative law and regulation, the central struggle in media regulation involves competing conceptions of the public interest. The Federal Communications Commission has historically interpreted its "public interest" mandate as involving three overlapping but distinguishable values: competition, localism, and diversity. ${ }^{7}$ While competition is more

6. We wrote the software in $\mathrm{C}++$ and the $\mathrm{R}$ statistical programming language, to be incorporated into MCMCpack. See generally BJARNE STROUSTRUP, THE C++ PROGRAMMING Language, Special Edition (2000); The R Dev. Core Team, R Found. For Statistical Computing, R: A LANguage and ENVIRONMENT For Statistical CoMPUTING (2008), available at http://cran.r-project.org/doc/manuals/refman.pdf; Andrew D. Martin \& Kevin M. Quinn, MCMCpack, http://mcmcpack.wustl.edu (last visited Feb. 13, 2009).

7. See, e.g., 2002 Biennial Regulatory Review-Review of the Commission's Broadcast Ownership Rules and Other Rules Adopted Pursuant to Section 202 of the Telecommunications Act of 1996, 18 F.C.C.R. 13,620, 13,627 (2003) [hereinafter Biennial Order]. The Commission's conceptualization of these three values and their interrelationships is complex. As to diversity, the Commission lists five types: "viewpoint, outlet, program, source, and minority and female ownership diversity." Id. As to competition, the Commission seeks to "promot[e] competition by ensuring pro-competitive 
readily susceptible to economic analysis, diversity and localism do not easily lend themselves to existing analytical tools, setting up what has been described by some as a clash between market and democratic models of the media. ${ }^{8}$ What do we mean by diversity? How is localism to be distinguished from diversity? How do we measure the attainment of each? While the Commission has grappled with such underlying questions for decades, the concepts remain elusive. Nonetheless, one central animating assumption behind the Commission's ownership regulations is that common ownership reduces viewpoint diversity, which we call the "convergence hypothesis." 9

Due to First Amendment constraints, Congress and the FCC have largely adopted a structural approach to regulating the media, as opposed to directly mandating content, based on the empirical assumption of convergence. Limiting concentration of media ownership is therefore a means to the ultimate end of furthering substantive viewpoint diversity, ${ }^{10}$ and, in turn, fostering broad democratic goals of an informed citizenry, deliberation, and accountability. ${ }^{11}$

The convergence hypothesis pervades federal law and regulation. The "newspaper/broadcast cross-ownership" rule, promulgated in 1975, restricts common ownership of a newspaper and broadcast station (television or radio) in the same market. ${ }^{12}$ The "radio/television cross-ownership" rule limits the

market structures," id. at 13,638 , which can be related to viewpoint diversity: "In limiting broadcast ownership to promote economic competition, we also take major strides toward protecting and promoting our separate policy goal of protecting competition in the marketplace of ideas-viewpoint diversity." Id. at 13,639. As to localism, the Commission seeks "to promote localism to the greatest extent possible through market structures that take advantage of media companies' incentives to serve local communities. In addition, we seek to identify characteristics of those broadcasters that have demonstrated effective service to individual local communities and to encourage their entry into markets currently prohibited by our existing rules." Id. at 13,644 . Localism similarly interacts with diversity, such as when the Commission considers "local diversity." Id. at 13,800.

8. See, e.g., Howard A. Shelanski, Antitrust Law as Mass Media Regulation: Can Merger Standards Protect the Public Interest?, 94 CAL. L. REV. 371 (2006).

9. See, e.g., FCC v. Nat'l Citizens Comm. for Broad., 436 U.S. 773, 780 (1978); Biennial Order, supra note 7, at 13,627-28 (stating that the Commission has long assumed "that a larger total number of outlet owners increased the probability that their independent content selection decisions would collectively promote a diverse array of media content"). The other assumption, which we do not directly address in this Article, is that common ownership reduces local coverage. As in the Commission's Biennial Order, and as we explain below, we view localism and diversity as substantively different goals.

10. See Biennial Order, supra note 7, at 13,633-34.

11. See, e.g., C. Edwin Baker, Media Structure, Ownership Policy, and the First Amendment, 78 S. CAL. L. REV. 733 (2005).

12. See 2006 Quadrennial Regulatory Review-Review of the Commission's Broadcast Ownership Rules and other Rules Adopted Pursuant to Section 202 of the Telecommunications Act of 1996, 23 F.C.C.R. 2010, 2018-19 (2007) [hereinafter Quadrennial Review] (explaining promulgation of newspaper/broadcast cross-ownership rule and subsequent changes); Biennial Order, supra note 7, at 13,747 (modifying newspaper/broadcast cross-ownership rule); Amendment of Sections 73.34, 73.240, and 
number of television and radio stations an entity may own in a single market. ${ }^{13}$ The "national television ownership" rule caps the aggregate television audience any single entity may reach at $39 \% .{ }^{14}$ The "dual network" rule prohibits a merger between any of the top four networks (that is, ABC, CBS, Fox, and NBC). ${ }^{15}$ And, from 1970 to 1995 , the "financial interest and syndication" rules barred television networks from having a financial stake in the syndication of programs. ${ }^{16}$

While the convergence hypothesis forms the empirical bedrock for media regulation, it remains contested terrain. The Commission and the courts have taken a sharp empirical turn, increasingly requiring greater evidence to validate the foundation of the convergence hypothesis. ${ }^{17}$ Scholars have come to no agreement on basic questions of whether consolidation has happened, and if so, whether it has any connection to viewpoint diversity. ${ }^{18}$ We sketch these developments below to demonstrate the pressing need for the reliable, valid, empirical measurements that we offer in this Article.

\section{A. Viewpoint Diversity and the Empirical Turn in the Law of Media}

For the better half of the existence of federal ownership regulations, which date back to the 1940s, the Commission offered and the courts required little evidence of the connection between ownership and viewpoint diversity. ${ }^{19}$

73.636 of the Commission's Rules Relating to Multiple Ownership of Standard, FM, and Television Broadcast Stations, 50 F.C.C.2d 1046, ๆ 102 (1975) [hereinafter Amendment of Multiple Ownership Rules].

13. See 47 C.F.R. $\S 73.3555$ (c) (2008). Prior to 2003, caps were placed on the total number of broadcast stations one owner could operate. See Biennial Order, supra note 7, at 13,767-68. The Biennial Order eliminated hard caps on television and radio ownership, instead tying licensing approval of each to the diversity index. See id. at 13,775. The Quadrennial Review reverts to the system in place prior to the Biennial Order. See Quadrennial Review, supra note 12, at 2058.

14. Consolidated Appropriations Act of 2004, Pub. L. No. 108-199, § 629, 118 Stat. 3 , 99. The Biennial Order increased the national television ownership cap from $35 \%$, mandated in the 1996 Act, to $45 \%$, which the Consolidated Appropriations Act subsequently lowered to $39 \%$. Id.; Telecommunications Act of 1996, Pub. L. No. 104-104, $\S 202$ (c)(1)(B), 110 Stat. 56, 111; Biennial Order, supra note 7, at 13,814; see also 47 C.F.R. $\S 73.3555(\mathrm{e})(1)$ (2008).

15. 47 C.F.R. $\S 73.658(\mathrm{~g})(2008)$.

16. 47 C.F.R. $\S 73.658(j)$ (1990); see also Schurz Commc'ns, Inc. v. FCC, 982 F.2d 1043 (7th Cir. 1992) (striking down the financial interest and syndication rules as arbitrary and capricious).

17. See discussion accompanying infra notes 19-62.

18. See discussion accompanying infra notes 63-83.

19. See, e.g., Nat'l Citizens Comm. for Broad. v. FCC, 555 F.2d 938, 944 (D.C. Cir. 1977) ("The Commission enacted these rules without compiling a substantial record of tangible harm; it rested instead on its belief that the effects of competition or its absence, are not readily susceptible of quantitative ascertainments." (internal quotation marks and citation omitted)). 
When the Commission first proposed the newspaper/broadcast crossownership rule in 1970, some twenty-five studies were submitted, but the Commission dismissed them as "inconclusive or unrealistic." ${ }^{20}$ Challenging the rule in the Supreme Court, the American Newspaper Publishers Association argued in FCC v. National Citizens Committee for Broadcasting (NCCB) ${ }^{21}$ that the Commission had failed to establish the connection between diversity and ownership. ${ }^{22}$ The Court made short shrift of the argument. While the Court conceded that the connection was not well supported, it held that the Commission hadn't acted irrationally because the connection would be difficult to document: "diversity and its effects are . . . elusive concepts, not easily defined let alone measured," 23 and abuses by common owners are difficult to detect. Because of these measurement difficulties, "the Commission was entitled to rely on its judgment, based on experience, that 'it is unrealistic to expect true diversity from a commonly owned station-newspaper combination." 24

While the $N C C B$ Court's deference to the Commission's expertise was par for the course for the better half of the lifespan of ownership regulations, the tide has turned over the past two decades. Courts and, in turn, the Commission have increasingly mandated some form of empirical evidence. ${ }^{25}$ Broadly speaking, three factors may account for this shift. First, the Telecommunications Act of 1996, which eliminated and revised several ownership rules, mandated review of the Commission's ownership rules every two years to determine "whether any of such rules are necessary in the public interest as the result of competition" and to "repeal or modify any regulation it determines to be no longer in the public interest." 26 The increasing requirement for an evidentiary basis for the convergence assumption has therefore been derived from the seemingly deregulatory mandate of the 1996 Act. $^{27}$ Second, the standard of review for informal rulemaking may generally have increased in scrutiny since $N C C B .{ }^{28}$ Third, empirical science has progressed significantly

20. Id. at 945 n. 13 .

21. 436 U.S. 775 (1978) (upholding the newspaper/broadcasting cross-ownership rule).

22. Id. at 796 .

23. Id. at 796-97 (quoting Nat'l Citizens, 555 F.2d at 961).

24. Id. at 797 (quoting Nat'l Citizens, 555 F.2d at 962).

25. See, e.g., Robert B. Horwitz, On Media Concentration and the Diversity Question, 21 INFO. SOC'Y 181, 195-96 (2005).

26. Telecommunications Act of 1996, Pub. L. No. 104-104, $\S 202($ h), 110 Stat. 56, $111-12$

27. See, e.g., Fox Television Stations, Inc. v. FCC (Fox I), 280 F.3d 1027, 1048 (D.C. Cir.) (vacating the cable and broadcast cross-ownership rule and remanding the national television station ownership rule), modified on reh'g, 293 F.3d 537 (D.C. Cir. 2002).

28. See, e.g., Motor Vehicle Mfrs. Ass'n, Inc. v. State Farm Mut. Auto. Ins. Co., 463 U.S. 27 (1983) (finding arbitrary and capricious the agency's failure to consider an alternative (airbags only) motor vehicle standard and explain the safety benefits of detachable seat belts); Syracuse Peace Council v. FCC, 867 F.2d 654 (D.C. Cir. 1989) (applying arbitrary and capricious review to examine Commission's rationale for rescission 
over the past 20 years, increasing both the supply and demand for empirical evidence. In its 2002 Biennial Review, for example, the FCC commissioned a dozen empirical studies to determine whether the ownership regulations were still necessary to the public interest. ${ }^{29}$

Even prior to the 1996 Act, appellate courts had become less deferential to the Commission than the NCCB Court. In Schurz Communications, Inc. $v$. $F C C{ }^{30}$ the Seventh Circuit, in an opinion by Judge Posner, struck down revised "financial interest and syndication" rules as arbitrary and capricious, finding that the FCC failed to explain how the rules would enhance diversity in programming. ${ }^{31}$ Judge Posner conceded that economic theory provided no solace: "[E]conomists do not agree on the relation between monopoly or competition, on the one hand, and the... variety of an industry's output ...."32 Like the NCCB Court, the Schurz Court noted the difficulty of measuring diversity, ${ }^{33}$ but unlike in $N C C B$, that difficulty provided no grounds for deference to the Commission. ${ }^{34}$ Despite the fact that the Schurz court admitted that economic theory provided no answers, it invoked the potential for monopoly diversification: "It has long been understood that monopoly in broadcasting could actually promote rather than retard programming diversity. 35 Combined with the fact that the Commission "made no attempt to explain" how "restrictions on network participation in programming... promote diversity," the theoretical possibility was fatal. ${ }^{36}$

Relying on the 1996 Act, the D.C. Circuit in a series of cases has questioned and demanded evidence for the Commission's invocation of the convergence hypothesis. In Time Warner Entertainment Co. v. FCC, the court found arbitrary and capricious the $40 \%$ "vertical" limit on the number of channels that can be occupied by affiliated programmers. ${ }^{37}$ The court found wanting the evidence for the $40 \%$ limit, compared to some limit above or below, noting that "given the pursuit of diversity, one might expect some inquiry into whether innovative independent originators of programming find greater success selling to affiliated or to unaffiliated programming firms, but there is none." ${ }^{38}$ In Fox Television Stations, Inc. v. FCC, the court vacated the

of the fairness doctrine). See generally JEFFREY S. LUBBERS, A GUIDE TO FEDERAL AGENCY RULEMAKING 472-89 (4th ed. 2006) (discussing evolution of arbitrary and capricious review).

29. Biennial Order, supra note 7 , at 13,621 .

30. 982 F.2d 1043 (7th Cir. 1992).

31. Id. at 1054 .

32. Id. at 1048 .

33. Id. at 1054 ("[W]hile the word diversity appears with incantatory frequency in the Commission's opinion, it is never defined.").

34. Id. at 1055.

35. Id. at 1054 .

36. Id. at 1055 .

37. 240 F.3d 1126, 1137-39 (D.C. Cir. 2001).

38. Id. at 1138 . 
cable/broadcast cross-ownership rule and remanded the national television station ownership rule to the Commission. ${ }^{39}$ For the cable/broadcast crossownership rule, it found the Commission's diversity rationale-which ignored the rule's arguably small marginal effect on diversity due to the historical increase in broadcast outlets-"woefully inadequate." 40 For the national television rule, the court pointed to an earlier FCC report, which found no evidence that group-owned stations were less responsive to local needs. ${ }^{41}$ The Commission had not shown any studies to the contrary, and thereby failed to establish that the rule enhanced diversity. ${ }^{42}$ In Sinclair Broadcast Group, Inc. v. FCC, the court reviewed the local television ownership rule, which limits common ownership of television stations to markets with at least eight remaining independent voices. ${ }^{43}$ Examining the empirical bases the Commission relied on (e.g., a Roper study of television behavior and data from the Commission's annual report), the court found arbitrary and capricious the Commission's exclusion of nonbroadcast media from the eight voices. ${ }^{44}$

In response to this increasing scrutiny on appeal, the Commission harnessed empirical evidence in its 2002 Biennial Review, commissioning twelve empirical studies on localism and diversity. ${ }^{45}$ Compared to the Commission's prior rulemakings, the Biennial Order is unique in this respect: the order is littered with discussions of, analyses of, and references to empirical studies on a full range of topics, from media penetration, to consumption and substitution patterns, to ownership. ${ }^{46}$ Defining viewpoint diversity as "the availability of media content reflecting a variety of perspectives,"47 the Commission specifically "sought comment on whether th[e] longstanding presumed link between ownership and viewpoint could be established empirically." 48 One of those studies, for example, collected information about news stories and editorials during the 2000 presidential campaign by ten crossowned television and newspaper combinations. ${ }^{49}$ The study coded each item as "slanted" in favor of Bush or Gore, finding inconsistent patterns. ${ }^{50}$ The

39. 280 F.3d 1027, 1033 (D.C. Cir.), modified on reh'g, 293 F.3d 537 (D.C. Cir. 2002).

40. Id. at 1051-52.

41. Id. at 1042-43.

42. Id. at $1042-44$.

43. 284 F.3d 148 (D.C. Cir. 2002).

44. Id. at $158-65$.

45. Biennial Order, supra note 7, at 13,621 .

46. Id.

47. Id. at 13,627 .

48. Id. at 13,628 .

49. David Pritchard, Viewpoint Diversity in Cross-Owned Newspapers and Television Stations: A Study of News Coverage of the 2000 Presidential Campaign (FCC Media Ownership Working Group, Study No. 2, 2002), available at http://www.fcc.gov/ ownership/materials/ already-released/viewpoint090002.pdf.

50. Id. at 8-12. 
Commission discussed the study at length in its order, but ultimately concluded that it suffered from the "significant methodological flaw" of no control group. ${ }^{51}$ The Commission pored over several other studies: an examination of news slant and editorial endorsements of Senate candidates, ${ }^{52}$ a Pew survey of journalists suggesting that journalists act to benefit the interest of the news organization, ${ }^{53}$ and a study finding a correlation between television revenue and editorializing on spectrum allocation. ${ }^{54}$ As to the newspaper/broadcast cross-ownership rule, the Commission found the record wanting: "[T]he record does not contain data or other information demonstrating that common ownership ... poses a widespread threat to diversity of viewpoint ...." 55 The Commission hence repealed the blanket ban on newspaper/broadcast crossownership, adopting instead "cross-media limits" based on its diversity index. ${ }^{56}$

On appeal, the Third Circuit, reversing other parts of the Biennial Order, affirmed the repeal of the newspaper/broadcast cross-ownership rule, citing to the mixed record, such as examples of newspaper owners' affecting news and editorial pages and Tribune company papers' endorsing different presidential candidates. ${ }^{57}$ But in a two-to-one split, the court struck down the cross-media limits and diversity index for failure to justify the market shares (despite the fact that they were empirically informed from a Nielsen media survey) and failure to justify why market shares are the same for all outlets of a given medium. ${ }^{58}$

On remand, in an order released in early 2008 , the Commission adopted a presumption that permits newspaper-broadcast combinations in the twenty largest media markets and a negative presumption in all other markets. It held that it "will require any applicant attempting to overcome a negative presumption about a major newspaper and television station combination to demonstrate by clear and convincing evidence that ... the merged entity will increase the diversity of independent news outlets."

51. Biennial Order, supra note 7, at 13,630 .

52. Id. at 13,763; Kim Fridkin Kahn \& Patrick J. Kenney, The Slant of the News: How Editorial Endorsements Influence Campaign Coverage and Citizens' Views of Candidates, 96 AM. POL. SCI. REV. 381 (2002).

53. Biennial Order, supra note 7, at 13,629; Pew RESEARCH CTR. FOR THE PEOPLE \& THE Press, Journalists AvoIding THE News: SElF CENSORShIP: How OfTEN AND Why (2000), available at http://people-press.org/reports/pdf/39.pdf.

54. Biennial Order, supra note 7, at 13,629; James H. Snider and Benjamin I. Page, Does Media Ownership Affect Media Stands? The Case of the Telecommunications Act of 1996 (Northwestern Univ. Inst. for Policy Research, Working Paper No. 97-12, 1997).

55. Biennial Order, supra note 7, at 13,767.

56. Id. at $13,790-801$.

57. Prometheus Radio Project v. FCC, 373 F.3d 372, 398-400 (3d Cir. 2004).

58. Id. at 402-12.

59. Quadrennial Review, supra note 12, at 2049. 
shown remains unclear, further underscoring the pressing need for empirical measurement of diversity.

The empirical turn has played prominently in the FCC and the courts, culminating the 2002 Biennial Order. The assessment of the convergence hypothesis is also not strictly limited to the Commission. Formally, antitrust considerations do not contemplate viewpoint diversity, ${ }^{60}$ but one section chief responsible for newspaper matters at the DOJ, Alan J. Marx, noted that "the theory we always had.[was] that if you find commercial competition for advertisers, you get the preservation of editorial competition. Preserving editorial voices was an important consideration .... Justice asks a lot of questions about editorial competition ... but has yet to see how to use the answers." 61

Our Article responds to this sweeping empirical turn in the law, providing direct measures of whether a merged entity continues to exercise "independent news and editorial judgment," the lynchpin of the Commission's current proposed approach. ${ }^{62}$

\section{B. Scholarly Dissensus}

At the same time that the law has mandated empirical verification of convergence, scholars have come to little theoretical or empirical agreement about the effects of consolidation on viewpoint diversity. ${ }^{63}$

60. For arguments that antitrust should displace the FCC's structural regulations, see Bruce M. Owen, Regulatory Reform: The Telecommunications Act of 1996 and the FCC Media Ownership Rules, 2003 MICH. ST. DCL L. REV. 671. See also Shelanski, supra note 8 (arguing that antitrust is unlikely to achieve the FCC's public interest goals). 77.

61. Jack Bass, Newspaper Monopoly, AM. JourNALISM REV., July-Aug. 1999, at 64,

62. Quadrennial Review, supra note 12, at 2051. Our measures inform primarily editorial opinions, but the full quote evinces the fact that the FCC has valued both news and editorial judgments. For how our measures relate to news, see discussion accompanying infra notes $174-77$.

63. To be sure, a large and productive scholarly literature examines the role of the media, but this work doesn't directly examine the connection between consolidation and viewpoint diversity. See, e.g., Shanto IYEngar \& Donald R. KInder, News That MATTERS (Benjamin I. Page ed., 1987) (finding evidence for the priming, framing, and agenda-setting power of news); Larry M. Bartels, Messages Received: The Political Impact of Media Exposure, 87 AM. POL. SCl. REV. 267 (1993) (finding, after accounting for measurement error, strong media exposure effects); Timothy Besley \& Andrea Prat, Handcuffs for the Grabbing Hand? Media Capture and Government Accountability, 96 AM. ECON. REV. 720, 720 (2006) (developing a model of "how and when government captures media and what affect [sic] this has on political outcomes" and finding evidence that ownership structure matters); Timothy Besley \& Robin Burgess, The Political Economy of Government Responsiveness: Theory and Evidence from India, 117 Q.J. ECON. 1415 (2002) (developing a model for governmental responsiveness and finding evidence that newspaper circulation is correlated with governmental responsiveness); Stefano DellaVigna \& Ethan Kaplan, The Fox News Effect: Media Bias and Voting, 122 Q.J. ECON. 1187 (2007) (finding Republican vote share gain in markets where Fox News Channel was introduced); Simeon 
On the one hand, a large number of media critics invoke the convergence hypothesis. Professor Wildman notes, "[I]t is widely accepted that ownership structure does influence viewpoint diversity and policy has generally reflected a presumption that viewpoint diversity increases with outlet diversity." 64 Professor Bagdikian, "dean of American media critics," conglomerate companies dominate media content, leading to dramatic homogenization of content. ${ }^{66}$ As evidence of convergence, Bagdikian points to homogeneity in editorials (e.g., on the FCC's fairness doctrine), uniformity in editorial endorsements of political candidates, and instances of executive pressure influencing editorial endorsement decisions. ${ }^{67}$

On its face, the convergence hypothesis seems plausible: it is tautologically true that if two media outlets merge, one "voice" is lost. Yet in the nontautological sense, when one outlet is acquired but not eliminated, the effects of consolidation may be more complex. Some have offered a directly contradictory theory of monopoly diversification. ${ }^{68}$ The intuition for monopoly diversification (really divergence with consolidation) is simple: in a competitive market, firms may compete for the median consumer, for example, by adopting centrist editorial positions. Any deviation from the median consumer may cause one firm to lose consumers to the other. ${ }^{69}$ But a monopolist's optimal strategy may be to cater products to different market segments, for example by producing a liberal and a conservative paper. Others suggest that, even in competitive markets, the media will reflect biases of consumers such that there's no convergence towards the median consumer. ${ }^{70}$ Sophisticated theoretical economic analyses of the impact of ownership rules

Djankov et al., Who Owns the Media?, 46 J.L. \& Econ. 341 (2003) (finding adverse effects of government ownership of media); James N. Druckman \& Michael Parkin, The Impact of Media Bias: How Editorial Slant Affects Voters, 67 J. PoL. 1030 (2005) (finding that editorial slant affects voting behavior); Alan Gerber et al., Does the Media Matter? A Field Experiment Measuring the Effect of Newspapers on Voting Behavior and Political Opinions (Yale Working Papers on Econ. Applications \& Policy, Working Paper No. 12, 2006) (reporting field experiment that measured the impact of newspaper subscriptions on political behavior and opinion).

64. Steven S. Wildman, Indexing Diversity, in DIVERsITY, supra note 3, at 151, 160-61.

65. See, e.g., Interview by Russell Schoch with Ben Bagdikian (Sept. 1995), available at $\mathrm{http}: / / \mathrm{www} . a m e r i c a n r e v i e w . u s / m o n o p o l y . h t m$. Bagdikian served as dean of Berkeley Graduate School of Journalism.

66. Ben H. BAGdikian, The New Media Monopoly 5, 11 (2004).

67. Id. at 139-40, 197, 201-02.

68. See, e.g., Jack H. Beebe, Institutional Structure and Program Choices in Television Markets, 91 Q.J. ECON. 15 (1977); Peter O. Steiner, Program Patterns and Preferences and the Workability of Competition in Radio Broadcasting, 66 Q.J. ECON. 194, 206 (1952); Matthew L. Spitzer, Television Duopoly in Small Markets and Diversity of the Airwaves 17 (USC Ctr. in Law, Econ. and Org., Research Paper No. C08-20, 2008).

69. This is, of course, a simple adaptation of the classic Hotelling model. See Harold Hotelling, Stability in Competition, 39 ECON. J. 41 (1929).

70. See Sendhil Mullainathan \& Andrei Shleifer, The Market for News, 95 AM. ECON. REV. 1031 (2005). 
suggest no clear answers as to the effects on viewpoint diversity. ${ }^{71}$

At an empirical level, there is even less agreement, primarily because of the conceptual and measurement difficulties of viewpoint diversity. A number of economic studies assess the effect of monopoly diversification on product variety but not viewpoint diversity. ${ }^{72}$ Economics Professor Owen notes that "content diversity is an impractical policy target because it cannot be defined or measured, and because there is no analytical linkage between ownership concentration and even abstract concepts of content diversity."73 Professor Barron, a leading authority on the media and the First Amendment, argues that "diversity resists both definition and quantification." 74 Communications Professor Einstein notes that conceptually defining diversity presents "a major stumbling block in this debate," 75 and that "no one has been able to develop a working definition of diversity - not the content providers, not the policymakers, not the scholars, and not the courts. Not only is diversity difficult to define, it is equally difficult to measure."76 Indeed, recently, Professor Napoli edited a landmark volume, with contributions by twenty-one scholars in the field, dedicated to the topic of measuring diversity and localism because of the "disappointing paucity of previous research addressing such issues."77 (We

71. See, e.g., Jean J. Gabszewicz et al., Press Advertising and the Ascent of the 'Pensée Unique', 45 EUR. ECON. REV. 641 (2001) (theorizing that convergence depends on relative weight of advertising); Peter $\mathrm{O}$. Steiner, Program Patterns and Preferences, and the Workability of Competition in Radio Broadcasting, 66 Q.J. ECON. 194 (1952) (theorizing that convergence depends on underlying distribution of consumer preferences); Christopher S. Yoo, Architectural Censorship and the FCC, 78 S. CAL. L. REv. 669, 674 (2005) ("[T]he relationship between media concentration and the quantity, quality, and diversity of media content is more complex than is generally realized."); Simon P. Anderson \& John McLaren, Media Mergers and Media Bias with Rational Consumers 34 (Mar. 2007) (working paper), available at http://www.virginia.edu/economics/papers/anderson/murdochs070308.pdf (theorizing that a no-merger rule can improve welfare outside of antitrust concerns and that a monopolist cannot publish ideologically diverse papers); David J. Balan, Patrick DeGraba \& Abraham L. Wickelgren, Ideological Persuasion in the Media (Dec. 16, 2004) (working paper), available at $\mathrm{http}: / / \mathrm{ssrn} . \mathrm{com} /$ abstract $=637304$ (theorizing that prohibition of common ownership does not guarantee viewpoint diversity).

72. See James T. Hamilton, All the News That's Fit to Sell 24-26 (2004); Bruce M. OWen \& STEVen S. Wildman, Video Economics 64-100 (1992); Steven T. Berry \& Joel Waldfogel, Do Mergers Increase Product Variety? Evidence from Radio Broadcasting, 116 Q.J. ECON. 1009 (2001); Lisa George, What's Fit to Print: The Effect of Ownership Concentration on Product Variety in Daily Newspaper Markets, 19 INFO. ECON. \& PoL'Y 285 (2007). One notable exception is Matthew Gentzkow \& Jesse M. Shapiro, What Drives Media Slant? Evidence from U.S. Daily Newspapers (Nat'l Bureau Econ. Research, Working Paper No. 12707, 2006), available at http://www.nber.org/papers/w12707.

73. Owen, supra note 60 , at 690 (emphasis omitted).

74. Jerome A. Barron, Structural Regulation of the Media and the Diversity Rationale, 52 FED. COMM. L.J. 555, 560 (2000).

75. Mara EINSteIN, MEdia Diversity: Economics, OWNERShIP, AND the FCC 4 (2004).

76. Id. at 6 .

77. Philip M. Napoli, Introduction, in DIVERSITY, supra note 3, at xv, xvi. 
discuss below some of the approaches taken in that volume.)

Because of the difficulty of measuring diversity, the results of extant studies have been wildly inconsistent. ${ }^{78}$ Professor Horwitz notes that "[m]ost empirical studies of the effects of ownership rules and other diversity remedies on media content and format are inconclusive at best." ${ }^{.79} \mathrm{He}$ attributes this largely to the problem of measurement:

$[\mathrm{H}]$ ow can an empirically oriented social scientist measure viewpoint diversity? ... Even approaching that particular problem resurrects the quandary of who does the measuring ... . [because] different people often read different messages into and derive different values from the same entertainment (and news) content .... Thus, it's not surprising that empirical social scientists trying to assess media diversity will gravitate to the stable, if less consequential, measures of format. The problem, of course, is that format or program diversity is just one of several gauges of diversity, yet commentators often leap to broad, general conclusions about the efficacy (or not) of the market in expanding diversity. ${ }^{80}$

Even more pessimistic, Professor Compaine, reviewing the literature on the effects of consolidation, concludes, "[A]ll that was written ... about the need for regulation to foster diversity and competition on television because of limited spectrum is irrelevant." 81 Professors Entman and Wildman insist that economic approaches fail to notice what cannot be quantified. ${ }^{82}$

While considerable work related to the question of how ownership structure affects viewpoint diversity exists in communications scholarship, ${ }^{83}$

78. See Richard Schultz, Measuring Media Diversity: Problems and Prospects (The Joan Shorenstein Ctr. on the Press, Politics \& Pub. Policy, Harvard Univ., Working Paper No. 2005-7, 2005), available at http://www.hks.harvard.edu/presspol/research_publications/ papers/working_papers/2005_7.pdf.

79. Robert B. Horwitz, On Media Concentration and the Diversity Question, in DIVERSITY, supra note 3, at 9, 13.

80. Id. at $45-46$ n. 10.

81. Benjamin M. Compaine, The Impact of Ownership on Content: Does It Matter?, 13 CARDOZO ARTS \& ENT. L.J. 755, 756 (1995).

82. Robert M. Entman \& Steven S. Wildman, Reconciling Economic and NonEconomic Perspectives on Media Policy: Transcending the "Marketplace of Ideas," $42 \mathrm{~J}$. COMM. 5, 14 (1992).

83. See, e.g., BENJAMIN M. COMPAINE, THE NEWSPAPER INDUSTRY IN THE 1980s 85-111 (1980) (discussing economic organization of the newspaper industry); PrESS CONCENTRATION AND MONOPOLY: NEW PERSPECTIVES ON NEWSPAPER OWNERShIP AND OPERATION (Robert G. Picard et al. eds., 1988) (providing multiple perspectives on newspaper consolidation); Roya Akhavan-Majid et al., Chain Ownership and Editorial Independence: A Case Study of Gannett Newspapers, 68 JoURNALISM Q. 59 (1991) (examining editorial independence of newspapers in the Gannett group); John C. Busterna \& Kathleen A. Hansen, Presidential Endorsement Patterns by Chain-Owned Papers, 1976-84, 67 JoURNALISM Q. 286 (1990) (finding no effect of chain ownership on presidential endorsements); John C. Busterna, Television Station Ownership Effects on Programming and Idea Diversity: Baseline Data, 1 J. MEDIA ECON. 63 (1988) (finding mixed evidence of association between cross-ownership and "ideas" diversity); Cecilie Gaziano, Chain Newspaper Homogeneity and Presidential Endorsements, 1972-1988, 66 JoURNALISM Q. 
the inconclusiveness of extant work is understandable: policy-relevant quantities are difficult to derive in this context with limited variation in policies of interest, even more limited data, and, to date, no reliable methods of measuring viewpoint diversity. Existing studies, as we demonstrate below, have largely focused on what is easy to measure, thereby ignoring viewpoints, diversity, or both. To overcome such challenges, we capitalize on rapid advances in statistics and bring to bear new data to unlock a central puzzle in media law.

\section{LIMITATIONS OF EXISTING MEASUREMENTS OF VIEWPOINT DIVERSITY}

The 2002 Biennial Order defines viewpoint diversity as the "availability of media content reflecting a variety of perspectives." 84 Measures of viewpoint diversity are central to the regulatory inquiry, but existing measures of viewpoint diversity suffer from considerable methodological problems. Measures commonly employed in research suffer from at least one of the following problems: (1) the measures are difficult to interpret and, in some cases, have little to do with media viewpoints; (2) crude proxies are employed; (3) measures tend to have no variation over time or in media outlets; (4) measurement uncertainty is not taken into account; (5) human inputs are highly subjective and difficult to replicate; and (6) measures are based on very small numbers of observations. The first two problems occur when researchers redefine the problem so as to use an easily quantifiable measure. To differing degrees, such approaches ignore viewpoints. The third through sixth problems ignore variability, uncertainty, and ultimately diversity. In the worst case, measures of viewpoint diversity ignore both viewpoints and diversity.

Measuring media viewpoints has a long scholarly tradition. Scholars have attempted to measure viewpoints using a wide array of approaches, including manual content analysis, ${ }^{85}$ counts of citations to think tanks, ${ }^{86}$ political

836 (1989) (finding homogeneity in newspapers' endorsements of presidential candidates); Ronald G. Hicks \& James S. Featherston, Duplication of Newspaper Content in Contrasting Ownership Situations, 55 JOURNALISM Q. 549 (1978) (finding little duplication in content of newspapers under common ownership); Stephen Lacy, Effects of Group Ownership on Daily Newspaper Content, 4 J. MEDIA ECON. 35, 40 (1991) (finding that group papers devote a greater percentage of all news and editorial space to editorial and op-ed material); Stephen Lacy, The Effects of Intracity Competition on Daily Newspaper Content, 64 JouRNALISM Q. 281 (1987) (finding that competitive newspapers have more reporters and buy more wire services than comparable papers without competition); Marilyn E. Lashley, Even in Public Television, Ownership Changes Matter, 19 COMM. RES. 770 (1992) (examining effects of executive turnover in public broadcasting on programming content).

84. Biennial Order, supra note 7, at 13,627 (emphasis added). While the Commission distinguishes between outlet diversity, program diversity, viewpoint diversity, source diversity, and minority/gender ownership diversity, it focuses primarily on viewpoint diversity.

85. See, e.g., Robert M. EnTMAN, Democracy Without Citizens: Media and the Decay of american Politics (1989); Warren E. Miller et al., Media Content 
endorsements, ${ }^{87}$ surveys of citizens ${ }^{88}$ and newspaper editors, ${ }^{89}$ counts of time and space allotted to political candidates or editorials, ${ }^{90}$ use of popularity ratings as measures of quality, ${ }^{91}$ counts of the number of "liberal" columnists and cartoonists appearing on a newspaper's opinion page, ${ }^{92}$ the number of

ANALYSIS StudY, 1974 (Inter-U. Consortium for Pol. \& Soc. Res., 1978); Robert M. Entman, How the Media Affect What People Think: An Information Processing Approach, 51 J. PoL. 347 (1989); William T. Gormley, Jr., An Evaluation of the FCC's CrossOwnership Policy, 6 POL'Y ANALYSIS 61 (1980); Hicks \& Featherston, supra note 83; Pritchard, supra note 49; Ralph R. Thrift Jr., How Chain Ownership Affects Editorial Vigor of Newspapers, 54 JouRNALISM Q. 327 (1977); Christopher Weare et al., Media Convergence and the Chilling Effect of Broadcast Licensing, 6 PRESS POL. 47 (2001).

86. See, e.g., Tim Groseclose \& Jeffrey Milyo, A Measure of Media Bias, 120 Q.J. ECON. 1191 (2005).

87. See, e.g., Stephen Ansolabehere et al., The Orientation of Newspaper Endorsements in U.S. Elections, 1940-2002, 1 Q.J. PoL. SCI. 393, 394 (2006) ("When newspapers endorse they take sides, and endorsements usually come at critical times in the campaign. Endorsements are a conscious political act. As such they reveal the political orientation of the press."); David Pritchard, A Tale of Three Cities: "Diverse and Antagonistic" Information in Situations of Local Newspaper/Broadcast Cross-Ownership, 54 FED. COMM. L.J. 31 (2001) (examining correlation between presidential endorsement and slant of news coverage for cross-owned outlets); Daniel B. Wackman et al., Chain Newspaper Autonomy as Reflected in Presidential Campaign Endorsements, 52 JoURNALISM Q. 411 (1975) (assessing impact of chain ownership on newspaper presidential endorsements from 1960-1972); see also Steven L. Coombs, Editorial Endorsements and Electoral Outcomes, in MORE Than News: Media Power IN Public Affairs 145 (Michael B. MacKuen \& Steven L. Coombs eds., 1981); Cecilie Gaziano, Chain Newspaper Homogeneity and Presidential Endorsements, 1972-1988, 66 JouRnalisM Q. 836 (1989); Matthew Gentzkow \& Jesse M. Shapiro, Media Bias and Reputation, 114 J. POL. ECoN. 280 (2006); John P. Robinson, Perceived Media Bias and the 1968 Vote: Can the Media Affect Behavior After All?, 49 JouRNALISM Q. 239 (1972); Ronald H. Wagenberg \& Walter C. Soderlund, The Effects of Chain Ownership on Editorial Coverage: The Case of the 1974 Canadian Federal Election, 9 CAN. J. POL. SCI. 682 (1976).

88. See, e.g., Russell J. Dalton et al., Partisan Cues and the Media: Information Flows in the 1992 Presidential Election, 92 AM. POL. SCI. REV. 111 (1998); Albert C. Gunther, Biased Press or Biased Public? Attitudes Toward Media Coverage of Social Groups, 56 PUB. OPINION Q. 147 (1992).

89. See, e.g., Byron St. Dizier, Editorial Page Editors and Endorsements: ChainOwned vs. Independent Newspapers, 8 NEWSPAPER RES. J. 63 (1986).

90. See, e.g., William T. Gormley, JR., The EfFects of NewsPaPer-Television Cross-OWNership on News HomogeneITY (1976); Peter J. Alexander \& Brendan M. Cunningham, Diversity in Broadcast Television: An Empirical Study of Local News in the United States, 6 INT'L J. MEDIA MGMT. 176 (2004); Maura Clancey \& Michael J. Robinson, General Election Coverage: Part I, in The Mass MEdia IN CAMPAign '84: ARTICles from PUbliC OpINION MAGazINE 27 (1985); Gentzkow \& Shapiro, supra note 87; Gormley, supra note 85; Gerald L. Grotta, Consolidation of Newspapers: What Happens to the Consumer?, 48 Journalism Q. 245 (1971); F. Dennis Hale, Editorial Diversity and Concentration, in PRESS CONCENTRATION AND MONOPOLY, supra note 83, at 161.

91. See, e.g., Thomas C. Spavins et al., The Measurement of Local Television News and Public Affairs Programs (FCC Media Ownership Working Group, Study No. 7, 2002), available at http://hraunfoss. fcc.gov/edocs_public/attachmatch/DOC-226838A12.pdf.

92. See, e.g., Hale, supra note 90 . 
topical areas (music, dining, international affairs, etc.) covered, ${ }^{93}$ counts of words and phrases used by media outlets, ${ }^{94}$ the amount of time and space political scandals are given, ${ }^{95}$ and selective use of anecdotes. ${ }^{96}$ Others have employed even more indirect measures of viewpoint diversity, such as the FCC's diversity index.

While a comprehensive review of such approaches is beyond the scope of this Article, we discuss here some of the major measurement strategies and demonstrate where they fall short. We use these examples not to disparage extant approaches, but to illustrate the considerable challenge of measuring viewpoint diversity. Existing approaches draw on insights from antitrust, survey sampling, content analysis, computational language processing, and econometrics. Our main point is that measuring viewpoint diversity is important-indeed, effectively mandated by law-but it is an enterprise fraught with pitfalls, requiring new methodological solutions.

\section{A. The FCC's Diversity Index}

The FCC's diversity index (DI), proposed in its Biennial Order, exemplifies measurement approaches that ignore substantive viewpoints of media outlets. Circumventing viewpoints may be attractive, as it offers the promise of an objective measure easily calculated for any media market, while overcoming First Amendment problems if used directly in review. ${ }^{97}$ Yet the

93. See, e.g., John C. Busterna, Television Station Ownership Effects on Programming and Idea Diversity: Baseline Data, 1 J. MEDIA ECON. 63 (1988); George, supra note 72; Gregory S. Crawford, Television Station Ownership Structure and the Quantity and Quality of TV Programming (FCC Media Ownership Working Group, Study No. 3, 2007), available at http://www.u.arizona.edu/ gsc818/research/papers/DA-07-3470A4.pdf; Jeffrey Milyo, The Effects of Cross-Ownership on the Local Content and Political Slant of Local Television News (FCC Media Ownership Working Group, Study No. 6, 2007), available at http://hraunfoss.fcc.gov/edocs_public/attachmatch/DA-07-3470A7.pdf.

94. See, e.g., Alexander Halavais, Convergence of Newspaper Election Coverage: 1992 to 2000, in DIVERSITY, supra note 3, at 97; Gentzkow \& Shapiro, supra note 72.

95. See, e.g., ENTMAN, supra note 85 .

96. See, e.g., In re Amendment of Sections 73.35, 73.240 and 73.636 of the Commission Rules Relating to Multiple Ownership of Standard, FM and Television Broadcast Stations, 22 F.C.C.2d 306 (Mar. 25, 1970) (citing GeORge H. LitWIN \& William H. WROTH, The EfFects of COMMON OWNERSHIP ON MEdia CONTENT AND INFLUENCE: A Research Evaluation of Media OWNERSHIP AND THE PUBLIC INTEREST (1969)). "The Litwin report . . . suggests that acrossthe-board rules limiting common ownership would be detrimental to the public interest in the majority of cases. We find weaknesses in the study so greatly affecting the conclusions reached therein as to render them of little value in our deliberations." Id. I 36. The FCC criticizes the report for relying on statements of interviewees rather than other data; for failing to ensure that comparisons focused on similar media; for relying on statistically insignificant differences and ignoring statistically significant ones; and for making certain blanket assumptions. Id. ๆ 37-40.

97. First Amendment problems would presumably arise if the FCC were to tailor 
basic problem, as the Third Circuit found, is that the DI is neither as rational as claimed nor clearly linked to viewpoint diversity. ${ }^{98}$

The DI is effectively a Herfindahl-Hirschman index (HHI) applied to what can be thought of as the market for ideas in a given locality. ${ }^{99}$ When used in antitrust analysis, the market shares are typically taken to be the firms' percentages of total revenue generated by the firms in the market. ${ }^{100}$ The HHI is simply the sum of the squared market shares. ${ }^{101}$ Larger values of the HHI indicate a more concentrated market. ${ }^{102}$

As proposed by the FCC, one critical assumption is that all outlets within the same medium have equal market shares (e.g., all newspapers contribute equally to diversity). Thus, despite the protestations to the contrary, the DI is closely related to raw counts of media outlets. ${ }^{103}$ The only portion of the DI that is empirically informed is the setting of the market share for each medium (e.g., newspapers represent $20.2 \%$ of the media), derived from a Nielsen survey. ${ }^{104}$

ownership policy in direct response to the past content, particularly political content, of media outlets. Such a regulatory approach would create strong incentives for media outlets to alter the views they express. At least for print media such content-based regulation would almost certainly not pass constitutional scrutiny. See Miami Herald Publ'g Co. v. Tornillo, 418 U.S. 241 (1974). But see Red Lion Broad. Co. v. FCC, 395 U.S. 367 (1969).

98. See Prometheus Radio Project v. FCC, 373 F.3d 372, 408 (3d. Cir. 2004) ("[The Diversity Index's] assign[ment of] equal market shares to outlets that provide no local news almost certainly presents an understated view of concentration in several markets, thus contravening the Commission's goal of making 'the most conservative assumption possible' about viewpoint diversity. . . A Diversity Index that requires us to accept that a community college television station makes a greater contribution to viewpoint diversity than a conglomerate that includes the third-largest newspaper in America also requires us to abandon both logic and reality." (citation omitted)).

99. Wildman, supra note 64 , at 153.

100. Id.

101. Mathematically: $H H I=\sum_{i=1}^{n} s_{i}^{2}$, where $i$ indexes media outlets and $s_{i}$ is the market share for firm $i$.

102. See U.S. Dep't of Justice \& Fed. Trade Comm'n, Horizontal Merger GUIDELINES $\S 1.5$ (1992).

103. One defense of weighting all outlets within a medium equally is that for viewpoint diversity the availability of, rather than actual, consumption of an outlet matters. See Owen, supra note 60, at 692.

104. See Biennial Order, supra note 7, at 13,783-84, 13,790 (explaining the FCC's calculation based on its survey results in Nielsen Media Res., Consumer Survey on Media Usage 113 (FCC Media Ownership Working Group, Study No. 8, 2002) (reporting survey responses as to any media "used in the past 7 days for local news and current affairs")). Originally, the percentage of responses added to $293 \%$, "due to multiple responses." Nielsen Media Res., supra, at 113. The FCC omitted magazines' share, and normalized the remaining outlets to $100 \%$. See Biennial Order, supra note 7 , at 13,783 . Nondaily newspapers are included in the normalization, but excluded from the calculation of concentration, $i d$. at 13,790 , due to "the absence of market-specific information on weekly newspaper availability," $i d$., so that the medium market shares do not sum to $100 \%$. 
Figure 1. Illustration of Diversity Index from Appendix C of Biennial Order

Nielsen Survey:

"[Any sources $u]$ sed in the past 7

days for local news and current affairs"

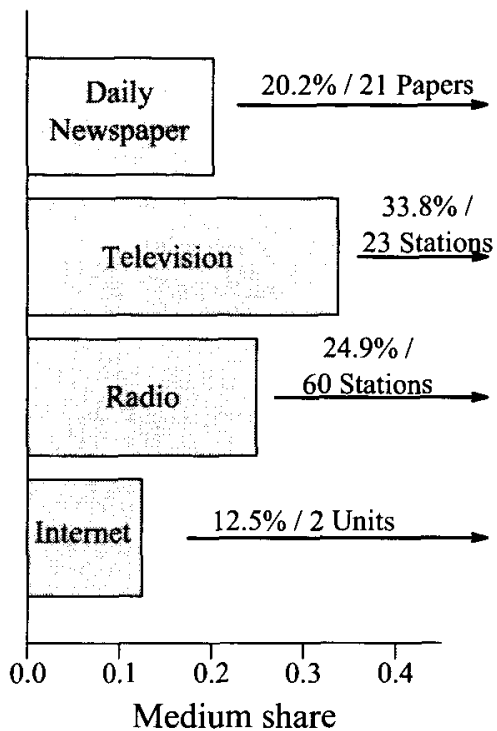

Diversity Share for Example Outlets (NYC)
NY Post

NY Times

Nowy Dzennik Polish Daily News

$\mathrm{ABC}$

Shop At Home Incorporated

Dutchess Community College

The left panel presents the "market" share for each medium identified as a source of local news. The right panel shows each specific outlet's share for purposes of measuring viewpoint diversity. This is calculated by dividing the medium's share by the number of outlets in the given market (as identified by Nielsen, Arbitron, or the US Dept. of Commerce, for TV, radio, and newspapers, respectively). Cross media companies' shares are calculated as a summation of their holdings. For example, the market share for the New York Times is calculated as the sum of $1 \%$ (the newspaper) and $0.4 \%$ (the radio station). This figure highlights the odd implications of the Diversity Index's calculation methodology: Nowy Dziennik-Polish Daily News contributes the same to the diversity index as the New York Post, and the New York Times newspaper and radio station count for less than the Dutchess Community College television station.

To see the sort of perverse results that arise from such a weighting system, Figure 1 presents selected entries from Appendix $\mathrm{C}$ of the Biennial Order. For example, daily newspapers represent $20.2 \%$ of market share, and this share is divided by 21 newspapers in the market to arrive at (equivalent) market shares for each newspaper (e.g., 20.2/21 $\approx 1 \%$ ). Nowy Dziennik-Polish Daily News is assumed to have the same market share as the New York Post, contributing equally to the index. The New York Times newspaper and radio station contribute less to the index than Shop At Home Incorporated, which contributes as much to diversity as the Dutchess Community College television station or 
$\mathrm{ABC}$. Bloomberg Radio, on the other hand, contributes to the index at the same level as Columbia University's radio station, as well as Radio Unica, one of the leading Spanish-language stations, which claims to reach $80 \%$ of the U.S. Hispanic population. All DSL or dial-up Internet connections are counted as a single outlet. Appendix C of the 2002 Biennial Order reveals similar glaring examples.

The DI, as discussed in the Prometheus case, ${ }^{105}$ has been subject to intense criticism, inheriting HHI's difficulties of determining the relevant market in an antitrust analysis. A crucial step becomes what media outlets can be conceived of as substitutes in the relevant market. More importantly, the DI has little to do with the direct outcomes of interest: diversity. As the Third Circuit rightly recognized, a count of voices does not substantive diversity make. ${ }^{106}$

\section{B. Manual Content Analysis}

The most prevalent approach to measuring viewpoints of media is to have humans read, view, or listen to the outlet in question and to then code it for a predefined set of characteristics. ${ }^{107}$ Such manual content analysis has a long history in the social sciences. ${ }^{108}$ Done well, content analysis can shed great light on texts. Unfocused use, however, may manufacture more problems than it solves. Conventional manual content analysis typically requires a great deal of human effort (both in terms of coding and supervision), can depend on essentially arbitrary categorizations, and may be highly subjective. All of these issues militate against the use of such methods in highly contentious settings such as administrative rulemakings where interested parties may have strong incentives to arrive at a particular result. Ideally, large amounts of data would be analyzed, the findings would be subject to scientific review, and other researchers would be able to validate and replicate the findings. Unfortunately, science doesn't abide by rulemaking deadlines. To illustrate some of the problematic aspects of manual content analysis, we look briefly at a classic study ${ }^{109}$ that has been used as primary data for much additional work. ${ }^{10}$

105. See Prometheus Radio Project v. FCC, 373 F.3d 372, 402-12 (3d Cir. 2004).

106. Cf. Shelanski, supra note 8 , at 414 (noting that a "market definition is an indirect way of showing the effects of economic conduct and should not stand in the way of considering direct evidence of harm to competition").

107. See sources cited supra note 85.

108. See Bernard Berelson, Content analysis in Communication Research (1952); Ole R. Holsti, Content ANalysis for the Social Sciences and Humantties (1969); KLAUS KRIPPENDORFF, CONTENT ANALYSIS: AN INTRODUCTION TO ITS METHODOLOGY (1980).

109. MILLER ET AL., supra note 85.

110. See, e.g., ENTMAN, supra note 85, at 75-88; Robert M. Entman, Newspaper Competition and First Amendment Ideals: Does Monopoly Matter?, 35 J. CoMM. 147 (1985); Lutz Erbring, Edie N. Goldenberg \& Arthur H. Miller, Front-Page News and RealWorld Cues: A New Look at Agenda-Setting by the Media, 24 AM. J. POL. SCI. 16 (1980); 
In several landmark studies, Professor Entman, a leading media scholar, makes use of data collected on ten days in the month preceding the 1974 election from ninety-six daily newspapers to gauge the political content of news articles and editorials. ${ }^{111}$ Of primary interest here are the two measures of (1) editorial liberalism, and (2) news diversity. Editorial liberalism is constructed as follows:

Each editorial item was coded for zero, one, or two assertions favoring or opposing liberal and conservative policy stands. The editorial liberalism index is a percentage formed by first counting the number of times a paper endorsed a liberal position or opposed a conservative position, then subtracting assertions favoring conservative stands or derogating liberal [sic]. The result was divided by twice the number of editorial items, since each item was coded for up to two liberal or conservative assertions. ${ }^{112}$

News diversity is similarly calculated:

Like most aspects of news slant, [the news diversity measure] is a subtle trait of reporting that few audience members would notice. The front-page news items were coded for mention of zero, one, or two problems. For each problem mention [sic], coders noted whether two different actors overtly disagreed with each other. Each news item was coded as having zero, one, or two instances of two actors asserting different points of view. The diversity index is the number of times two actors expressed different positions divided by twice the number of stories. 113

While the approach pioneered the quantification of news outputs, it comes with several limitations. First, both the liberalism and diversity indices require coders (typically students) to make value judgments about the nature of liberal and conservative positions. While this may be relatively uncontroversial for some issues (tax policy) it may be quite difficult for others (agricultural subsidies). Divining news slant may be particularly difficult since the codebook itself admits that what is being coded is "a subtle trait ... that few audience members would notice."114

Second, while the liberalism index attempts to measure the viewpoint of the editorial page, the news diversity measure primarily measures the diversity of viewpoint within a single news story. Such a measure may be valuable, but it deviates considerably from viewpoint diversity as relevant for federal media regulation, and, if anything, may represent lack of viewpoint. It would not be surprising if the diversity measure were related to newspaper viewpoint in an inverted-U relationship, with extreme newspapers reporting few disagreements

Arthur H. Miller, Edie N. Goldenberg \& Lutz Erbring, Type-Set Politics: Impact of Newspapers on Public Confidence, 73 AM. POL. SCI. REV. 67 (1979).

111. MiLlER ET AL., supra note 85. For a description of the data, see Inter-Univ. Consortium for Political and Soc. Research, Media Content Analysis Study, 1974, http://www.icpsr.umich.edu/cocoon/ICPSR/STUDY/07586.xml (last visited Feb. 12, 2009).

112. ENTMAN, supra note 85 , at 198 n. 6 .

113. Id.

114. Id. 
between actors and relatively centrist newspapers moderating between two positions.

Third, because the index is constructed from ten days in the fall of 1974, it remains difficult to say anything authoritatively about trends in media viewpoints in the face of consolidation. The comparison across ninety-six newspapers is complicated by the fact that the period immediately surrounding an election is highly politically charged and often not representative of a newspaper's decisions over the course of the rest of the year. Opines one editorial page editor, "So many editorial pages carry a moderate-to-liberal tone for 47 months, and on the 48th month of reckoning turn conservative. Some call the presidential endorsements the publishers' four-year itch, and others, the editorial writers' agony." 115

Lastly, all of the above limitations are compounded by the failure to account for uncertainty in measurement. While the naïve standard errors capture sampling variability (which might be fairly small), they ignore the measurement uncertainty (which might be quite large) that is introduced by relying on subjective judgments of students. As such, measures may be falsely precise.

To be sure, the pioneering work of Entman is not to be faulted; indeed, unlike most approaches, it directly attempts to assess viewpoint diversity, and methods we adapt here to overcome the pitfalls of content analysis weren't developed at the time.

\section{Language Processing}

One promising approach to avoid the subjectivity of manual content analysis is automated computational language processing. Over the past few years, rapid advances in computer science and linguistics have enabled scholars to process text information in automated ways, thereby facilitating statistical analysis of large amounts of news. ${ }^{116}$ Text, after all, conveys viewpoints, and automation has the promise of eliminating the subjectivity and fragility of manual content analyses. Indeed, in other work, one of us has capitalized on work in these fields to study legislative speech. ${ }^{117}$ Yet just as with content

115. Hale, supra note 90 , at 169-70 (quoting editorial page editor).

116. See Steven Bird et al., InTRoduction to Natural Language Processing (2005); Daniel JuRafsky \& James H. Martin, Speech and LaNguage Processing: AN Introduction to Natural Language Processing, Computational Linguistics, and SPEECH RECOGNITION (2000); CHRISTOPHER D. MANNING \& HinRICH SchÜTZE, Foundations of Statistical NatURal LaNGUage Processing (1999).

117. Kevin M. Quinn, Burt L. Monroe, Michael Colaresi, Michael H. Crespin \& Dragomir R. Radev, How to Analyze Political Attention with Minimal Assumptions and Costs (July 14, 2008) (working paper), available at http://scholar.iq.harvard.edu/files/ scholar/uploads/5/How_to_Analyze_Political_Attention.pdf. 
analysis, executing such language processing well requires considerable effort, and casual implementation may mislead.

To illustrate this approach, we focus on Professor Halavais's measurement based on word frequencies in editorials and news articles of eight major newspapers covering the 1992,1996 , and 2000 presidential campaigns. ${ }^{118}$ Each newspaper's coverage is represented by a vector of word frequencies. Using "cosine similarity" between these vectors, ${ }^{119}$ the study finds some evidence that news coverage, but not editorial coverage, is converging over time.

To illustrate the intuition of the approach, take an example of three newspapers each using a two-word vocabulary. The left panel of Figure 2 represents the newspapers as vectors in two-dimensional word-space. For instance, newspaper $A$ used word 1 twice and word 2 once, while newspaper $B$ used word 1 four times and word 2 once. One might be tempted to calculate the distance between these vectors as a measure of similarity, to infer that $A$ and $C$ are most similar. But $A$ and $B$ use word 1 more frequently than word 2, while $C$ uses word 2 more often than word 1. Using the cosine between these vectors prevents similarity as an artifact of document length. As seen in the right panel of Figure 2, each of the three vectors is shrunk to length one, and the cosine is related to the distance around the arc between two vectors. By this measure, $A$ and $B$ appear most similar.

Several problems present themselves in Halavais's implementation. First, word frequency counts ignore meaning. Counts can prove useful for topicdetection, ${ }^{120}$ but can be dramatically wrong for detecting effect. For instance, the following two sentences would be viewed as identical under this approach: (a) "The majority got it right, and the minority wrong"; and (b) "The majority got it wrong, and the minority right." Second, measures are not model-based and have no measure of uncertainty. Thus, even if word counts reflect viewpoint diversity, differences may be due to chance variation alone. Third, despite using cosine similarity, the study uses the mean word frequency across all newspapers as a reference point, which effectively captures the amount of coverage. Fourth, the implementation is prone to capture essentially neutral stylistic diversity. Differences across newspapers may be the result of

118. Halavais, supra note 94 , at 97.

119. Formally, if $y_{i}$ and $y_{j}$ are two vectors of word frequencies then the cosine of the angle between these vectors is given by

$$
c_{i j}=\frac{y_{i} \cdot y_{j}}{\left\|y_{i}\right\|\left\|y_{j}\right\|} .
$$

It should be apparent that the cosine of the angle between two vectors is very closely related to the correlation between those two vectors.

120. See Quinn et al., supra note 117. 


\section{Figure 2. Illustration of Word Frequency "Cosine (Dis)similarity"}
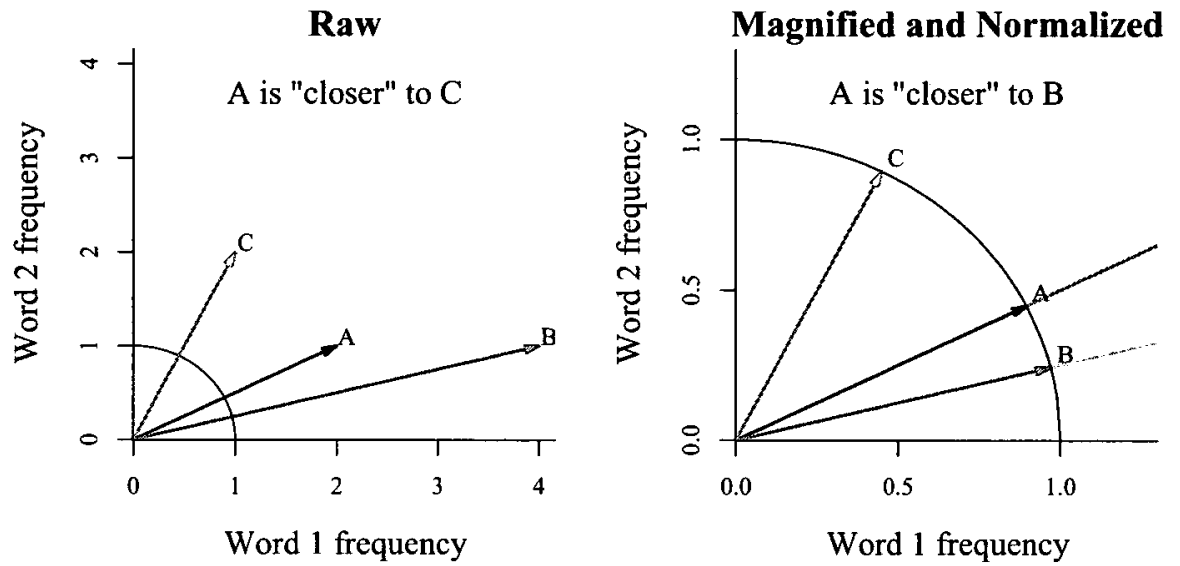

The left panel shows how three newspapers using a two-word vocabulary can be represented as vectors. The right panel normalizes all three vectors to have unit length. The distance around the arc between each vector is related to the "cosine dissimilarity" between the vectors. Newspapers $A$ and $C$ are the closest based on Euclidean distance of the nonnormalized vectors, but newspapers $A$ and $B$ are the most similar based on cosine similarity.

essentially neutral "stop words" such as "nevertheless," "although," and "furthermore." While it is well known that such words tend to provide information about authorship, ${ }^{121}$ there is little reason to think that they provide much leverage on substantive viewpoint diversity.

To demonstrate how difficult it is to interpret such measures of similarity, we apply the same method to all editorials on Supreme Court decisions from 1998-2004 from six newspapers-the Boston Globe, the New York Post, the New York Times, USA Today, the Wall Street Journal, and the Washington Times. The left panel of Figure 3 plots dissimilarity of all six newspapers. Newspapers with values closer to zero are closer to the average over all six newspapers. By this measure, the New York Times and the Washington Timesnewspapers widely believed to be on the extreme liberal and conservative ends of the ideological spectrum - are the most centrist newspapers of these six. The most ideologically centrist of the papers, USA Today, is farthest away from the center. The middle panel of Figure 3 shows that there is a strong negative relationship between dissimilarity and the total number of words of the

121. See Frederick Mosteller \& David L. Wallace, Inference in an Authorship Problem, 58 J. AM. STAT. Ass'N 275 (1963). 
Figure 3. Halavais Dissimilarity Methods Applied to Supreme Court Editorials From Six Major Newspapers
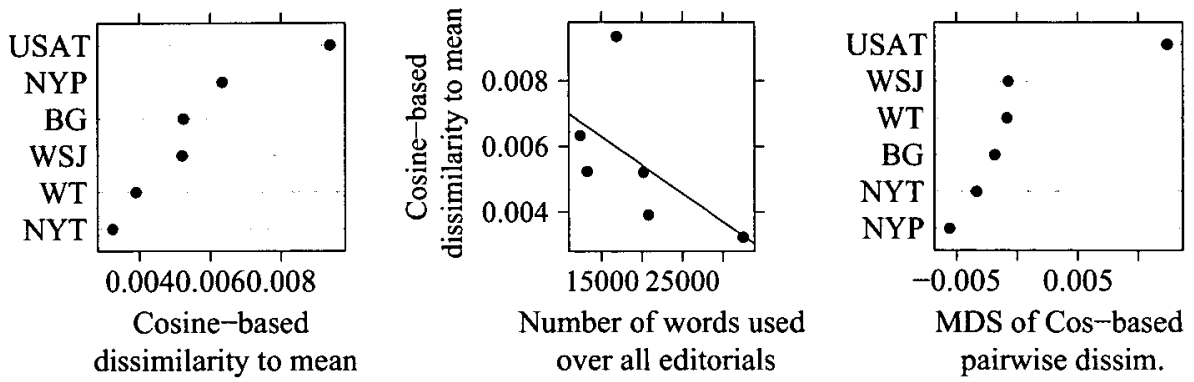

The left panel presents the comparisons of newspapers based on cosine-based similarity to the mean, resulting in the Washington Times and New York Times being most proximate. The center panel plots this measure against the word count of all editorials, showing that the measure effectively measures editorial attention to the Court. The right panel plots results from multidimensional scaling, showing again that the measure does not provide a readily interpretable distinction between newspapers.

editorials. This pattern stems from the fact that the "center" overweights newspapers spilling more ink on a topic. Even ignoring problematic overweighting, the measurement makes little sense. Examining pair-wise measures of dissimilarity, one would hope for some consistency with ideological viewpoints of the papers. Papers widely viewed as fairly liberalthe Boston Globe and the New York Times - should be on one end of the scale and the newspapers commonly understood to be more conservative - the New York Post, the Wall Street Journal, and the Washington Times - should fall on the other. The right panel of Figure 3 uses multidimensional scaling (MDS) to estimate positions, but the results are inconsistent with what nearly all readers would take to be the relative ideological positions of these papers.

While there are problems with this particular implementation, other approaches similar in spirit are promising. For example, Professors Gentzkow and Shapiro - in one of the strongest empirical studies of media news slant ${ }^{122}$ - use automated methods to discern the partisan slant of numerous words and phrases used in congressional speeches. They use this information to infer the ideological position of major newspapers, based on the relative usage of such phrases. Their results are consistent with a model in which consumers demand news slanted to their prior viewpoints and news outlets deliver appropriately slanted news. We view their approach as complementary to ours and show in related work that news and editorial measures are highly correlated. ${ }^{123}$ While they focus on the cross-sectional analysis of news articles

122. See Gentzkow \& Shapiro, supra note 72.

123. See Daniel E. Ho \& Kevin M. Quinn, Measuring Explicit Political Positions of 
and provide a broad-brush analysis of general patterns, we focus on the longitudinal analysis of editorial positions and detailed analysis of specific mergers and acquisitions.

\section{Political Endorsements}

Another common approach to measuring viewpoint diversity is to use endorsements of political candidates made by newspapers as a proxy for the underlying ideological viewpoint of the newspaper. ${ }^{24}$ Indeed, the FCC itself commissioned and relied on studies making use of presidential endorsements. ${ }^{125}$ The advantages of this approach are that (a) it is transparent and easily understood, (b) has good face validity, and (c) is easily calculated. All of these factors might weigh heavily in favor of such a measure. Nonetheless, there is one major problem with such a measure-in an essentially two-party system such as the U.S., the measure can take only two possible values at any time point and thus much nuance is lost. A slightly rightwardleaning newspaper such as the Rocky Mountain News appears to be just as conservative as a newspaper that frequently takes much more extreme positions such as the Investor's Business Daily since both typically endorse the Republican candidate. Further, as we show in Figure 4, through data we've collected about all presidential endorsements from 1992-2004 for our set of newspapers, there is very little variation in endorsement decisions within a newspaper over time. Anecdotal assessments of newspaper viewpoints based on endorsements, such as the statement that "[s]ince Jimmy Carter ran for president in 1976 and 1980 the two newspapers have endorsed different candidates every four years," 126 become significantly less surprising and informative in light of this evidence. While transparency and face validity of this approach are to be applauded, the fact that endorsement-based measures ignore much of the variability of interest makes it difficult to recommend using these measures to assess media diversity.

Media, 3 Q.J. PoL. ScI. 353 (2008).

124. See sources cited supra note 87.

125. See, e.g., Kahn \& Kenny, supra note 52 (examining correlation between Senate candidate endorsement and news coverage); Milyo, supra note 93 (using 2004 presidential endorsement to measure newspaper political ideology to assess effects of cross-ownership rule, as commissioned by the FCC for the 2006 Quadrennial Review); Pritchard, supra note 49 (comparing 2000 presidential endorsement with slant of the news, as commissioned by the FCC).

126. Mike King, Our Aim: Stimulate Dialogue, Exchange Ideas, ATLANTA J.-CONST., Nov. 3, 2001, at 11A. 
Figure 4. Presidential Endorsements of Major Newspapers, 1992-2004
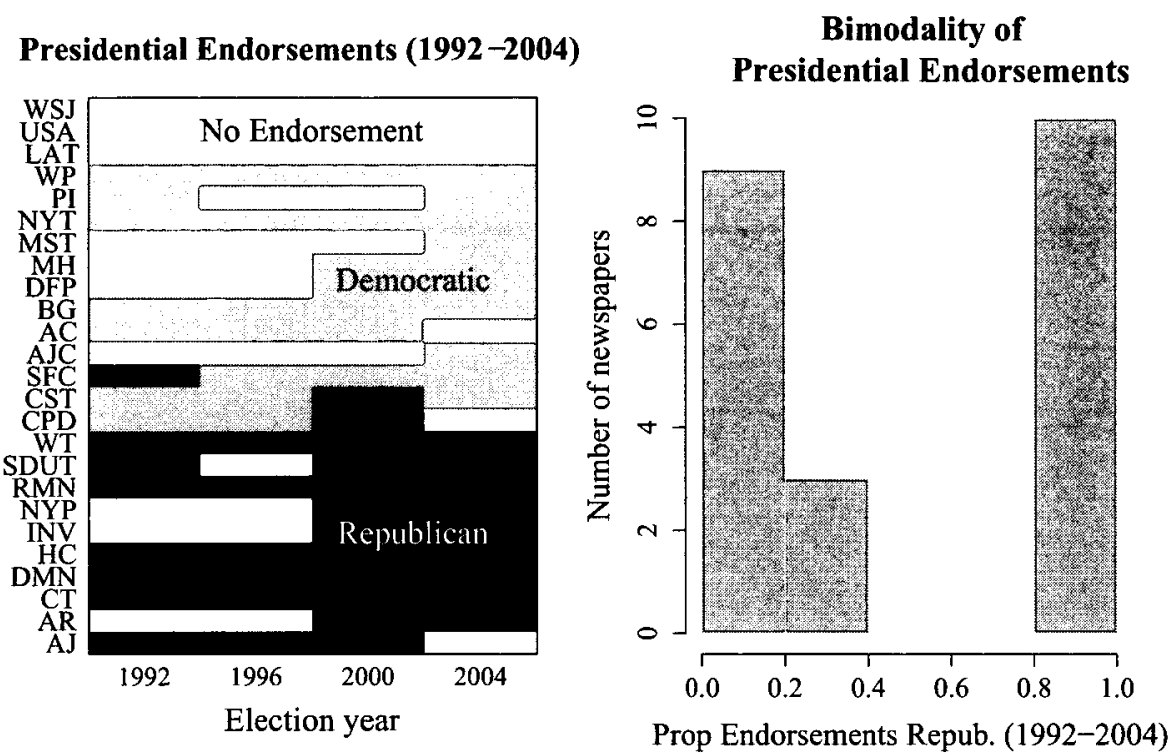

The left panel plots all endorsements of presidential candidates by newspapers for the 1992, 1996, 2000, and 2004 general elections. Newspapers are grouped by endorsement, where white corresponds to no endorsement, gray to Democratic endorsement, and black to Republican endorsement. The Wall Street Journal, USA Today, and Los Angeles Times have policies against endorsing candidates. The right panel plots the histogram of the proportions of each paper's endorsements for the Republican. Proportions are shown because not all newspapers editorialize for all four races. The data are almost completely bimodal, showing that we gain little fine-grained insight into the differences of papers from endorsements.

\section{EMPIRICALLY CAPTURING SUBSTANTIVE VIEWPOINT DIVERSITY}

As Part I shows, the empirical turn in communications law calls for systematic assessment of the convergence hypothesis, but at the same time has run into deep dissensus in academic work over the conception and measurement of diversity. In Part II, we canvassed extant approaches to measuring viewpoint diversity, an enterprise fraught with methodological difficulties. In practice, researchers have been forced to make tradeoffs between validity, replicability, interpretability, and specificity. Some measures-such as the use of presidential endorsements to proxy viewpoint-have good validity, replicability, and interpretability but miss much of the nuance in viewpoints of interest. Other measures-such as the FCC's diversity index-are easily replicable and would seem to offer substantial market-specific information, but fail to provide valid measures of viewpoint diversity. Indeed, the diversity 
index assumes the very answer to whether structural regulations can stem convergence associated with consolidation. Moreover, the large majority of existing approaches fall short of accurately representing uncertainty in viewpoint measures.

In this Part we offer a solution that capitalizes on rapid advances in the statistics of measurement. The key insight is that because "viewpoints" can be complex and elusive, we cannot capture them deterministically with any single measure. Instead, the resounding consensus in empirical measurement is to treat such a concept as an unobserved variable measured with error. ${ }^{127} \mathrm{We}$ collect as much information about newspaper viewpoints as possible and use a probabilistic model that captures systematic differences between them. Any single indicator (e.g., a Washington Post editorial that sides with a dissent by Justice Scalia) can be off by pure chance alone, so the challenge is to collect information where newspapers are opining on common issues. To solve this, we use Supreme Court cases as "bridges" across all of these editorials. Even when only a handful of newspapers write on a particular case, these cases are connected by the fact that the Justices almost all vote on each case. The result is a reliable and substantively meaningful scale, on which we can compare newspapers to judicial ideology in the descriptive sense.

We focus on editorial viewpoint diversity for several reasons. First, and most importantly, it plays a central role in communications law. ${ }^{128}$ Time and

127. See Georg RASCH, Probabilistic MOdEls for SOME INTELligence AND ATtAINMENT TESTS (1960); Simon Jackman \& Shawn Treier, Democracy as a Latent Variable, 52 AM. J. POL. SCI. 201 (2008); Simon Jackman, Measurement, in OXFORD HANDBOOK OF POLITICAL METHODOLOGY 119 (Henry Brady et al. eds., 2008).

128. See, e.g., Biennial Order, supra note 7, qा 18-35, at 13,627-31, ๆ9 361-64, at 13,762-65 (discussing numerous studies measuring express editorial viewpoint); Review of the Commission's Regulations Governing Television Broadcasting, 10 F.C.C.R. 3524, at 62 n.79, 96 n.122 (1994) (discussing editorial endorsements and noting that "[s]tations that editorialize; we believe, are contributing to the mix of ideas and, thus, are making a contribution to viewpoint diversity"); Amendment of Section 73.3555 of the Commission's Rules, the Broadcast Multiple Ownership Rules, 4 F.C.C.R. 1741, I 18 (1989) (discussing differing editorial endorsements of political candidates by commonly owned stations); Amendment of Section 73.3555, [formerly Sections 73.35, 73.240, and 73.636] of the Commission's Rules Relating to Multiple Ownership of AM, FM and Television Broadcast Stations, 100 F.C.C.2d 17, at 9 (1984) ("Evidence in this proceeding suggests that group owners do not impose a monolithic editorial viewpoint on their stations."); Amendment of Multiple Ownership Rules, supra note 12, 132 (discussing and endorsing separation of editorial boards as protection for diversity); Amendment of Sections 73.35, 73.240 and 73.636 of the Commission's Rules Relating to Multiple Ownership of Standard, FM, and Television Broadcast Stations, 28 F.C.C.2d 662, If 25 (1971) (discussing survey results including, inter alia, editorializing); Amendment of Sections 73.35, 73.240 and 73.636 of the Commission Rules Relating to Multiple Ownership of Standard, FM, and Television Broadcast Stations, 22 F.C.C.2d 306, T19 (1970) ("[S]ection 315 of the Communications Act, the Commission's Fairness Doctrine, and the Commission's rules relating to personal attacks and station editorials on candidates for public office all contribute substantially toward insuring that, whatever a station's ownership, and the views of the licensee, each station will present conflicting viewpoints on controversial issues."). 
again, the Commission has focused on editorials that take concrete positions on public policy issues, not merely editorializing in the sense of editing. By the Commission's own conception of viewpoint diversity, editorializing stands front and center.

Second, and relatedly, the underlying policy goal of fostering viewpoint diversity stems from deliberative democratic values. Viewpoint diversity is seen to promote a healthy, functioning democracy, by improving the audience's political choices, increasing democratic participation, and furthering voter knowledge. ${ }^{129}$ "[D]iversity of opinion" has been "tied intrinsically to the "public interest." "130 Focus on program or outlet diversity (e.g., the amount of sports reporting) does not capture this crucial pro-"social" aspect of viewpoint diversity. ${ }^{131}$ Our measure attempts to capture one central element of this democratic conception of viewpoint diversity.

Third, as we discuss below, using editorial viewpoints circumvents many of the conventional problems of subjectivity of measurement and allows us to directly account for the uncertainty of viewpoints.

Schematically, our measurement approach works as follows. First, in a considerable undertaking, we collect all editorials from major newspapers that opine on a Supreme Court decision. We read and code every editorial as either expressing clear agreement or clear disagreement with the majority position of the Court. We then use these editorial positions to infer the ideological viewpoint of each newspaper's editorial board by state-of-the-art statistical adjustment. ${ }^{132}$ The statistical adjustment allows us to directly account for differences of positions within the same newspaper, newspaper decisions not to write (i.e., "missing" editorials), newspaper positions that fail to adopt a clear stance on the merits of a case, differences between cases, and differences across time. In what follows, we elaborate on the components of our research design - data collection, coding, the statistical framework for inferring editorial viewpoints, mergers and acquisitions of interest, and limitations of our approach.

129. See Wildman, supra note 64 , at 170 .

130. MARA EINSTEIN, MEDIA DIVERsity: ECONOMICS, OWNERSHIP, AND THE FCC 1 (2004) (emphasis added) (equating "diversity" with "diversity of opinion" (emphasis added)); see also Compaine, supra note 81, at 771 ("Measuring diversity is more difficult than tracking differences in programming, but presumably more to the point of concerns about ownership. Ultimately the objective is to promote content diversity: of ideas or attention to issues."); Philip J. Weiser, The Ghost of Telecommunications Past, 103 MiCH. L. REV. 1671, 1690 n.50 (2006) (using "the term [diversity] to represent different ideological viewpoints").

131. See Shelanski, supra note 8 , at $384,397-99$.

132. See Ho \& Quinn, supra note 123. The method developed in the current Article extends this earlier work by allowing viewpoints to change over time. 


\section{A. The Data: Supreme Court Editorials, 1988-2004}

We focus primarily on the period of the last natural Rehnquist Court (19942004), but also backdate our database to 1988 to take into account the New York Times's acquisition of the Boston Globe. Table 1 lists the papers along with the Terms we cover.

These newspapers include seventeen of the top twenty newspapers by circulation. ${ }^{133}$ Excluding the Atlanta Constitution and the Atlanta Journal (which merged into the Atlanta Journal-Constitution), the combined circulation figures for these newspapers accounts for $48 \%$ of the total circulation of the 100 highest circulation newspapers in 2004. ${ }^{134}$ Our data include every newspaper the Commission considers a national news source. ${ }^{135}$

During this observation period, we focus our attention on 1186 cases (691 from the 1988-1993 Terms and 495 from the 1994-2004 Terms ${ }^{136}$ ) on which editorials could be written. We selected cases from the Original U.S. Supreme Court Judicial Database ${ }^{137}$ using standard criteria, yielding all nonunanimous, formally decided cases before the Court during this period. ${ }^{138}$ We restrict our attention to nonunanimous cases for two reasons. First, a unanimous decision contains no information to distinguish the Justices and only contains information about the viewpoint of a newspaper if that newspaper disagrees with the Court's decision. Pilot data collection suggested extremely few instances where an editorial board writes on a unanimous decision, not to mention where it explicitly disagrees with the Court. Second, given that roughly half the decisions were unanimous, searching for editorials on all decisions would roughly double data collection costs while making little difference for our substantive conclusions. With a large research team of law students and undergraduates at Harvard and Stanford University, we searched for all (unsigned) editorials, representing the official position of the

133. Three of the top twenty newspapers from which we did not collect editorials are the New York Daily News, Newark Star-Ledger, and Newsday (N.Y.). Given the costs of collecting these data, these newspapers were ignored to obtain more even geographic coverage.

134. These figures are based on the circulation figures published by the Detroit Free Press. 100 Largest U.S. Newspapers, 2004, DetroIT FrEE PRESS (2006), available at http://www.freep.com/legacy/jobspage/links/top100_04.htm.

135. See Biennial Order, supra note 7 , at 13,886 .

136. Two of these 495 cases are actually from the 2005 Term but were decided by the last natural Rehnquist Court.

137. Harold J. Spaeth, The Original United States Supreme Court Judicial DATABASE (2007), available at http://www.cas.sc.edu/poli/juri/sctdata.htm.

138. See, e.g., Andrew D. Martin \& Kevin M. Quinn, Dynamic Ideal Point Estimation via Markov Chain Monte Carlo for the U.S. Supreme Court, 1953-1999, 10 POL. ANALYSIS 134,137 (2002) (using same mechanism to select cases). 
Table 1. Newspapers, Abbreviations, and Supreme Court Terms Covered

\begin{tabular}{|c|c|c|}
\hline Newspaper & Abbreviation & $\begin{array}{l}\text { Court Terms } \\
\text { Covered }\end{array}$ \\
\hline Arizona Republic & $\mathrm{AR}$ & $1999-2004$ \\
\hline Atlanta Constitution & $\mathrm{AC}$ & $1994-2000$ \\
\hline Atlanta Journal & $\mathrm{AJ}$ & $1994-2000$ \\
\hline Atlanta Journal-Constitution & AJC & $2001-2006$ \\
\hline Boston Globe & $\mathrm{BG}$ & $1988-2004$ \\
\hline Chicago Sun-Times & CST & 1994-2004 \\
\hline Chicago Tribune & CT & $1994-2004$ \\
\hline Cleveland Plain Dealer & $\mathrm{CPD}$ & $1994-2004$ \\
\hline Dallas Morning News & $\mathrm{DMN}$ & $1994-2004$ \\
\hline Detroit Free Press & DFP & $1997-2003$ \\
\hline Houston Chronicle & $\mathrm{HC}$ & $1994-2004$ \\
\hline Investor's Business Daily & INV & $1997-2004$ \\
\hline Los Angeles Times & LAT & 1994-2004 \\
\hline Miami Herald & $\mathrm{MH}$ & 1994-2004 \\
\hline Minneapolis Star-Tribune & MST & $2001-2004$ \\
\hline New York Post & NYP & $1997-2004$ \\
\hline New York Times & NYT & $1988-2005$ \\
\hline Philadelphia Inquirer & $\mathrm{PI}$ & 1994-2004 \\
\hline Rocky Mountain News & RMN & 1994-2004 \\
\hline San Diego Union-Tribune & SDUT & $1999-2004$ \\
\hline San Francisco Chronicle & SFC & 1994-2004 \\
\hline USA.Today & USA & 1994-2004 \\
\hline Wall Street Journal & WSJ & 1994-2004 \\
\hline Washington Post & WP & 1994-2004 \\
\hline Washington Times & WT & 1994-2004 \\
\hline
\end{tabular}

Terms are more limited for some newspapers due to limited availability on Lexis and America's Newspapers. Coverage for New York Times and the Boston Globe extends to 1988 to examine the impact of the Times's acquisition of the Globe.

newspaper's editorial board, on these cases. Through this exhaustive data collection, we collected over 1500 newspaper editorials that expressed 1618 editorial-case positions. Subpart A of the Appendix provides additional information about the editorial collection process.

To provide a sense of this data, the left panel of Figure 5 plots the fraction of nonunanimous cases that each newspaper covered in editorials from 19942004. The panel shows substantial variability in coverage of the Court-the New York Times and the Washington Post cover over $25 \%$ of cases, whereas 


\section{Figure 5. Supreme Court Editorial Publication Rates by Newspaper and Prominence of Case}

\section{Editorial Coverage of Supreme Court}

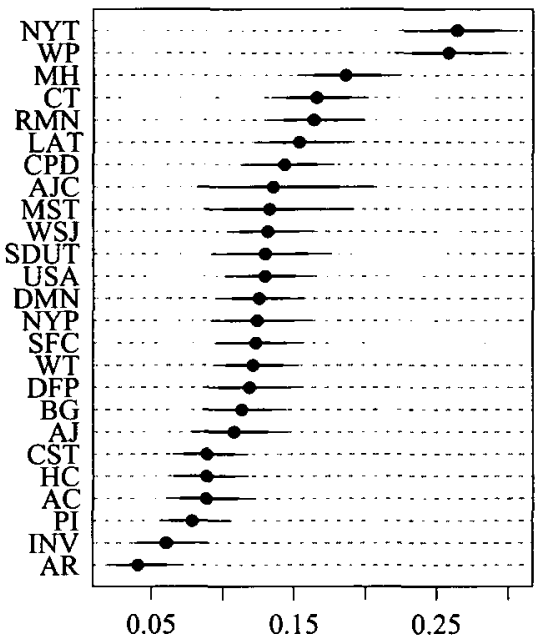

Publication rate
Distribution of Editorials

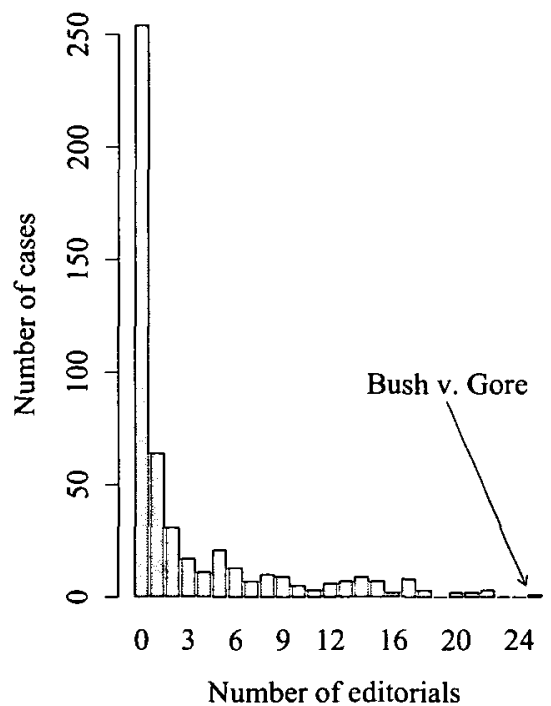

The left panel plots the proportion of all nonunanimous opinions that a newspaper covered in an editorial, with $80 \%$ and $95 \%$ intervals. This shows considerable variation in editorial coverage, ranging from as high as a quarter of all cases, e.g., by the New York Times and the Washington Post, to less than $5 \%$ of all cases by the Arizona Republic. The right panel plots the number of cases by the number of editorials written on each case. The right-most bar represents Bush $v$. Gore, which every editorial board covered. This histogram shows skewed case coverage.

the Arizona Republic covers only about $2 \%$. On average, newspapers wrote editorials on about $10 \%$ of nonunanimous decisions. The right panel of Figure 5 plots a histogram of the number of editorials written per case. Roughly half of all nonunanimous decisions were not covered by any newspaper in our study. Only a small number of cases were dealt with on the editorial page of more than ten of the twenty-five newspapers under study. These highly prominent cases include Bush v. Gore, ${ }^{139}$ which received editorial coverage from all papers (more than any other case from 1994-2004), Hamdi v. Rumsfeld, ${ }^{140}$ and Grutter v. Bollinger, ${ }^{141}$ to which 22 editorials were devoted each, and 
Figure 6. Editorial Coverage of the Supreme Court by Term
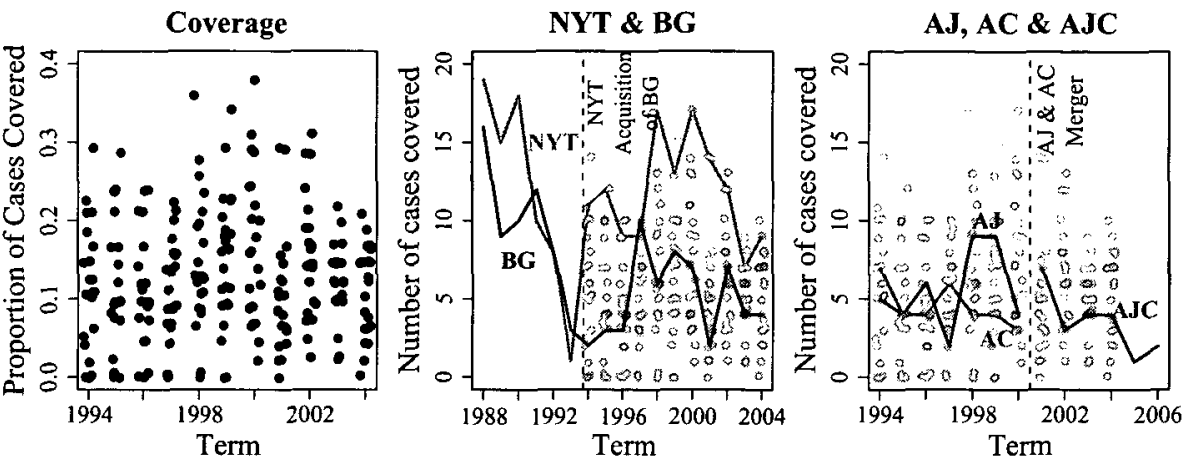

The left panel plots the proportion of the Court's nonunanimous cases covered on the editorial pages of each newspaper. Dots are jittered along the $x$-axis for visibility. The middle panel retains these in the background in light grey, and overlays the New York Times and Boston Globe counts in the foreground. The right panel plots counts for the Atlanta Journal, Atlanta Constitution, and the Atlanta Journal-Constitution.

Lawrence v. Texas, ${ }^{142}$ on which 21 editorials were written. ${ }^{143}$ The data also include less prominent cases, such as Rogers v. Tennessee ${ }^{144}$ and Koon v. United States, ${ }^{145}$ which each received only one editorial (from the Washington Post and the Los Angeles Times, respectively).

The left panel of Figure 6 plots out the proportion of editorials over time, with Court Terms on the $x$-axis. On average the newspapers in our study write on just over $10 \%$ of the nonunanimous decisions per Term, which amounts to only 5 editorials per year. This ranges from a low of 0 in some cases to a high of almost 20 for the New York Times. While we have considerable information about each newspaper (far more, for example, than any approach relying on presidential endorsements), taking into account this "sparseness" over time will be critical in our analysis. Our statistical approach described in Subpart C does this directly, allowing for "smoothing" over time, while accurately capturing uncertainty.

\section{B. Coding of Editorials}

With these editorials in hand, we coded the position advanced by the

142. 539 U.S. $558(2003)$.

143. Note that because of differences in the observation period for newspapers (e.g., the Atlanta Journal per se ceased to exist in 2001), see infra Subpart III.D, we would not necessarily expect a maximum of 25 editorials for a single case.

144. 532 U.S. 451 (2001).

145. 518 U.S. 81 (1996). 
editorial board on each case. Research assistants provided a preliminary coding of one if the newspaper clearly agreed with the position of the majority on the merits of the case, zero if the newspaper clearly agreed with the position of the minority on the merits, and "missing" if the newspaper's position on the merits was unclear. ${ }^{146}$ For example, for Lawrence, we coded the Washington Times as agreeing with the minority for editorializing:

The Supreme Court turned the Constitution upside down yesterday. ... In a brazen example of judicial overreach, the court ... ruled against all sodomy laws in all states. This is bad law; the Constitution protects the rights of the states to legislate on these matters. ${ }^{147}$

The Arizona Republic, on the other hand, was coded as agreeing with the majority:

It is fair to say that in this instance the law is only now catching up to conclusions regarding justice and decency.... Conservatives and liberals alike can, and do, look at such laws as an outrageous intrusion into the privacy of adults.

…

A right to privacy is a fundamental part of the American experience. More important, it is a right that is meaningless unless it applies across the board, to all Americans. Now, by a $6-3$ vote, it does. ${ }^{148}$

We were particularly conscientious not to impute an opinion unless an editorial board took a clear stance on the legal merits of a case. For example, we coded as unclear the Washington Post's editorial on Burlington Industries, Inc. v. Ellerth, ${ }^{149}$ when it opined that "[t]he good news is that the Court's decision[] clarif[ies] significantly the circumstances under which employers incur liability for the sexually coercive or obnoxious behavior of their employees" but that "[t]he bad news is that the decision[] could well subject employers to liability for behavior they could not reasonably have stopped and, as a consequence, could encourage them to regulate obtrusively their workplaces." 150

A major advantage of our approach is that coding was by and large easy, as newspaper editorials typically make the position of the newspaper quite clear. Research assistants made a simple-essentially dichotomous-coding decision.

146. The coding was not blind in that research assistants could have learned the identity of the newspaper, but research assistants were specifically instructed to ignore the identity of the newspaper for purposes of determining the position of an editorial. The fact that editorials weren't strictly blinded does not present a serious problem because each editorial was read and coded by at least one research assistant and principal investigator.

147. Editorial, Privacy Amok, WASH. TIMES, June 27, 2003, at A22.

148. Editorial, Legal Relics; Our Stand: 'Texas' Sodomy Law Example of Biases We'd Like to Forget, ARIZ. REPUBLIC, June 28, 2003, at 8B.

149. 524 U.S. 742 (1998).

150. Editorial, More Harassment, WASH. Post, June 28, 1998, at C6. 
Figure 7. Direction Position of Newspapers on the Legal Merits

Direct Position on Legal Merits

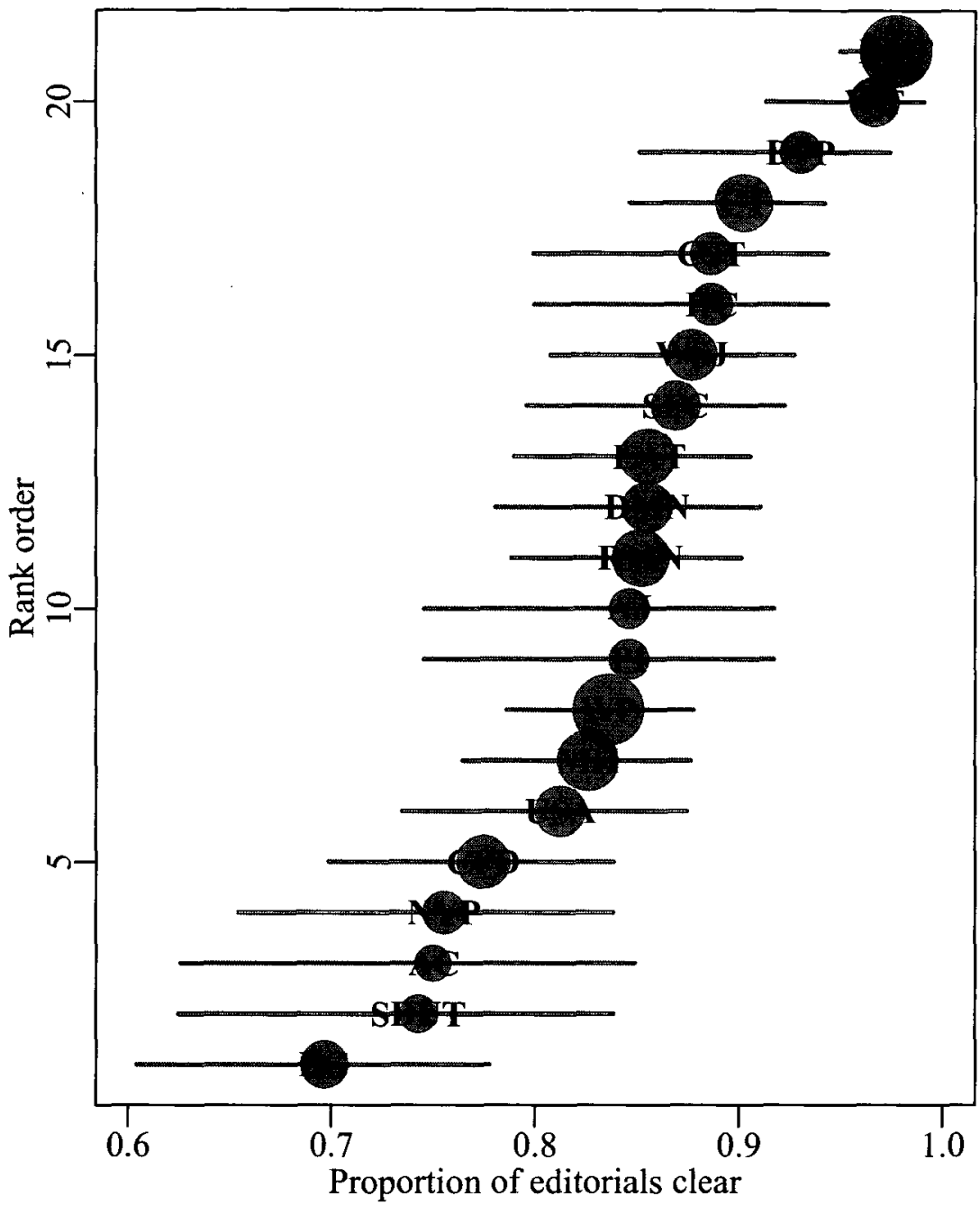

Newspapers are sorted by the proportion of clear editorials. Only newspapers with more than 30 editorial positions on cases are included in this panel. Points are weighted by the number of editorial positions, and horizontal lines represent $80 \%$ exact binomial intervals.

Contrary to coding whether a decision was "liberal" or "conservative," only agreement or disagreement with the majority was required, facilitating reliability and consistency of coding. With preliminary coding decisions, we personally read all the editorials to validate the data. While this process was exhaustive and time-intensive, the result is that we are extremely confident in 
the accuracy of the coded editorial positions. Intercoder variation was negligible.

Figure 7 plots the proportion of editorials on a case that took a clear stance on the legal merits. The newspapers are sorted in order of clarity. The Boston Globe is the least clear, expressing clear agreement or disagreement on the legal merits of a decision only $70 \%$ of the time. The New York Times and Washington Times, on the other hand, almost always take a clear position. The fact that even the lowest rate of clarity is around $70 \%$ ensures that we are efficiently collecting information about the newspapers.

\section{Statistical Inference of Viewpoint Diversity}

With the coded editorials in hand, it becomes possible to estimate the relative viewpoints of the newspapers. A simple approach, one we do not espouse, would be to use preexisting liberal-conservative coding of Supreme Court decisions such as those of Spaeth ${ }^{151}$ to simply tabulate the fraction of editorials that supported the conservative bloc of the Court. Figure 8 presents the results of doing this for all of the nonunanimous cases and associated editorials from 1994-2004. This intuitive measure of viewpoint diversity would seem to have good face-validity; newspapers commonly viewed as being liberal, such as the New York Times and the Detroit Free Press, rarely support "conservative" decisions of the Court while papers such as the Wall Street Journal and the Washington Times, which are widely perceived to be conservative, frequently do. One can also track changes over time by calculating these fractions of support for conservative decisions in each year. This is plotted for a subset of newspapers and Justices in Figure 9, which shows that the yearly data comport with the conventional wisdom. While the simple approach described above has several positive attributes, it is severely limited. First, it depends on the accurate liberal-conservative coding of Supreme Court decisions. Even with truly neutral coders working for purely academic purposes this can be a difficult and value-laden enterprise (and indeed might be a result of newspaper coverage). In the context of rulemaking, where strong incentives exist to arrive at particular outcomes, it may be inappropriate to rely on subjective human judgment to this degree.

Second, the simple counting approach described above weights all caseeditorials equally, resulting in two problems: (a) not all "conservative" decisions are equally conservative, and (b) not all decisions are driven by the same underlying latent viewpoint. Regarding (a), a newspaper that sides with the majority in an eight-to-one decision with Stevens dissenting would appear

151. Spaeth hand codes whether a decision of the Court was liberal or conservative based on a formal coding scheme. The resulting variable is the "DIR" variable. See SPAETH, supra note 137. 
Figure 8. Fraction of Conservative Decisions on Cases from 1994-2004 Terms for Justices and Newspapers

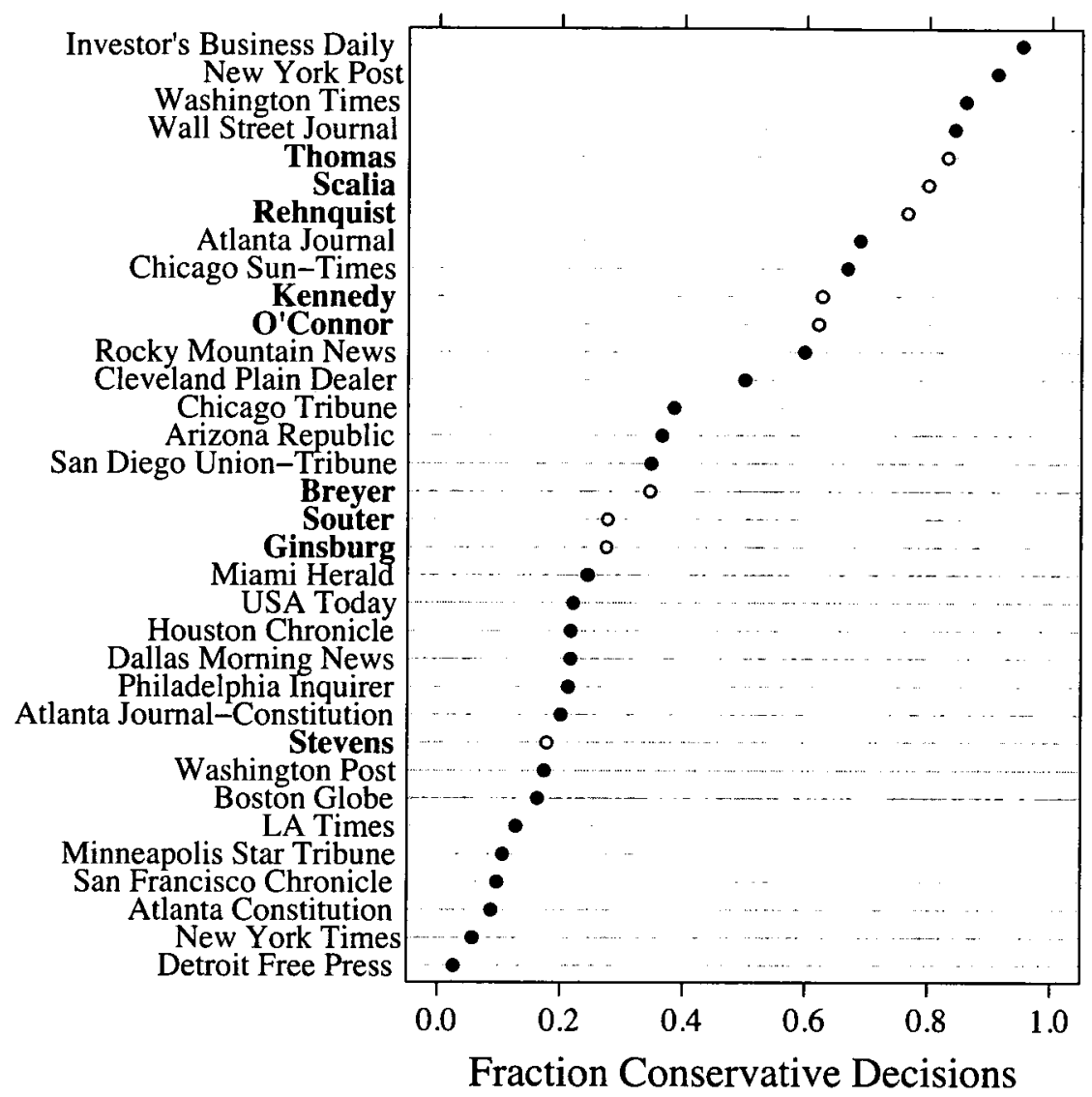

The solid dots represent newspapers, and the hollow dots represent the Justices. This figure shows that a naïve, unadjusted comparison would suggest that a considerable number of newspapers are more extreme than the most extreme Justices.

to be as conservative as a newspaper that disagreed with an eight-to-one decision in which Thomas dissented. Yet agreeing with a one-Justice minority is likely more informative than siding with an eight-Justice majority. On (b), a modest number of decisions - such as Blakely v. Washington, ${ }^{152}$ with Justices Rehnquist, Kennedy, O'Connor, and Breyer in the minority-are less obviously explained by some common underlying viewpoint. Nonetheless, the conventional (inappropriate) approach in the Supreme Court database is to treat 
nearly all votes ${ }^{153}$ as being either liberal or conservative. ${ }^{154}$ This threatens the validity of the simple measure, since the editorial in favor of the minority position in Blakely is counted as equally conservative as an editorial expressing support for Justice Scalia's lone dissent in United States $v$. Virginia. ${ }^{155}$ The problem is exacerbated by the fact that newspapers affirmatively choose cases on which to editorialize and the fact that the coverage rate differs considerably across papers. Any method of inferring editorial viewpoints should take into account differences in both Supreme Court decisions and coverage.

Finally, the naïve method of tracing viewpoint diversity over time as in Figure 9 assumes the fraction of conservative editorials is independent of conservatism in nearby time periods. Not only is this implausible, but it also results in excess variability of the measures, especially for newspapers filing a relatively small number of Court editorials per year. It is unlikely, for example, that the Wall Street Journal went from being as conservative as possible in 1994, to a moderate position just to the right of O'Connor in 1995, back to being uniformly conservative in 1997 . Such variability is likely due to chance alone. Statistically, we need a way to borrow strength from neighboring time periods to reduce the variability of estimates in a substantively reasonable way.

The model-based method of measuring viewpoint diversity used in this Article addresses all three of these concerns while remaining facially valid and easy to interpret. In essence, our method treats the newspaper editorials as phantom votes on the merits and then analyzes the editorials jointly with the real votes on the merits, adapting and improving on a model one of us has developed elsewhere. ${ }^{156}$ This allows us to place the editorial pages of major newspapers on a long-validated and substantively meaningful descriptive scale of judicial ideology. In addition, it provides for a principled way to partially pool information across Terms while retaining appropriate measures of uncertainty.

At the heart of our model is an assumption that the majority of merits decisions can be summarized by a probabilistic "spatial" model: that is, the majority of decisions are assumed to be probabilistically driven by a single underlying viewpoint dimension, which may be interpreted as "liberal" to "conservative" (but is in fact empirically defined, as the only information about the Justices is whether they voted to affirm or reverse the lower court). We extend that logic to include the editorial decisions of major newspapers. While this is clearly not a comprehensive model of decision making on the Court (or

153. For some limited number of entries, directional codings are not assigned.

154. In the case of Blakely, Spaeth codes the majority opinion as liberal.

155. 518 U.S. 515, 566 (1996) (Scalia, J., dissenting).

156. See Martin \& Quinn, supra note 138. 


\section{Figure 9. Fraction of Conservative Decisions by Term for Selected Justices and Newspapers, 1994-2004}

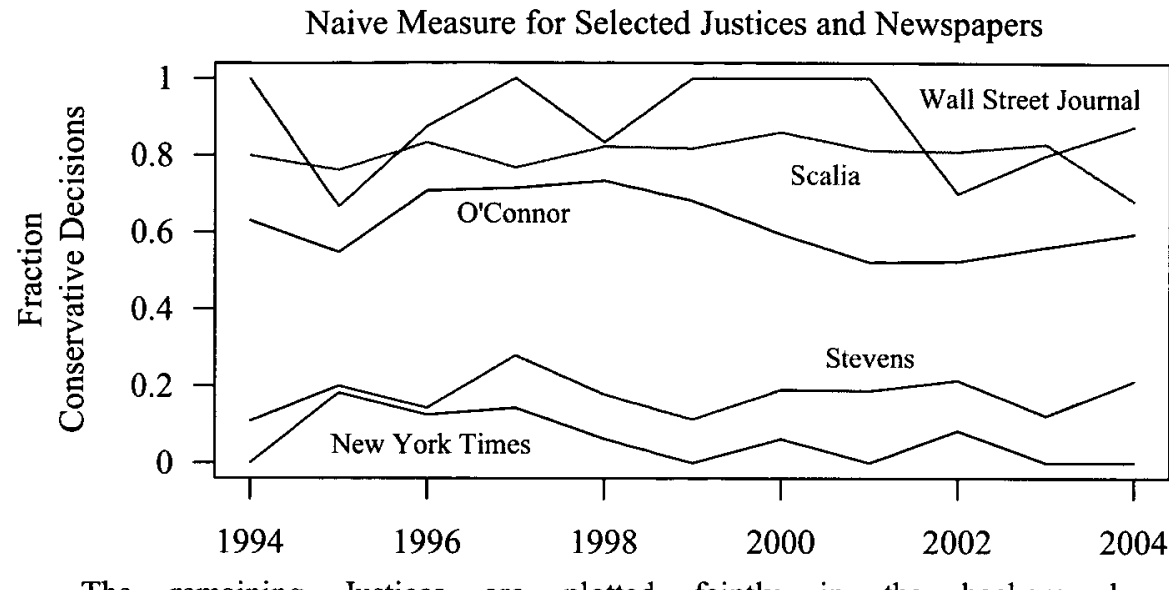

The remaining Justices are plotted faintly in the background.

editorial boards), it is a reasonable descriptive approximation. ${ }^{157}$ The class of models we utilize stems from well-established research in psychological measurement and has long been adapted and validated for political science and economics, where the models are known as "ideal-point" models. ${ }^{158}$ The viewpoint or ideology (in the nonpejorative sense) of an actor is represented by an "ideal point" on the real line. The model assumes that the probability of an actor voting for a specific option (e.g., writing an editorial in favor of the majority in Lawrence) is a function of that actor's viewpoint and two casespecific parameters: the first models how much disagreement the case will generate and the second models how much the disagreement is driven by the underlying dimension. We jointly estimate actor viewpoints and case parameters given the available data and modeling assumptions. A key point is that the model does not treat all cases equally - each unique voting pattern may contribute a different amount of information about the locations of Justices and viewpoints of newspapers. Nor is the model deterministic, allowing for decisions that deviate from the underlying dimension. We see these as major

157. A number of studies have independently made use of our model's scores. See, e.g., Brandice Canes-Wrone, Bureaucratic Decisions and the Composition of the Lower Courts, 47 AM. J. Pol. SCI. 205, 210 (2003); Keith Krehbiel, Supreme Court Appointments as a Move-the-Median Game, 51 AM. J. POL. SCI. 231 (2007); Jeffrey Segal et al., Congress, the Supreme Court, and Judicial Review: Testing a Constitutional Separation of Powers Model (July 4, 2007) (unpublished paper presented at Empirical Legal Studies Conference, November 2007), available at http://papers.ssrn.com/sol3/papers.cfm?abstract id=998164.

158. See Keith T. Poole \& Howard Rosenthal, Congress: A Political-Economic History of Roll Call Voting 12-13 (1997); Joshua Clinton et al., The Statistical Analysis of Roll Call Data, 98 AM. POL. SCI. REv. 355 (2004). 
advantages over simple approaches based on counting conservative or liberal decisions.

Figure 10 provides some intuition about how our procedure works and illustrates some of its advantages. ${ }^{159}$ The upper-left panel of Figure 10 displays the probability of siding with the five-Justice majority in Printz $v$. United States ${ }^{160}$ as a function of the estimated viewpoints of the newspapers and Justices. Cases such as Printz tell us that newspapers that sided with the majority composed of Justices O'Connor, Kennedy, Rehnquist, Scalia, and Thomas are likely somewhere to the right of the midpoint between Justice O'Connor (the most leftward located member of the majority) and Justice Breyer (the most rightward located member of the minority). Similarly, newspapers that sided with the minority composed of Justices Breyer, Souter, Ginsburg, and Stevens are likely somewhere to the left of the midpoint between Justice O'Connor and Justice Breyer. A single case cannot tell us anything about where to the right or to the left of the cut point a newspaper is located.

To learn where a particular newspaper's viewpoint is located we need to look at multiple cases with distinct voting patterns. The lower-left panel of Figure 10 plots the observed votes and editorials on Lawrence v. Texas, ${ }^{161}$ along with the estimated probability of siding with the majority. In this case, the six-to-three vote provides more information about the viewpoints of newspapers that sided with the minority (they are probably to the right of the midpoint between Chief Justice Rehnquist and Justice Kennedy) while at the same time providing somewhat less information about the viewpoints of newspapers that sided with the majority (they are probably to the left of the midpoint between Chief Justice Rehnquist and Justice Kennedy). Making this point even more strongly is the lower-right panel, which displays vote and editorial information from United States v. Virginia. ${ }^{162}$ Here we see a seven-toone decision with Justice Scalia in the minority. This case provides a great deal of information about the location of newspapers-such as the Wall Street Journal and the Washington Times - that sided with Justice Scalia but little information about newspapers that sided with the majority.

The model also allows for cases that do not result in a decision consistent with the simple unidimensional ordering of the Justices and newspapers, such as Blakely $v$. Washington, ${ }^{163}$ presented in the top-right panel. The four-person minority consisted of Justices Breyer, O'Connor, Kennedy, and Rehnquist. As we can see by the flat fitted probability line, this case does a poor job of discriminating between leftward-leaning and rightward-leaning Justices and

159. All estimates in this figure are from an analysis in which the 1994-2004 data are pooled and ideal points and viewpoints are assumed constant over time. We relax this assumption for the substantive viewpoint analysis we conduct later in the paper.

160. 521 U.S. 898 (1997).

161. 539 U.S. 558 (2003).

162. 518 U.S. 515 (1996).

163. 542 U.S. 296 (2004). 
newspapers. Consequently, the model downweights its contribution to any estimates of viewpoints. (We refer the reader to Subpart $\mathrm{C}$ of the Appendix for a more formal treatment of the model.)

\section{Mergers and Acquisitions}

In order to assess the convergence hypothesis, we focus on all major ownership changes occurring within our set of newspapers from 1988-2004. Five such changes occur during our observation period. This strategy has several crucial advantages. First, it allows us to circumvent difficult questions of how to measure market concentration over time. Sharp disagreement, for example, surrounds whether the media has in fact become more concentrated. ${ }^{164}$ It is difficult to assess the impact of direct changes in ownership regulations using raw measures of market concentration, as many other factors are changing at the same time. Second, our design has the critical advantage of allowing us to hold constant crucial market characteristics (and to assess changing market dynamics) in a given market. This overcomes the weakness of simple "cross-sectional" analyses of media markets in different geographic regions. A dynamic media market like that of New York City may exhibit lots of viewpoint diversity and low concentration, but to compare it to the media market of Palo Alto, California (where there is perchance less diversity and more concentration) would be a mistake. By matching acquired and acquiring newspapers, we capitalize on both temporal and cross-sectional variation, thereby using many of the well-known features of matched panel designs, which have proven particularly useful in empirical legal studies. ${ }^{165}$ To our knowledge, this is the first work embedding this type of panel design in an "item-response theoretic" measurement framework.

Lastly, our data allow us to examine three types of ownership changes: mergers, direct acquisitions by other newspapers, and an acquisition by a conglomerate group (so-called "chain" ownership). For acquisitions, convergence implies a decrease in the difference of viewpoints between the

164. For example, compare Eli NoAm, Media OwNERShip AND Concentration IN AMERICA (forthcoming 2009), with BAGDIKIAN, supra note 66.

165. See Jefrrey M. WoOldridge, EConometric ANAlysis of Cross SECtion AND Panel Data (2002); David H. Autor et al., The Employment Consequences of WrongfulDischarge Laws: Large, Small, or None at All?, 94 AM. ECON. REv. 440 (2004); David Card \& Alan B. Krueger, Minimum Wages and Employment: A Case Study of the Fast-Food Industry in New Jersey and Pennsylvania, 84 AM. ECON. REv. 772 (1994); John J. Donohue III \& Daniel E. Ho, The Impact of Damage Caps on Malpractice Claims: Randomization Inference with Difference-in-Differences, 4 J. EMPIRICAL LEGAL STUD. 69 (2007); Daniel E. Ho, Kosuke Imai, Gary King \& Elizabeth A. Stuart, Matching as Nonparametric Preprocessing for Reducing Model Dependence in Parametric Causal Inference, 15 PoL. ANALYSIS 199 (2007); Albert Yoon, Damage Caps and Civil Litigation: An Empirical Study of Medical Malpractice Litigation in the South, 3 AM. L. ECON. REV. 199 (2001). 
Figure 10. Illustration of Model-Based Differential Weighting of Votes with Four Cases

Printz v. United States

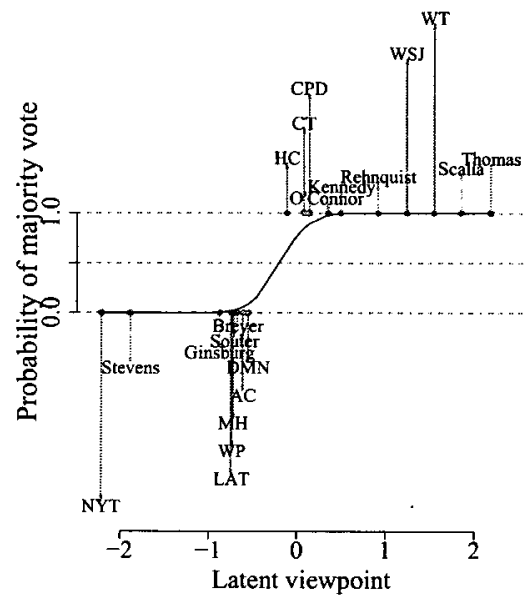

Lawrence v. Texas

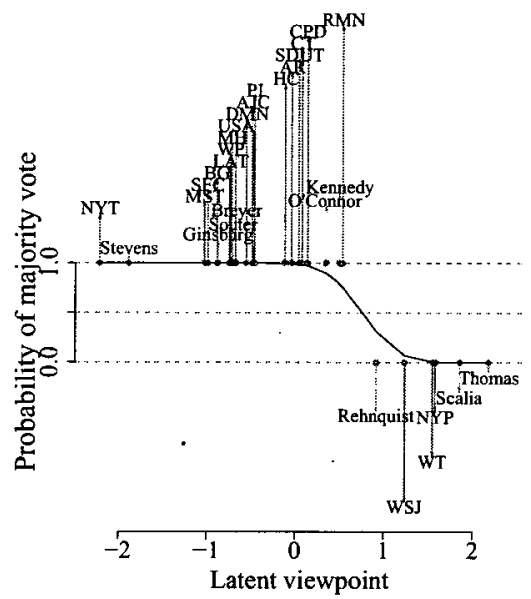

Blakely v. Washington

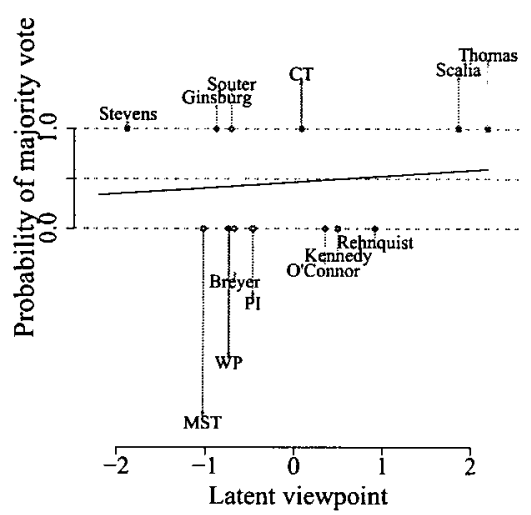

United States v. Virginia

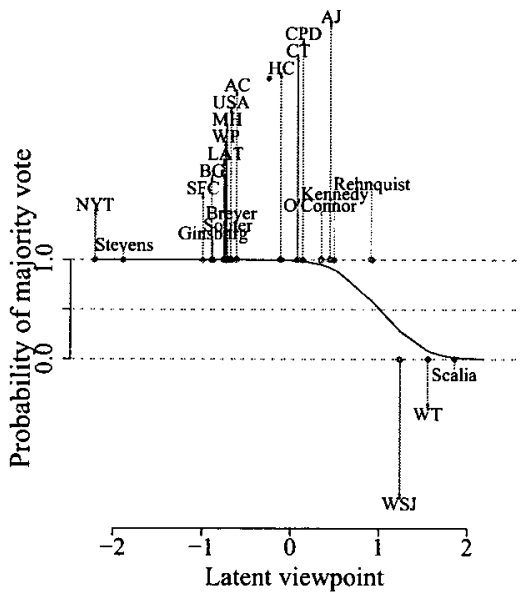

Justices and newspapers are plotted according to the posterior median for their latent viewpoint on the $x$-axis. The curve represents the (logistic) prediction of the probability that each actor casts a majority vote, using the posterior median of the model parameters. The top-left panel plots results for Printz $v$. United States, which illustrates a case for which there is high discrimination between underlying viewpoints, and the direction is in what we might call a conservative direction. The top-right panel plots results for Blakely $v$. Washington, illustrating a case not predicted well by the underlying viewpoint dimension, and therefore contributing little to our understanding of the newspapers. The bottom panels plot data for Lawrence $v$. Texas and United States $v$. Virginia, both of which discriminate extremely well between different actors. 
major newspaper of the acquiring party and the acquired newspaper. For mergers, convergence implies that the merged newspaper reflects a position between the two merging newspapers. We provide a brief overview of the three types of ownership changes, reserving detailed analysis of particular mergers and acquisitions for Part V.

Our ownership changes include one merger of the editorial boards of the Atlanta Journal and the Atlanta Constitution to form the Atlanta JournalConstitution. Strictly speaking, the merger is not an ownership change per se. Cox Enterprises acquired both papers prior to our observation period. The papers merged newsrooms in 1982, with the Constitution serving as the morning and the Journal as the evening paper, but retained separate editorial boards, editorial pages, and mastheads until 2001. In November 2001 the merger became complete, with a unified editorial board and a new masthead for the now-morning paper. Despite the continuity of Cox, the Atlanta JournalConstitution provides an interesting test case for a variety of reasons. First, both papers in principle serve the same metropolitan region, thereby allowing us to hold constant (cross-sectionally) underlying demographic factors. Second, the merger of the editorial boards can be conceived of as the final stage of the merger process that began with Cox's acquisitions of the two papers. Third, the merger certainly represents a form of consolidation of media outlets. Of course, at first blush, the elimination of one outlet would seem trivially to satisfy the consolidation hypothesis, one voice having been silenced. Yet examining the evolution of viewpoints across this critical change further permits us to assess whether consolidation mattered, and if so how.

Our data include two acquisitions by newspapers, not (relatively) large chain conglomerates. In 1993, the New York Times Company acquired the Boston Globe for $\$ 1.04$ billion in the largest newspaper acquisition at the time. Rumors had it that the Globe had been shopping for a buyer for some time, and the New York Times was willing to pay the right price, both monetarily and editorially. The Times guaranteed editorial independence to the Globe, thereby ostensibly ensuring that the Taylor family retained control of the newspaper. ${ }^{166}$ We also collect information about the Chicago Tribune's acquisition of the Los Angeles Times in June 2000.

Lastly, we observe two "conglomerate" acquisitions: Gannett's acquisition of the Arizona Republic in August 2000 (after receiving a waiver for its

166. On the date that the acquisition was publicly announced the Times wrote: "Under the agreement, The Globe's current management is to remain in place for at least five years. After that, Mr. Taylor said last night, he had received a 'moral commitment' from The Times that members of the Taylor family could have the chance to run the newspaper. Mr. Taylor, 60 , also said he had won a promise to select his successor when he retires." The Times further wrote that Arthur Ochs Sulzberger (the chairman of the New York Times Company) stated: "We're not going to come in and shake it up because there's nothing broken." He also stated: "The New York Times Company will own it. But the newspaper will maintain its editorial independence." William Glaberson, The Media Business: Times Co. Acquiring Boston Globe for $\$ 1.1$ Billion, N.Y. TIMES, June 11, 1993, at A1. 
newspaper-broadcast combination in Phoenix ${ }^{167}$ ) and Hearst's acquisition of the San Francisco Chronicle in August 1999. What constitutes convergence with conglomerate acquisitions is not entirely clear. Hearst, for example, already owned the Examiner, the Seattle Post-Intelligencer, Cosmopolitan, Motor, Good Housekeeping, Harper's Bazaar, Town \& Country, Redbook, Esquire, WCVB-TV (Boston), A\&E Network, and Lifetime Television, to name a few. Our strategy is to contrast viewpoints of comparable national newspapers that are clearly under Gannett/Hearst control to determine whether acquired outlets converge in viewpoints. We focus specifically on USA Today, founded by Gannett in 1982, and thereby most likely to reflect the viewpoints of ownership, and the Houston Chronicle, which was bought by Hearst in May 1987. We do not focus on the Examiner, which might otherwise seem like a natural comparison paper (both being based in San Francisco) as Hearst divested itself of the Examiner for antitrust reasons when it acquired the Chronicle, and because the Chronicle and Examiner already published under a joint operating agreement prior to the Hearst acquisition. ${ }^{168}$

\section{E. Caveats}

While our approach offers crucial advantages over extant methods of measuring viewpoint diversity, it is not without limitations. First, because we focus on newspaper viewpoints, our results do not speak directly to questions about the impact of modifying the newspaper-broadcast cross-ownership rule (or other ownership rules) per se. Nonetheless, our analysis speaks to important policy questions dealing with media regulation, chiefly the convergence hypothesis. This hypothesis has not been applied with nuance to different outlets, and in its strongest version states that any consolidation should be associated with a reduction in viewpoint diversity. ${ }^{169}$ We provide detailed empirical evidence to suggest that such convergence does not inexorably occur, and our approach is in principle generalizable to study other ownership rules. Moreover, scholars have long relied solely or primarily on data from newspapers to examine the convergence hypothesis. ${ }^{170}$ And of course the FCC

167. See Quadrennial Review, supra note 12, 1158.

168. See Newspaper Preservation Act, 15 U.S.C. $\$ \S 1801-1804$ (2006); see also ABA SECTION OF ANTITRUST LAW, 1 ANTITRUST LAW DEVELOPMENTS 350-51 (5th ed. 2002) (describing how joint operating agreements, by keeping failing newspapers in business, may promote independent editorial voices). The Examiner's evolution of viewpoints postdivestiture may of course independently shed light on the convergence hypothesis, but is not something we examine here.

169. See supra text accompanying notes 64-67.

170. See, e.g., ENTMAN, supra note 85; Gentzkow \& Shapiro, supra note 72; George, supra note 72; Halavais, supra note 94 ; Hicks \& Featherston, supra note 83; Kahn \& Kenney, supra note 52. 
has itself relied on studies and comments using exclusively newspaper information. ${ }^{171}$

Second, as our results are derived from Supreme Court editorials, views may not extrapolate to other substantive areas. But of course Supreme Court cases (and associated editorials) span a staggering array of policy issues, from the Commerce Clause to the line-item veto, from affirmative action to ERISA, and from sentencing guidelines to gay rights. The extent to which views on the Court differ from other areas is, in the end, an empirical question, which our measures allow one to test with additional data. The fact that our viewpoint measures square with the conventional wisdom about most papers suggests consistency in viewpoints across issue areas. Further, work in political science suggests that most citizens' ideological orientation can be captured by a low dimensional space. ${ }^{172}$ To the extent that this is also true of editorial board members, our methods may be relatively unbiased but not fully efficient.

Third, because we only examine major newspapers, our measures may ignore the types of newspapers whose viewpoints are most threatened by media consolidation (e.g., small locally owned papers). ${ }^{173}$ Our results should certainly not be extrapolated to contexts that differ fundamentally from the data examined. That said, our data comprise nearly one half of all readers of top 100 newspapers and speak directly to speculations about convergence about this set of papers.

Fourth, our match of comparison newspapers may be imperfect. The influence of chain ownership on editorial viewpoints, such as for Gannett and the Arizona Republic, may not be best captured by a comparison group of a national paper, such as Gannett's USA Today. A Gannett regional paper may provide a more appropriate comparison group to the Arizona Republic. Of course, this weakness applies primarily to chain acquisitions, where the relevant comparison is less clear, as there are more potential outlets in which ownership could manifest itself. These chain acquisitions also happen to be the cases where we detect relative stability, arguably making the choice comparison more innocuous.

Fifth, our focus on editorial positions ignores news reporting. Some might argue that this is the more central role that newspapers play in society. ${ }^{174}$ Of course, to the degree that viewpoints in news reporting and editorializing are related (a potentially testable proposition), our. analysis may still provide some

171. See supra discussion accompanying notes $48-57$.

172. See, e.g., MELVIN J. HINICH \& MiChael C. MUNGER, IDEOlogy AND THE THEORY of Political Choice 3 (1994).

173. There is relatively little empirical work that deals explicitly with small local newspapers. Notable exceptions include Gentzkow \& Shapiro, supra note 72; Jeffrey S. Peake, Presidents and Front-page News: How America's Newspapers Cover the Bush Administration, 12 HARV. INT'L J. PRESS/POL. 52 (2007).

174. For empirical work assessing the news slant of newspapers, see Gentzkow \& Shapiro, supra note 72; and Peake, supra note 173. 
information about news reporting. Most newspapers, on the other hand, formally exercise some degree of separation between the news and editorial boards. While it is conceptually possible that the slant of a newspaper's hard news is entirely independent of its editorial position, this may be unlikely in many situations - especially in situations where a corporate owner is exerting pressure on the newspaper to hew to a particular ideological position. ${ }^{175}$ Of course, the Commission itself considers editorializing crucial to viewpoint diversity, ${ }^{176}$ and our study speaks with full force to this fundamental tenet of viewpoint diversity.

Sixth, the temporal domain of the study is limited to sixteen years from 1988 to 2004 . This means that, at best, we examine data from eight years on either side of a merger or acquisition. In reality, we will typically have less data either before or after an ownership change. If the effects of ownership changes on viewpoint are largely incremental (or manifested more than a decade after consolidation), our lack of lengthy time-series may prevent us from seeing the full change in viewpoint that results from an ownership change.

Finally, one might wonder whether some of the sharp changes we detect are the result of chance. Conversely, one might question whether our methods have sufficient power to detect moderate changes in viewpoints. One response to this is that we do in fact detect considerable differences across papers and time. In addition, we can conduct a series of sensitivity analyses to assess these methodological challenges. For example, we can randomly break viewpoint trajectories of newspapers that did not consolidate and fit our model to these new data. Here we should see no differences between the pseudo premerger series and the pseudo postmerger series. If we do observe a sizable number of differences, there is evidence that our procedure tends to produce too many false positives. ${ }^{177}$ We view the ability to engage in such robustness checks as one of the strengths of our statistically grounded approach.

\section{EMPIRICAL RESULTS}

We proceed in Subpart A by presenting overall summaries of the newspapers, assuming no changes in viewpoints over time. Our approach provides an intuitive and directly interpretable solution to the central measurement problem of viewpoint diversity. We then allow for newspaper (and Justice) views to evolve over time, and assess whether ownership changes account for any comovement of newspapers in Subpart B. Our dynamic estimates shed considerable light on how newspapers reacted in the face of

175. See Ho \& Quinn, supra note 123, at 21-23 (providing evidence of the positive relationship between editorial positions and news slant).

176. See sources cited supra note 128.

177. This is similar to the kind of randomization inference employed by other studies. See Marianne Bertrand et al., How Much Should We Trust Differences-in-Differences Estimates?, 119 Q.J. ECON. 249 (2004); Donohue \& Ho, supra note 165. 
consolidation: depending on the context, we document stability, convergence, and divergence.

\section{A. Static Newspaper Viewpoints}

Before presenting time-varying viewpoints that change smoothly over Terms, we present results from a model that assumes that newspapers and Justices have time-invariant viewpoints for the entire observation period. Since these static estimates do not change in response to ownership, they cannot directly speak to the issue of how consolidation affects viewpoints. Nevertheless, we report these results because they are a limiting case of timevarying viewpoints ${ }^{178}$ and provide an intuitive and accessible way to validate and interpret the measures based on conventional characterizations of the newspapers and the Justices. For this analysis we use all nonunanimous cases from 1994-2004 and all associated editorials to jointly estimate the location of the nine Justices as well as the viewpoints of all twenty-five newspapers under study. ${ }^{179}$

Figure 11 displays viewpoint estimates based on data from 1994-2004. Each horizontal line presents the $60 \%$ and $95 \%$ credibility intervals for the location of each Justice and newspaper. The grey $x$-axis represents the latent viewpoint dimension, which can be interpreted as going from "liberal" to "conservative" as we move from the left to the right. Since the $x$-axis represents a latent (unobservable) scale, the cardinal values are irrelevant-what matters is the relative position of each of the outlets, which indicates how much systematic distinction along one underlying viewpoint dimension exists. For example, the New York Times is the most liberal newspaper in our dataset, falling just to the left of Justice Stevens, while the Wall Street Journal is estimated to be conservative, falling roughly between Justices Rehnquist and Scalia. The results are consistent with rough conventional wisdom. Newspapers widely seen to be quite liberal-such as the New York Times, Detroit Free Press, and San Francisco Chronicle - are indeed at the far left of the viewpoint scale. Similarly, newspapers commonly believed to be quite conservativesuch as the Wall Street Journal, Washington Times, New York Post, and the Investor's Business Daily — are estimated to be at the far right of the viewpoint

178. Static viewpoint measures are essentially a weighted average across time-varying viewpoints.

179. We treat here as separate newspapers the Atlanta Constitution, the Atlanta Journal, and the Atlanta Journal-Constitution. As we discuss below, this presents some complications. While the Journal and Constitution maintained entirely separate editorial boards premerger, for weekend editions they pooled resources. Both the Journal and Constitution pools incorporate weekend premerger editorials, since we care about the viewpoint that a reader is exposed to. Because the number of premerger weekend editorials dedicated to Supreme Court decisions is low, estimates are not affected by this inclusion. 
Figure 11. Editorial Viewpoints and Judicial Ideal Points from Pooled Analysis of 1994-2004 Data

\section{Pooled Viewpoint Measures (1994-2004)}

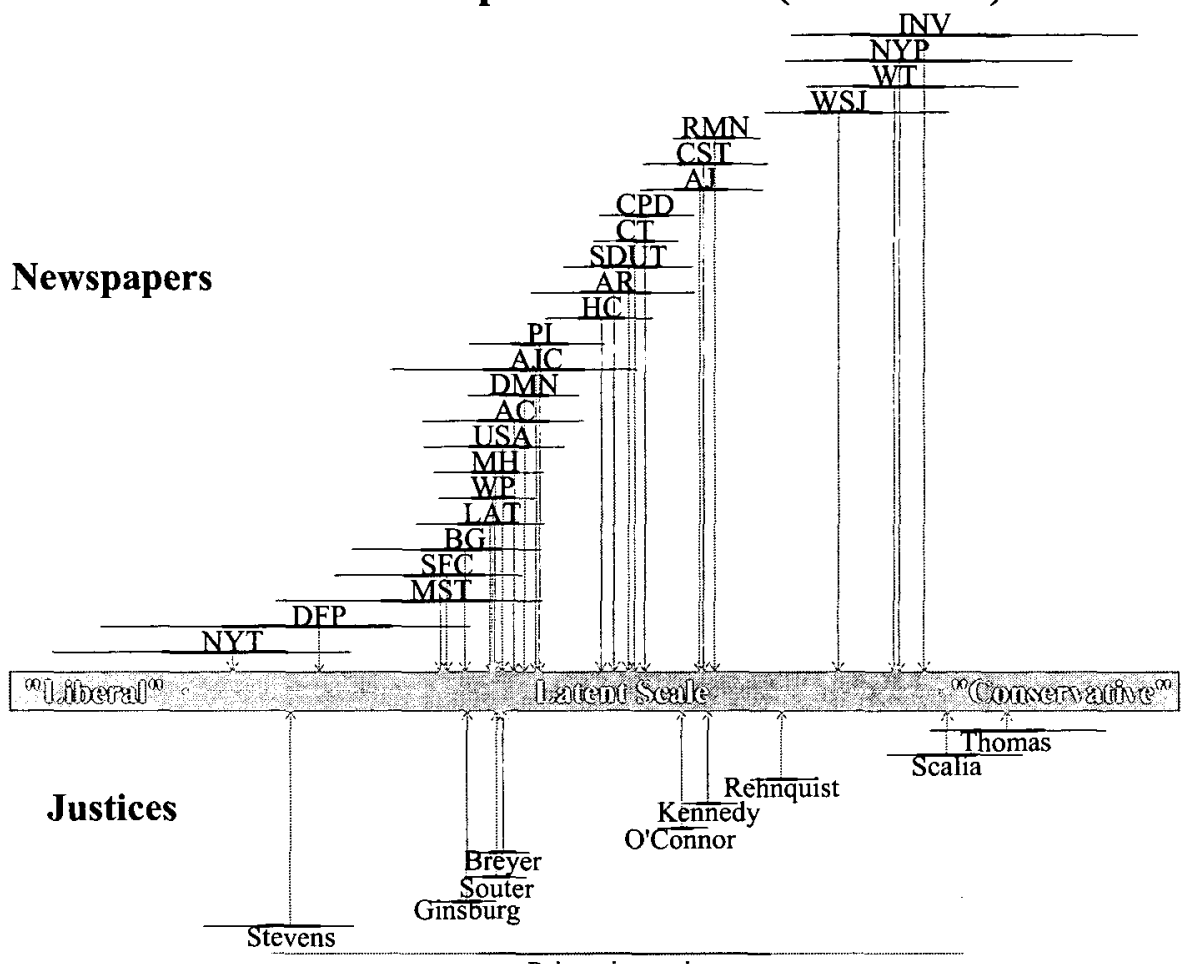

Prior viewpoint

This panel plots the results from a model jointly estimating the positions of the Justices and newspapers. The Justices are presented below the grey horizontal axis and newspapers are presented above the axis. The horizontal lines represent $60 \%$ and $95 \%$ intervals, and labels are centered around the posterior median. This figure demonstrates that our results quantify with much more reliability and precision than conventional conceptions of liberal and conservative papers.

scale. We can also compare the newspaper viewpoints to the locations of the Justices. Here we see that the New York Times and Detroit Free Press are closest to Justice Stevens while the New York Post and Investor's Business Daily are closest to Justice Scalia.

Note that there is considerably more uncertainty about the viewpoints of the newspapers than about the locations of the Justices, as can be seen by the fact that the horizontal lines are generally longer for newspapers than for the Justices. The reason for this is that the newspapers are taking positions on far 
fewer cases than the Justices. Nonetheless, even with much less information than is available for the Justices, we are still able to discern differences in viewpoints among most of the papers.

While these measures are consistent with conventional wisdom, they shed light on viewpoint diversity with significantly more precision and force. As we have outlined in an earlier paper that develops our methodological approach, ${ }^{180}$ we can directly answer any number of questions about the relative viewpoints of these measures, such as the probability that (a) the New York Times is more liberal than the San Francisco Chronicle (approximately 99\%), (b) the Washington Post is more liberal than USA Today (roughly 60\%), or (c) the Atlanta Journal is more conservative than the Atlanta Constitution (roughly $100 \%$ ). These measures also account for uncertainty in viewpoints, a key benefit of the model-based approach: because the Arizona Republic writes relatively infrequently, its interval is significantly wider than that of the Houston Chronicle, which is estimated to be just to the left of the Republic.

\section{B. Time-Varying Newspaper Viewpoints}

The static analysis above suggests that our method of measuring viewpoint diversity is easily understood and facially valid. We now extend that analysis to allow the newspaper viewpoints (and judicial ideology) to vary smoothly over time. Subpart C of the Appendix provides technical details about the statistical model we employ. The intuition is that we use a "prior" distribution that imposes some smoothness across each Term. In other words, the viewpoint of the Wall Street Journal in 1999, all other things being equal, is assumed to be closer to its position in 1998 than its position in 1997. The same is true for other newspapers. The prior distribution used in our model drives our results faintly toward estimating more homogenous viewpoints, although we allow for sharp breaks with ownership changes. ${ }^{181}$ Despite this effect of the prior, our results show that viewpoints comprise a diverse set.

We begin by presenting in Figure 12 newspaper-specific evolution of viewpoints over the period of our study. Each panel presents the estimate of a newspaper's viewpoint over time. The viewpoint dimension is on the $y$-axis, and can be interpreted as going from liberal to conservative when we move from the bottom to the top. The lines represent the point estimates (posterior

180. See Ho \& Quinn, supra note 123.

181. The viewpoints are shrunk slightly toward homogeneity because the initial viewpoints of the newspapers are assumed to be drawn from a common distribution (and hence have identical prior means) and because of the temporal smoothness assumption noted above which (very loosely) links viewpoints at all time periods to the initial viewpoint. Sharp breaks in viewpoints corresponding to ownership changes are allowed by splitting a newspaper's data into pre- and postownership change data and then using only the data before the change to estimate the viewpoint in that time period and only the postchange data to estimate the viewpoint after the ownership change. 
medians) of the newspaper's viewpoint over Terms on the $x$-axis, with $95 \%$ credibility intervals presented in the shaded bands. The overall level of each newspaper's viewpoint is roughly consistent with the static results of the previous section, but Figure 12 reveals some intriguing temporal variation. For instance, the Chicago Sun-Times begins moving to the right around 1996 or 1997 only to return to a more moderate right-of-center position around 2000. The Los Angeles Times, New York Times, Philadelphia Inquirer, San Diego Union-Tribune, and the Washington Post all appear to have become more liberal over time, while the Atlanta Journal, New York Post, and the Wall Street Journal trend to the right.

While these results are themselves interesting, the central question is whether ownership consolidation is associated with a reduction in viewpoint diversity. We thereby focus on five pairs of newspapers for which we have both pre- and postconsolidation data. The dashed vertical lines in Figure 12 represent newspapers associated with ownership changes. As described in Subpart III.D, each pair, with the exception of the Atlanta Journal and Atlanta Constitution, represents a match between the newspaper being acquired and a newspaper already owned by the acquiring party.

If consolidation reduces viewpoint diversity, we should see viewpoints converge after consolidation compared to the preconsolidation period. Concretely, for acquisitions the vertical space between the solid lines should decrease if we plot the newspaper estimates on the same panel. For a merger, the postacquisition viewpoint should fall between the preacquisition viewpoints. In order to eliminate any artifacts that may be caused by incorrectly assuming a smooth transition in viewpoint after a merger or acquisition we split the observed time series into pre- and postconsolidation series and estimate them separately. We proceed here to present results for the five ownership changes in turn.

\section{Atlanta Journal-Constitution}

The merger of the Atlanta Constitution and the Atlanta Journal into the Atlanta Journal-Constitution presents a compelling case study for editorial consolidation. Our quantitative results, plotted in Figure 13, provide a clear visual summary of the complicated dynamics of this case. Figure 13 shows that in the early-to-mid 1990s, the viewpoints of the Journal and the Constitution were distinct, but relatively moderate with the Journal leaning to the right and the Constitution leaning leftward. In 1995, both papers supported the five-tofour majority in United States v. Lopez. ${ }^{182}$ The Constitution opined, "the U.S. Supreme Court ruled quite properly that Congress does not [have the power to

182. 514 U.S. 549 (1995). 
Figure 12. Dynamic Editorial Viewpoint Estimates for 25 Major Newspapers, 1988-2004
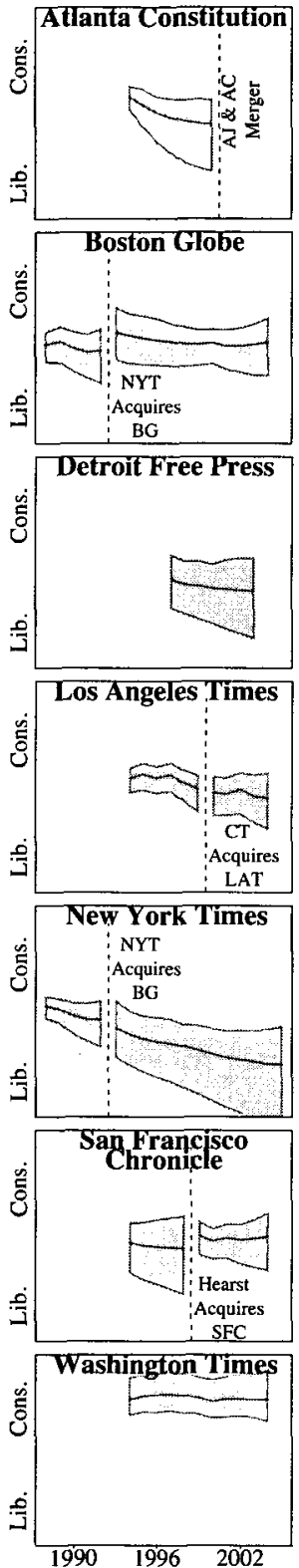
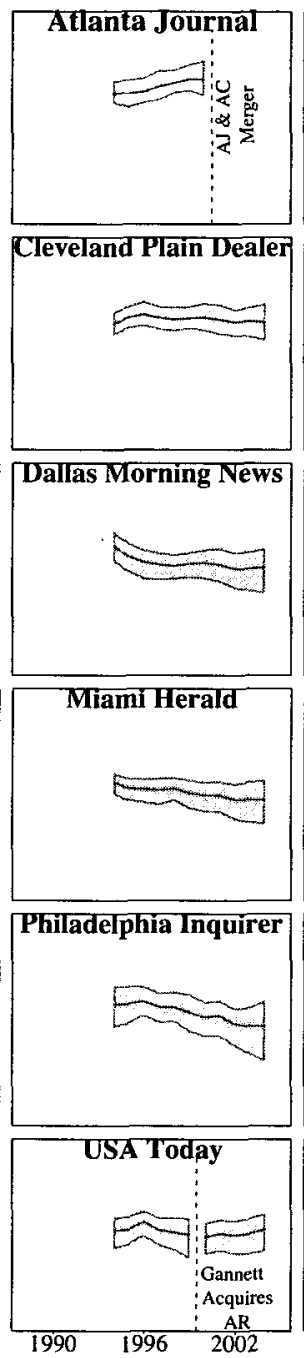
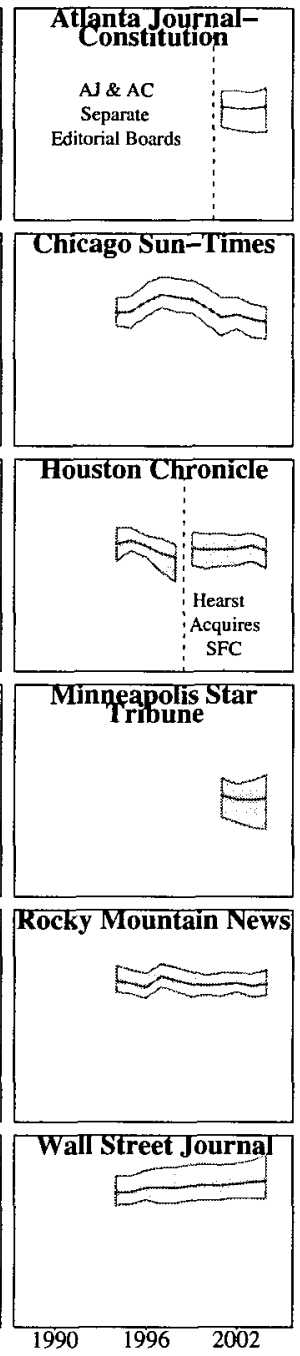
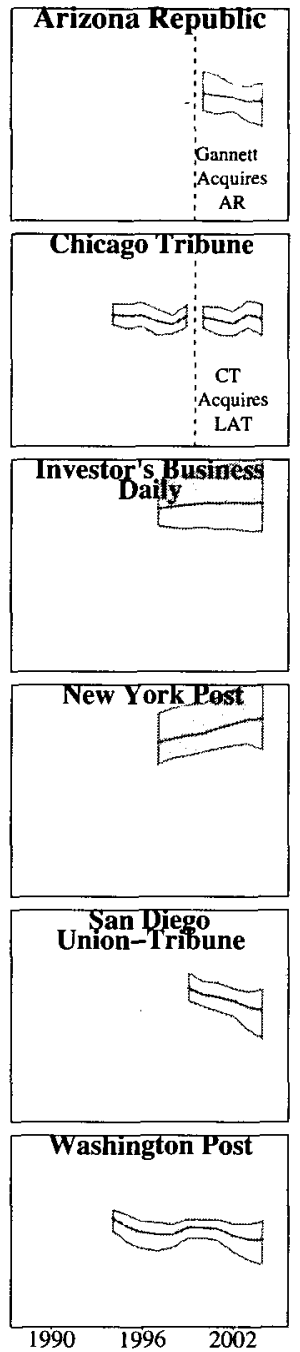

The $y$-axis represents viewpoints, ranging from liberal viewpoints at the bottom and conservative viewpoints at the top. The dark solid line represents the posterior median for each newspaper at each time period. The shaded region represents the pointwise central 95\% credible region for each newspaper viewpoint. Vertical lines correspond to ownership changes occurring during the observation period. 
criminalize possession of a firearm in the vicinity of schools],"183 and the Journal agreed that "the [C]ourt's conservative majority, in this case, has drawn the proper line." 184 The moderate liberal and conservative estimates are consistent with the conventional wisdom regarding the ideological leanings of these newspapers. ${ }^{185}$ During the mid-to-late 1990s, however, a wide gulf opens between the editorial viewpoints of the two papers. While the Journal and Constitution never disagreed on a case on which they both editorialized from 1994-1997 (although they did write separately on many cases), in the 1998 Term they began to openly disagree on the same cases at high frequency. On a case involving school liability for discriminatory acts by students, ${ }^{186}$ the Journal lamented the ruling as "unwise," arguing that Title IX was "[n]ever ... intended to apply to the inappropriate conduct of students" and that "[t]he Supreme Court has opened yet another floodgate to lawsuits," 187 while the Constitution argued that "[t]he U.S. Supreme Court ruled wisely and well Monday in declaring that school districts can be held liable for refusing to protect students from sexual harassment." ${ }^{188}$ The result of this movement is that in the late 1990s the Constitution is estimated to be between Justices Stevens and Ginsburg while the Journal is estimated to be between Justices Rehnquist and Kennedy. This divergence occurs in spite of the fact that both papers are under the common ownership of Cox Enterprises.

In the fall of 2001, as the editorial boards of these papers merge into the Atlanta Journal-Constitution, the postmerger editorial board takes a position between that of its two parents, but leans slightly toward the viewpoint of the Constitution-the newspaper that, by most accounts, was the more economically viable of the two premerger newspapers. Looking at the bottom panel of Figure 13 we see that with $80 \%$ to $90 \%$ probability the JournalConstitution is to the right of the Constitution (using its last year in existence) and it is a near certainty that the Journal-Constitution is to the left of the last Journal viewpoint.

183. Editorial, Congress Oversteps Its Bounds on Guns, AtLANTA Const., May 3, 1995, at $12 \mathrm{~A}$.

184. Editorial, High Court Rightly Clips Commerce Clause Wings, ATLANTA J., Apr. 28,1995 , at $16 \mathrm{~A}$.

185. See, e.g., Alex S. Jones, Comeback by the Atlanta Papers Isn't All Hurrahs, N.Y. TIMES, Apr. 24, 1988, $\S 1$, at 26 (describing the newspapers as having "moderately liberal editorial pages").

186. Davis ex rel. LaShonda D. v. Monroe County Bd. of Educ., 526 U.S. 629 (1999).

187. Editorial, Expanding Liability of Schools Unwise, ATLANTA J., May 25, 1999, at $10 \mathrm{~A}$.

188. Editorial, Taunts Schools Can't Ignore; The High Court Was Right To Open the Door for Lawsuits in Cases of Extreme Sexual Harassment, ATLANTA CONST., May 26, 1999, at 18A (quotation mark omitted). 
Figure 13. Viewpoint Estimates for the Atlanta Constitution (solid), Atlanta Journal (overlaid), and the Atlanta Journal-Constitution

\section{Atlanta Journal-Constitution}

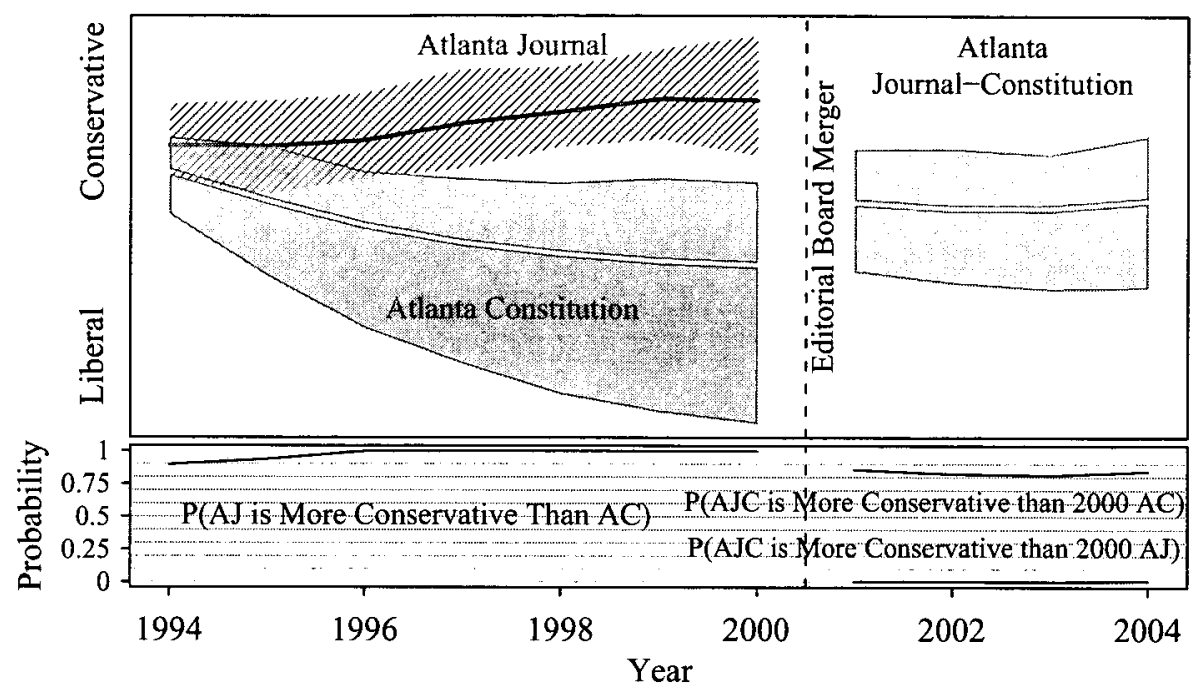

The solid lines depict the posterior median of each paper's viewpoint and the shaded regions represent pointwise central $95 \%$ credible regions. The bottom panel calculates the (posterior) probability that the Journal is more conservative than the Constitution (almost 100\%) and that the merged entity is more conservative than either the Journal and Constitution in their last year of publication. This figure shows that the Journal and Constitution diverged sharply in editorial viewpoint prior to the merger while under common ownership, and that the merged board falls between the premerger viewpoints, thereby demonstrating convergence.

These results challenge extant accounts in several ways. At first blush, the merger tautologically reduces viewpoint diversity by reducing the number of papers from two to one. But as we see below, the story of the merger becomes much more complex, in part due to the fracturing of the editorial board. Second, divergence in the face of common ownership seems to corroborate monopoly diversification, but the divergence occurs many years after Cox's acquisition of both papers in 1950, rendering the evidence less than compelling. Third, the fact that the merged editorial board appears between its parent papers provides considerable evidence in favor of the convergence hypothesis, when consolidation is taken to include staff consolidation. We return to this case below to help elucidate the mechanisms that could explain the complex dynamics we detect. 
Figure 14. Viewpoint Estimates for the Boston Globe (solid) and the New York Times (overlaid)

\section{Boston Globe and New York Times}

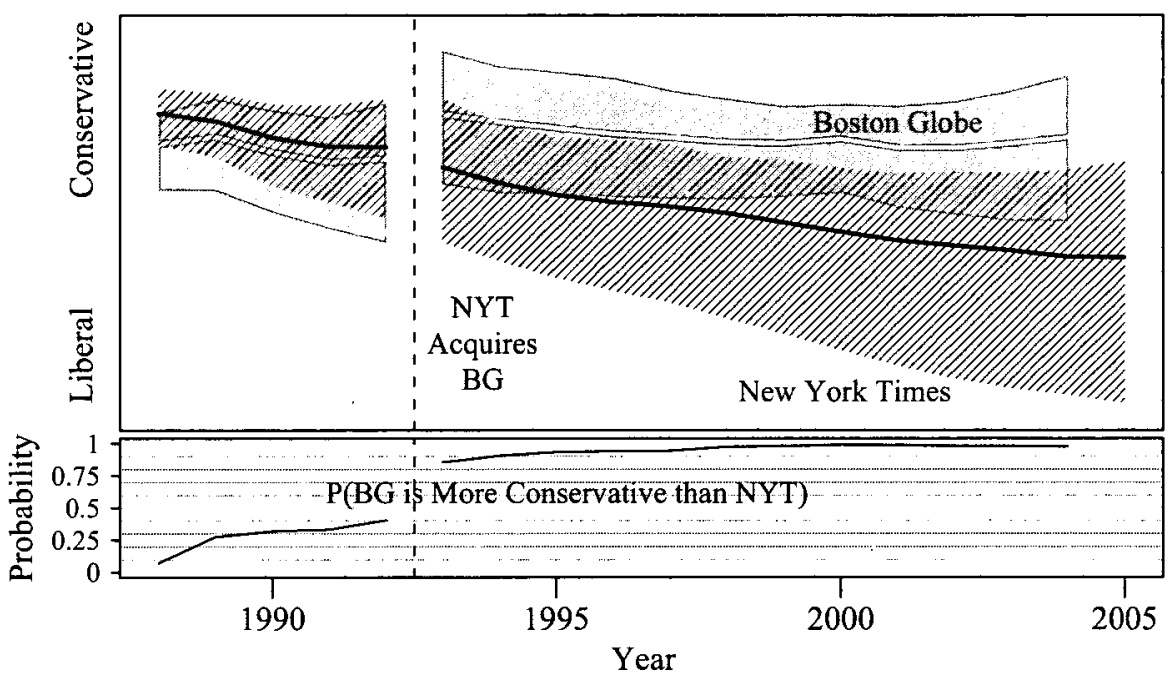

The solid lines depict the posterior median of each paper's viewpoint and the shaded regions represent pointwise central $95 \%$ credible regions. The bottom panel plots the (posterior) probability that the Boston Globe is more conservative than the New York Times. This figure demonstrates that the two papers flip positions postacquisition, providing suggestive evidence of monopoly diversification.

\section{New York Times-Boston Globe}

If the merger of the Journal and Constitution provides evidence for consolidation, the acquisition of the Boston Globe by the New York Times provides a counterpunch. First, as Figure 14 shows, the postacquisition viewpoints of the two newspapers are significantly more dispersed than the preacquisition viewpoints. Second, in addition to postacquisition dispersal, the relative viewpoints actually switch after the acquisition. While the Globe was just to the left of the Times before the acquisition, it moves noticeably to the Times's right after the acquisition (with $83 \%$ probability it is more conservative the year after, than the year before the acquisition), while the Times continues its preacquisition trend to the left.

Since Figure 14 only presents marginal information, it is difficult to tell from the top panel alone whether there are truly significant differences between the Times and Globe viewpoints after the acquisition. To formally assess this, we calculate the (posterior) probability that the Globe is more conservative than the Times for each time period under study. We present these numbers graphically in the bottom panel. Here we see that prior to the acquisition the 
viewpoints of the Times and the Globe were largely statistically indistinguishable (save for 1988). However, after the acquisition, there is over a $90 \%$ chance that the Globe is to the right of the Times, which increases to almost $100 \%$ as time progresses. This observed pattern defies the convergence hypothesis. ${ }^{189}$ At a surface level, the pattern of shifting viewpoints exhibited here might seem consistent with some economic accounts of monopoly diversification, an interpretation we examine below in closer detail.

\section{Chicago Tribune-Los Angeles Times}

The remaining three acquisitions present somewhat simpler stories. Figure 15 shows the time-varying viewpoints of the Chicago Tribune and the Los Angeles Times. As noted above, the Tribune Company acquired Times Mirror - which owned the Los Angeles Times - in June of 2000. Although the Tribune company stated that the change would not "compromise ... decisionmaking on news and editorial issues," 190 some have speculated that the ownership affected the Times's editorial viewpoints. One commentator opined that the "Chicago Tribune[] predictably endorsed Bush ... while ... the Los Angeles Times, also under new ownership, abandoned its liberal inclinations ... by declining to support either Bush or Gore." ${ }^{\prime 191}$ As our endorsement data in Figure 4 shows, such endorsements are not attributable to the ownership change. Our broader data further suggest that such speculation is wrong. Prior to the acquisition, we see that the Tribune leans to the right, while the Times espouses a more liberal viewpoint. With the exception of 1997, the viewpoints of the two papers are easily distinguished in all preacquisition years. After the acquisition we see much of the same-the Tribune maintains a slightly right-of-center orientation while the Times continues to espouse relatively liberal views. If anything, there is very slight evidence to suggest that the distance between the viewpoints of the papers increases somewhat after the acquisition.

189. See, for example, the claim made by Ben Bagdikian shortly after the acquisition was announced: "In terms of high-quality buyers, the Globe could not do much better than the Sulzbergers .... But there is a deep philosophical problem in leaving so few people in control of most the printed news in this country. In the long run . . . even the best protect themselves in the news columns when central corporate interests are at stake." Tom Mashberg, The Modest Mogul; Punch Sulzberger, Times Co. Chairman Has Made His Mark with Low-Key Style, BosTON GLOBE, June 13, 1993, at 87 (internal quotation marks omitted).

190. David Shaw, New Publisher, Editor Take Helm at Times; Merger: John Puerner, John Carroll Join Paper as Part of Reorganization by Tribune. Both Vow To Protect Editorial Integrity, L.A. TIMES, Apr. 25, 2000, at A1.

191. Chris Powell, The Courant's Curious Endorsement, Providence J.-Bull., Nov. 2,2000 , at $6 B$. 
Figure 15. Viewpoint Estimates for the Chicago Tribune (solid) and the Los Angeles Times (overlaid)

\section{Chicago Tribune and Los Angeles Times}

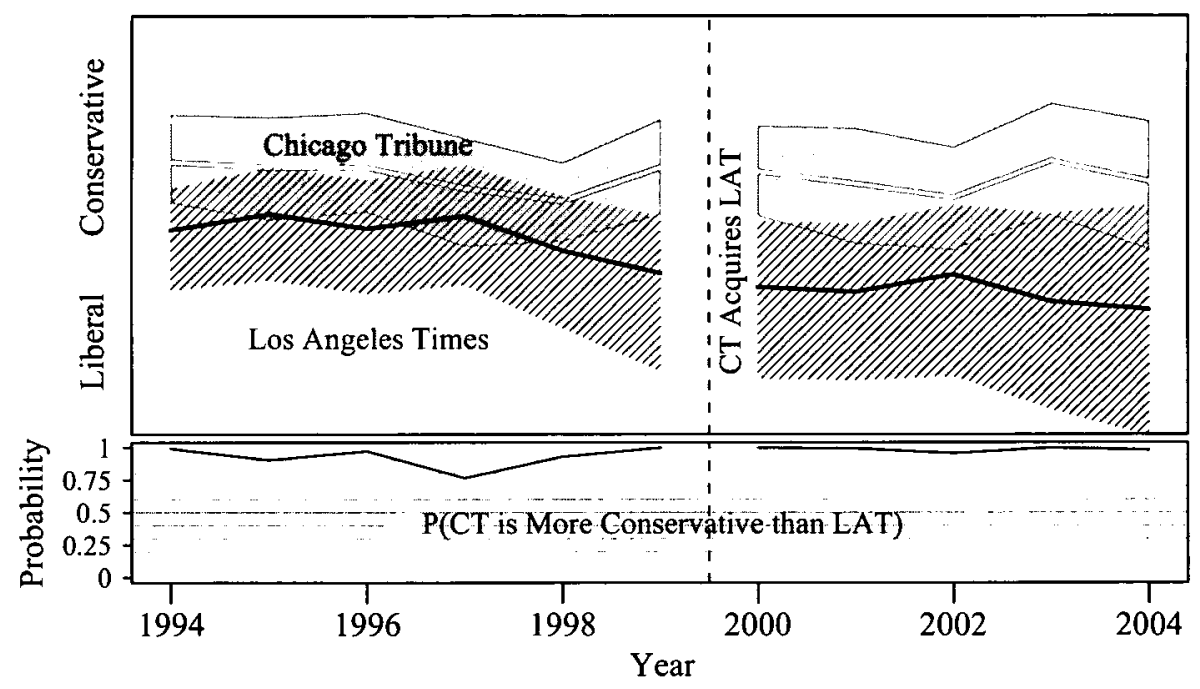

The solid lines depict the posterior median of each paper's viewpoint and the shaded regions represent pointwise central $95 \%$ credible regions. The bottom panel plots the (posterior) probability that the Tribune is more conservative than the Times. This figure shows that the acquisition was not associated with any shift in the relative positions of the papers.

\section{Houston Chronicle-San Francisco Chronicle}

Hearst already owned the Houston Chronicle prior to our observation period, and acquired the San Francisco Chronicle in August 1999. If parent companies exert pressure on subsidiaries to exhibit similar ideological viewpoints, as many have speculated, ${ }^{192}$ we might expect to see the San Francisco Chronicle take positions more similar to the Houston Chronicle after the acquisition than before. The evidence presented in Figure 16 fails to provide support for this hypothesis. Both newspapers are clearly distinguishable from each other in both the pre- and postmerger periods. Of course, our data can only speak to the issue of whether there is a fairly immediate shift in viewpoint after the acquisition. It might still be the case that the viewpoints will grow more similar in time as editorial board replacement occurs, such that the effect of Hearst will not be observable until much later. Such delayed effects of course compound the empirical challenge of assessing the convergence hypothesis.

192. See, e.g., BAGDIKIAN, supra note 66 . 
Figure 16. Viewpoint Estimates for the Houston Chronicle (solid) and the San Francisco Chronicle (overlaid)

\section{Houston Chronicle and San Francisco Chronicle}

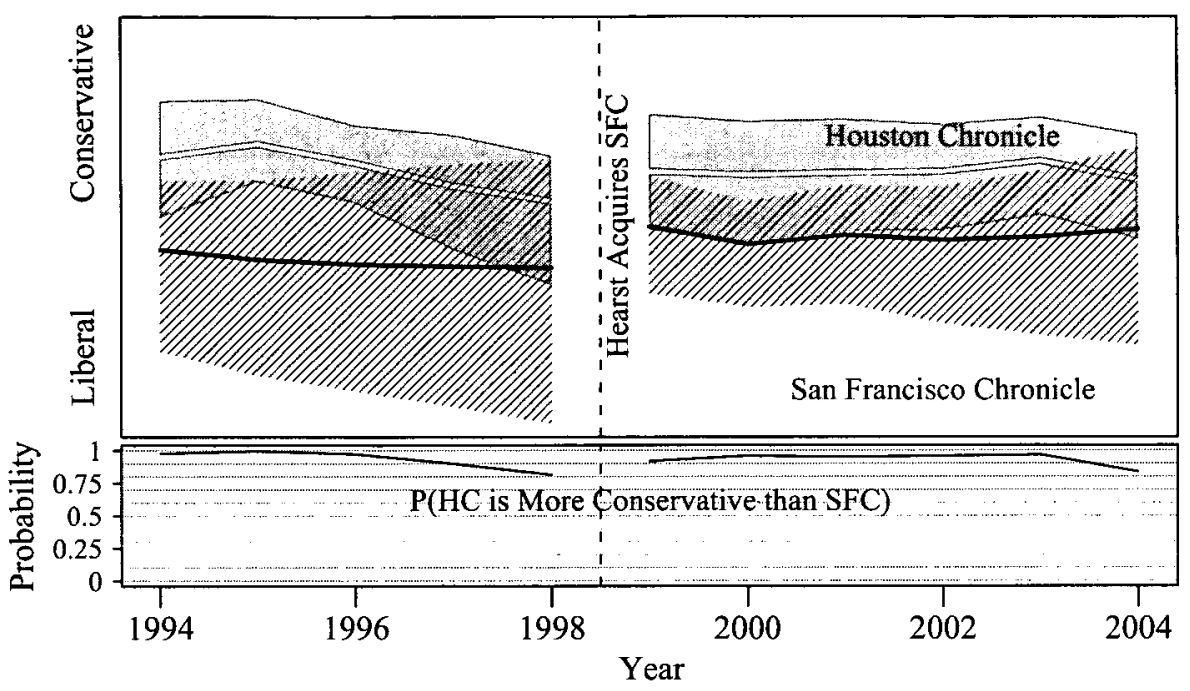

The solid lines depict the posterior median of each paper's viewpoint and the shaded regions represent pointwise central $95 \%$ credible regions. The bottom panel plots the (posterior) probability that the Houston Chronicle is more conservative than the San Francisco Chronicle. This figure shows that the acquisition was not associated with any shift in the relative positions of the papers.

\section{USA Today-Arizona Republic}

Finally, we examine the limited results from USA Today and the Arizona Republic, primarily for completeness of examining all mergers and acquisitions amongst papers in our sample and observation period. ${ }^{193}$ In August 2000 Gannett acquired Central Newspapers, which owned the Republic. Since Gannett founded and continues to own USA Today, we evaluate the convergence hypothesis by comparing its viewpoint to that of the Republic preand postacquisition. The evidence for convergence is minimal. First, we only have editorial data from the Republic for one year in the preacquisition period. Second, as shown in Figure 7, the Republic writes extremely few editorials on the Supreme Court. Taken together, these points constrain what we can infer

193. The data is limited because of the availability in existing databases of the Arizona Republic. Both Lexis and America's Newspapers archive the Republic beginning only in 1999. 
Figure 17. Viewpoint Estimates for the Arizona Republic (solid) and USA Today (overlaid)

USA Today and Arizona Republic

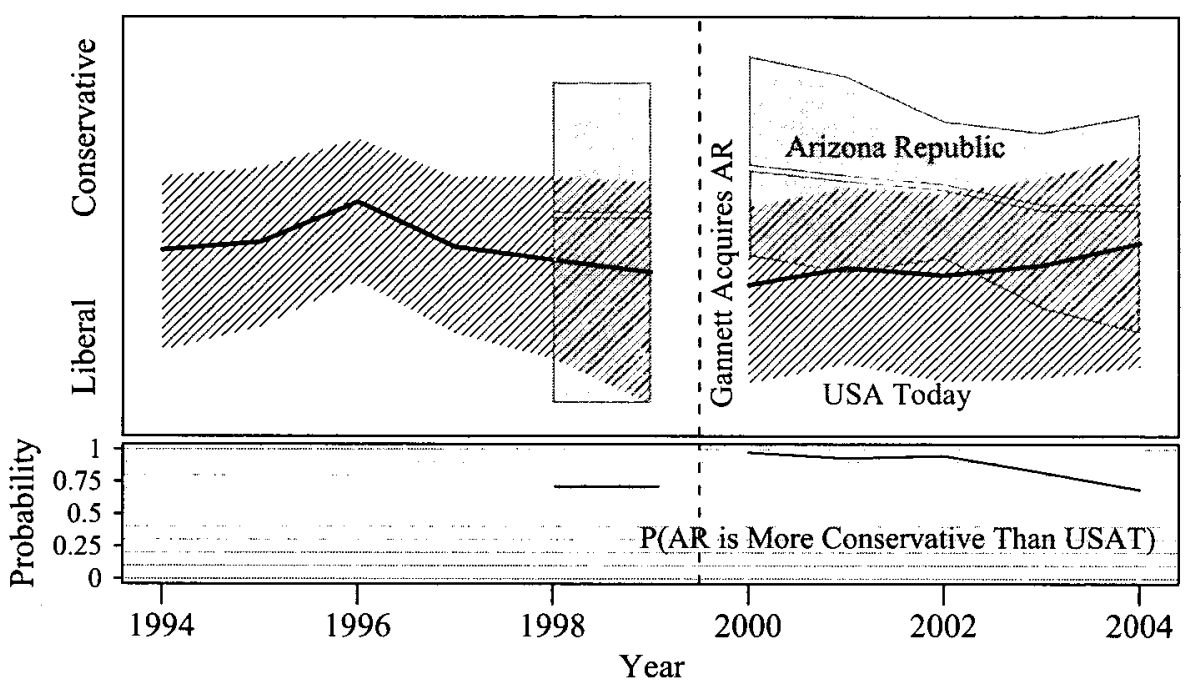

The solid lines depict the posterior median of each paper's viewpoint and the shaded regions represent pointwise central $95 \%$ credible regions. The bottom panel plots the (posterior) probability that the Arizona Republic is more conservative than USA Today. The two papers converge slightly in 2003 and 2004 but the probability that the Republic is more conservative than USA Today is only at the preacquisition level, suggesting little evidence for convergence.

about the Republic. On the other hand, we view this as a positive attribute of our statistical measurement approach, as it directly accounts for the uncertainty and limited availability of editorials. Unlike other approaches that fail to take into account such inherent variability in the data, we can directly assess how informative (or not) our data are. Figure 17 suggests that it is difficult to make strong statements about how the viewpoints of these newspapers are evolving over time. While the lines do appear to converge, the uncertainty is large. The lower panel plots the (posterior) probability that the Republic is more conservative than USA Today, showing that probability in 2004 is roughly the same as in 1999. Without observing a longer preacquisition period and more editorials, little can be learned about convergence from this case study.

\section{CONVERGENCE OR MONOPOLY DIVERSIFICATION? AN IN-DEPTH VIEW}

Our results decidedly question existing accounts. For two of our cases (the Los Angeles Times and the San Francisco Chronicle), the newspapers are 
Figure 18. Circulation for the Atlanta Journal (top-left), the Atlanta Constitution (top-middle), and the Atlanta Journal-Constitution (top-right)

Atlanta Journal

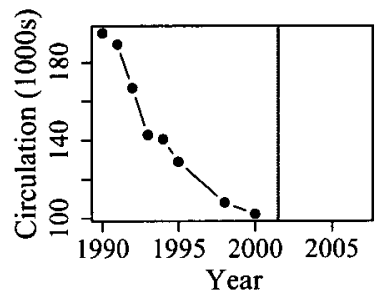

Atlanta Constitution

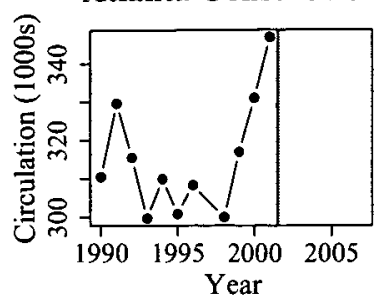

Journal-Constitution

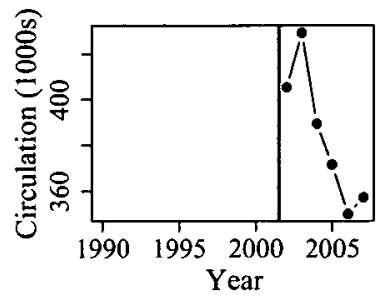

All

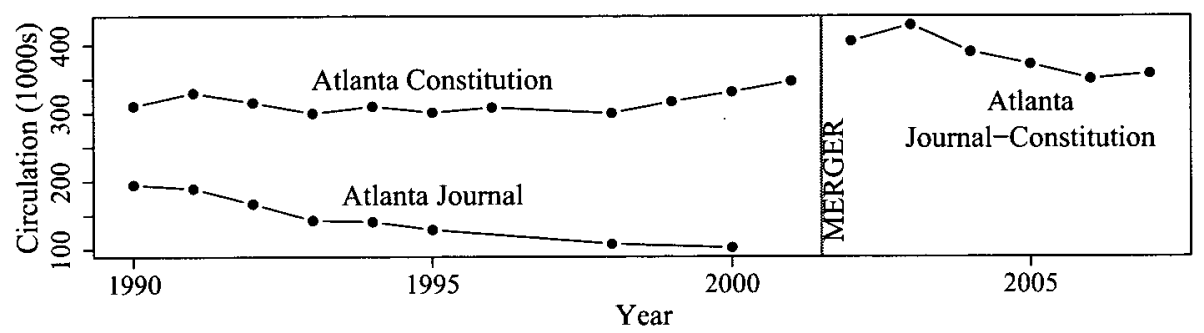

The top panels allow $y$-axes of circulation to float to visualize outlet-specific trends. The bottom panel plots all three outlets on the same $y$-axis. This figure shows the dramatic drop in the Journal's circulation prior to the final merger, as well as the short-term spike postmerger when the Journal and Constitution combined subscribers. Data is compiled from Audit Bureau of Circulations' Monday through Thursday circulation figures.

clearly distinguishable, but exhibit no convergence in viewpoints postacquisition. The Arizona Republic moves slightly toward the center, converging slightly onto the centrist editorial position of USA Today, but the shift is most likely attributable to limited information: after all, the Republic is statistically indistinguishable from its preacquisition viewpoint. The Atlanta Journal-Constitution validates the convergence hypothesis in a trivial and in a nontrivial sense. By removing one outlet (the evening Journal) fewer editorial viewpoints are represented in the Atlanta market. The fact that the merged editorial board moderates between the two preexisting positions appears to confirm convergence. On the other hand, the two papers diverged prior to the merger while under the same ownership. More damaging for the convergence hypothesis would seem to be the Times-Globe acquisition. The Boston Globe shifts substantially toward the center in the postacquisition period, while the New York Times moves gradually toward the left throughout the entire period. To understand these somewhat puzzling results, we study these two cases in more detail in this Part. 
Specifically, we turn to evidence we've amassed from subscriber databases, census data, and an exhaustive search to recreate the editorial board composition of the papers over time. At the outset, we had hoped to collect this information for all newspapers to examine the role of individual editorial board members on viewpoints. We thought that collecting this information, particularly for the editorial board composition over time, would be easy. Not so. In an interesting but unintended study of editorial transparency, we encountered a host of problems in collecting this data: the daily mastheads of most newspapers do not list the full editorial board; online versions, which sometimes provide names of editorial board members, do not span our observation period; and we discovered that standard newspaper resources, such as Bowker's News Media Directory, ${ }^{194}$ were wildly inaccurate when it came to the full editorial board and other characteristics. ${ }^{195}$ In our research process, we called editors of every newspaper in our dataset, receiving largely reticent (if not hostile) responses. ${ }^{196}$ Two Stanford communications professors specializing in journalism informed us that the data are simply not available and the joint collections of Harvard and Stanford did not have certain microfiche volumes available. We document our research steps more fully in Subpart B of the Appendix. The data are necessarily tentative, but to our knowledge represent the first and most complete publication of editorial board compositions for these papers for this time period.

Our study reveals that the merger of the Atlanta Journal-Constitution, with no clear editorial policy, was fraught with tension on the board, resulting in the demise of formal editorial board positions and the rise of individually signed editorials. Counterintuitively, Atlanta readers may now be exposed to more viewpoint diversity, even when only a single paper remains. Our study of the Globe-Times case demonstrates that in the Boston metropolitan area the data support the market conditions for monopoly diversification, but the historical evidence suggests that diversification is an artifact of exogenous events (mandatory retirements and death) that had nothing to do with the acquisition. Overall, our results point to the centrality of individual editors, organizational structure, and editorial policies.

\section{A. Atlanta Journal-Constitution}

Consolidation in Atlanta had long been coming. In 1939, James Cox, thenowner of the Dayton Daily News, the Springfield Press-Republican, the Miami

194. See, e.g., 1 BowKER's NEWS MEDIA DIRECTORY $\S 2$, at 38 (54th ed. 2004).

195. For example, Bowker's continues to list the Atlanta Journal as a separate paper after the merger, and records its circulation as constant for most of the observation period. Id. exception.

196. The Atlanta Journal-Constitution, evincing Southern hospitality, is the notable 
Figure 19. Nationwide Circulation Trends in the Newspaper Industry
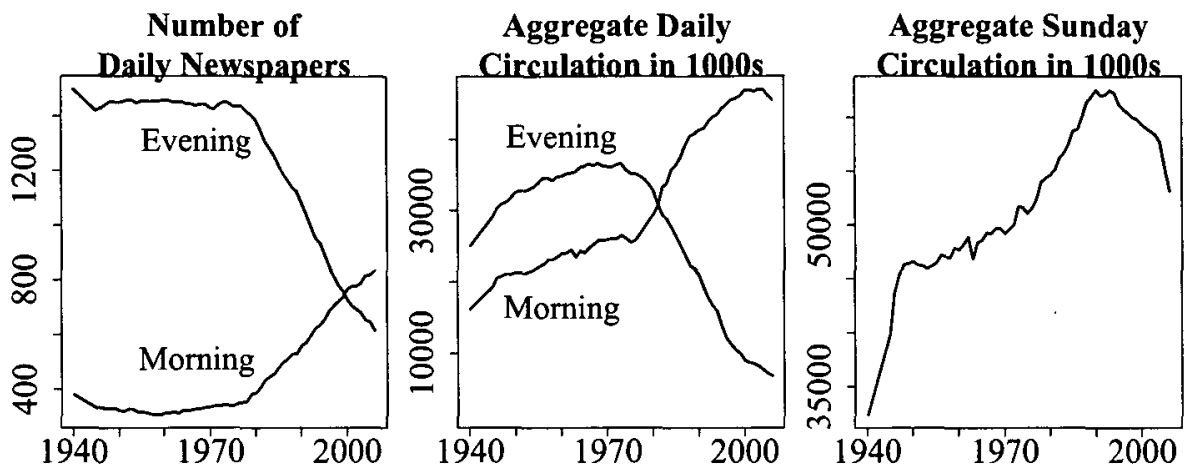

The left panel plots the yearly time-series of the number of evening and morning newspapers. The middle panel plots the daily circulation of evening and morning papers. The right panel plots the rise of Sunday circulation. Source: Newspaper Association of America.

Daily News, and WHIO (a Dayton radio station) bought the Journal and its radio station WSB. In 1950, Cox also snapped up the Constitution, quickly combining the Sunday editions of the two papers. ${ }^{197}$ During the week, the Constitution served as the morning paper and the Journal as the evening paper: "the newsrooms remained separate and competed fiercely for stories." the 1970s, the evening Journal had higher circulation figures than the morning Constitution, but its circulation waned as afternoon papers faded. In 1976, the papers began to publish a joint weekend edition. In 1982, the newsrooms formally merged, but the papers continued to be published separately. Our results of Subpart VI.B.1 raise basic questions about the merger.

\section{Divergence in the face of common ownership}

Why is it that the Journal and the Constitution diverged in editorial outlook prior to the merger? There are at least.two potential explanations for premerger divergence between the newspapers. First, in light of dwindling market position the Journal attempted to capture the wealthier suburban (and more conservative) market, but failed, while the Constitution attempted to capture the urban market and succeeded. Second, broader demographic shifts forced the Journal into a position where liberal subscribers (particularly in downtown Atlanta) were substituting toward the Constitution. While the former is

197. See James E. Cebula, James M. Cox: Journalist and Politician 131-32 (1985); Chuck Perry, Atlanta Journal-Constitution, NEw GA. ENCYClOPEDIA, Jan. 5, 2004, http://www.georgiaencyclopedia.org/nge/Article.jsp?id=h-1807.

198. Perry, supra note 197. 
purposive (i.e., there was an affirmative effort by the Journal and/or Constitution to resituate themselves) and the latter is not, we do not view these explanations as exclusive. To the degree that they are purposive, of course, that does not necessarily undercut the monopoly diversification argument: indeed, at first glance it might support it.

To contextualize the position of the Journal and Constitution, Figure 18 plots circulation statistics for the papers pre- and postmerger. The top-left panel shows that the Journal was bleeding subscribers, losing close to half of its subscribers in the ten years going from over 190,000 subscribers in 1990 to some 102,000 in 2000 . The top-middle panel shows that the Constitution's circulation hovered just over 300,000 until spiking in the run-up to the merger. The top-right panel shows that immediately after the merger, the JournalConstitution effectively combined circulations of the Journal and Constitution (roughly 100,000 and 300,000 , respectively), but circulation dropped in the immediate years after the merger.

What accounts for these circulation trends? The gorilla in the room is that U.S. newspaper readership over the past half century shifted dramatically away from evening to morning newspapers. The broader reasons for this shift are complex, including the difficulty of evening distribution, the rise of evening broadcasts, increasing suburbanization, and shifting work and commuting patterns of the U.S. population. Figure 19 plots this dramatic current in the newspaper market. The left panel plots the total number of papers on the $y$-axis against year on the $x$-axis: while over 1800 evening papers existed in 1940, that number was down to 614 in 2006 . Even more telling is the fact that the roles of evening and morning papers have reversed, with the number of morning papers outstripping the number of evening papers for the first time in 2000. The middle panel documents this reversal by plotting daily circulation (in 1000s) on the $y$-axis against year on the $x$-axis. In circulation, morning papers supplanted evening papers beginning in 1980, with circulation over six times as large for morning papers in 2006, amounting to over 45 million papers per day. At the same time, the role of Sunday papers has increased, as demonstrated by the right panel. The story of the Journal-Constitution tracks these broad trends remarkably well. Although the Journal dominated the Constitution for decades, as evening papers generally did, its position began to erode in the 1970 s, losing out to the morning Constitution.

In light of these drastic demographic shifts, it is perhaps not surprising that the editorial positions shifted. Figure 20 plots basic income data for the counties in the designated market area of the Journal-Constitution (the Atlanta metropolitan statistical area). The four panels on the left identify the counties in the area and are arranged in income quartiles. The four panels on the right plot median household income (in $\$ 1000$ s) by county over our observation period. The figure illustrates considerable income stratification. The top row plots 
Figure 20. Median Household Income in Atlanta Journal-Constitution Designated Market Area

Quartile 1: Wealthy Suburbs

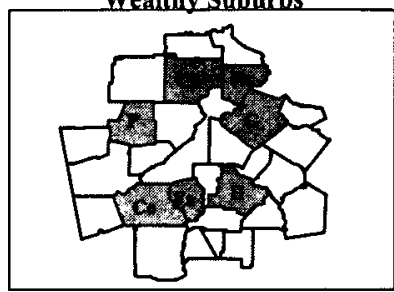

Quartile 2:

Working-Class Suburbs

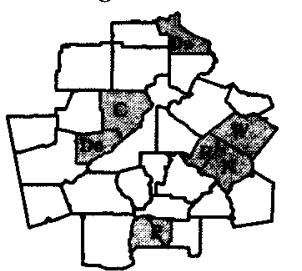

Quartile 3:

Urban and Rural

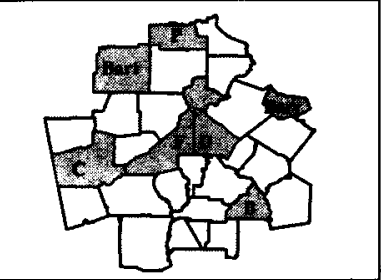

Quartile 4:

Rural

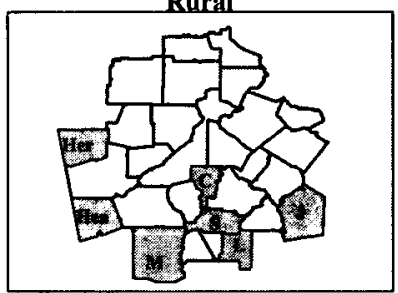

Median Household Income (1000s)

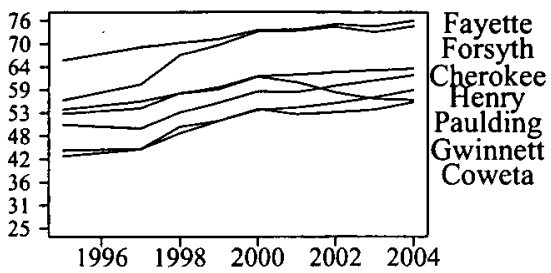

Median Household Income (1000s)

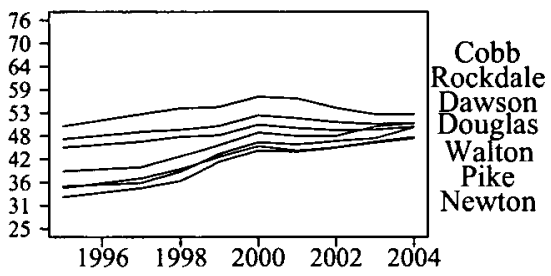

Median Household Income (1000s)

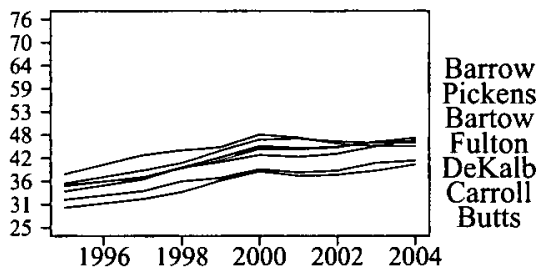

Median Household Income (1000s)

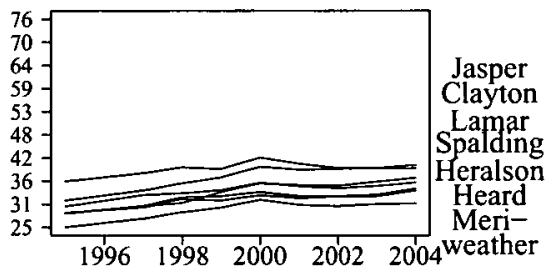

The left-side panels plot counties in the immediate Atlanta JournalConstitution circulation area. Each row represents a quartile, split by income group. The right-side panels plot median household income (in $\$ 1000$ s) over time. Counties included in each quartile are listed to the right, ranked by 2004 household income. This graph shows the demographic background of the Atlanta metropolitan region, with outlying poor, rural suburbs in the south and wealthy suburbs surrounding the downtown area (quartiles 4 and 1 , respectively). 
largely wealthy, outlying suburbs. (Downtown Atlanta falls roughly in the middle of the map.) The second row plots what we might call working-class suburbs with lower income. The third row includes downtown Atlanta and outlying rural counties. Row four plots rural, southern counties with the lowest income.

To connect this to the reality of what these papers faced, the left panel of Figure 21 plots the percentage of each paper's readership by county, decreasing by population and averaged across the premerger period. The solid and hollow dots represent the readership of the Journal and Constitution, respectively. This panel shows that the Constitution drew substantially more readers from Fulton County, home to downtown Atlanta (overlaid in white on the right panel). The right panel plots the difference in percent readership, with dark and light shades corresponding to areas where the Constitution and Journal disproportionately drew readers, respectively. Two things are of note. First, the penetration of both the Journal and Constitution into the suburbs was low. Both papers retained the core of their readership in downtown Atlanta. Second, the Journal was nonetheless more evenly spread across these suburbs, particularly in the wealthy suburbs identified in the first column of Figure 20. (The readership percentage is scaled to sum to one for each paper, so as to account for the large mean differences in subscribers between the two papers.) This suggests demand- and supply-based explanations of the evolving viewpoints of the two papers. On the demand side, as resident moved into the suburbs, the subscription base may have pulled the Journal in a more conservative direction. On the supply side, the conservative viewpoint may have been an affirmative effort by the Journal to reposition itself in a market, although the strategy ultimately failed.

Competition for suburban subscribers with other papers was considerable. As the New York Times noted: "Perhaps the biggest threat to the papers comes from suburban newspapers ringing the city, including The Gwinnett Daily News . ..."199 One of the fast-growing counties, Gwinnett, as Figure 20 shows, presented the possibility of a wealthy subscriber base. The New York Times had bought Gwinnett Daily News in 1987, but closed it in 1992 because it wasn't profitable. ${ }^{200}$ Other suburban dailies, such as the Gwinnett Daily Post and the Newnan Times-Herald, competed in the suburbs with the Journal and the Constitution. ${ }^{201}$

199. Jones, supra note $185, \S 1$, at 26.

200. See Kelvin Childs, Georgia Papers Fight Over Paid Circulation, EdIToR \& Publisher MAG., Feb. 28, 1998, at 10. at 22 .

201. See Barbara Z. Gyles, Atlanta Suburbs Spawn New Daily, Presstime, Dec. 1997, 


\section{Figure 21. Geographic Readership Distribution of the Journal and Constitution}

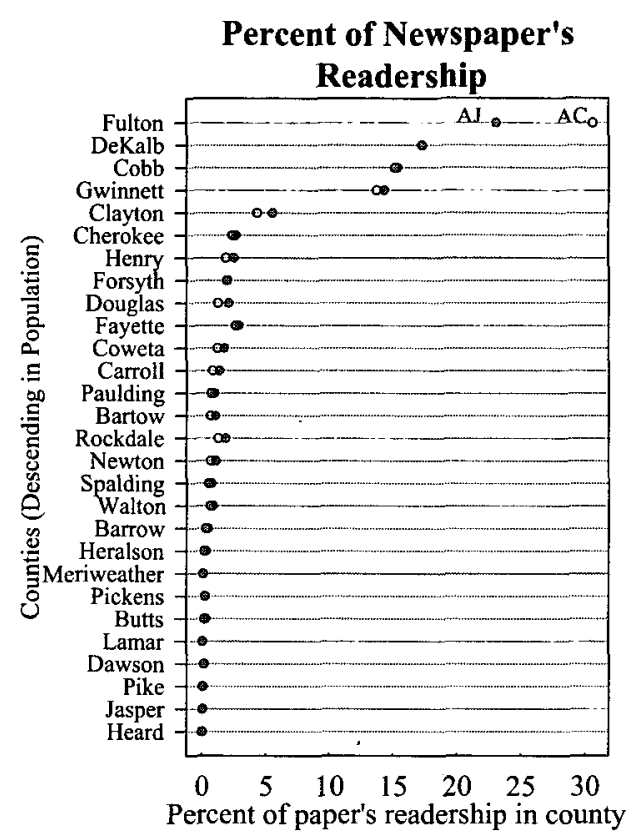

\section{Difference in Readership}

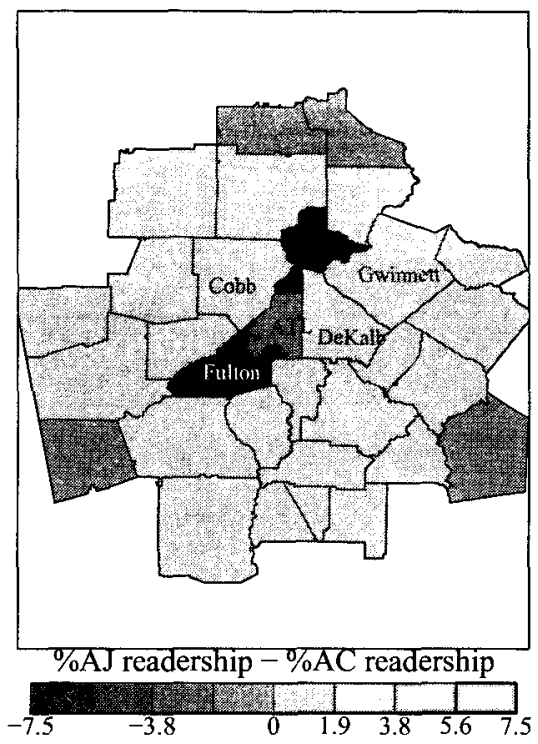

The left panel plots the percentage of each paper's readership falling in particular counties. Counties are in descending order of population, and percentages are averaged across the premerger period (1994-2001). Hollow circles represent the Constitution and solid dots represent the Journal. This panel shows that Fulton County, home to downtown Atlanta, accounts for the major subscriber difference between the papers. The right panel plots the difference in percentage readership between the Journal and the Constitution. The light white shading represents Atlanta. The relatively dark shading in Fulton county shows that while the Constitution draws a much larger proportion of its subscribers from close to downtown Atlanta, the Journal has relatively more subscribers in outlying (particularly wealthy) counties. Source: Census data and Audit Bureau of Circulations.

Figure 22 plots the circulation statistics for the six largest counties in the region by population. The top panels plot the raw circulation over the premerger period (in 1000s). Averaged over the premerger period, these counties comprised $78 \%$ and $84 \%$ of all Journal and Constitution subscribers, respectively, in the designated market area. The dashed lines represent the Journal and the solid lines represent the Constitution. The panels on the left keep the circulation fixed, while the panels on the right plot the difference between the Constitution and Journal, allowing the $y$-axes to float. The strongest evidence for substitution occurs in the most populous counties 
Figure 22. Readership Substitution in Largest Counties
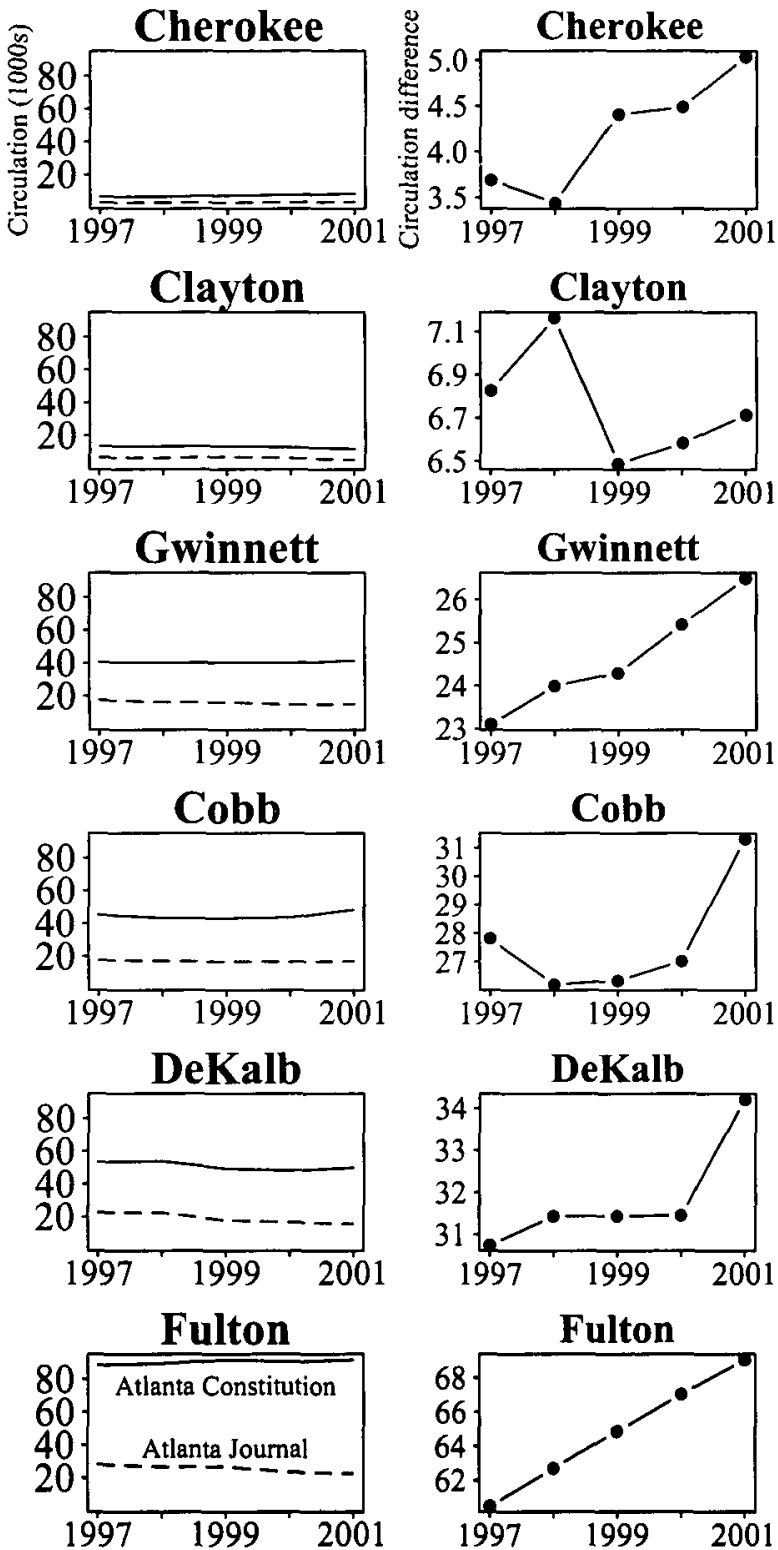

The left-side panels plot the raw circulation (in 1000s) for the Constitution (solid) and the Journal (dashed) over time for the six most populous counties around Atlanta. The right-side panels plot the circulation difference between the Constitution and the Journal over time. Upward trends provide strong evidence for Journal subscribers switching to the Constitution. 
(Fulton, DeKalb, Cobb, and Gwinnett). As the Journal lost subscribers, the Constitution gained. In Fulton, for example, the relationship was effectively one to one. While these counties include outlying suburbs such as Gwinnett, given that the core subscribers for both papers were from downtown Atlanta, these panels show that substitution was acute in the urban counties of Fulton and DeKalb.

\section{Viewpoint diversity in the face of convergence}

While we can't pin down the mechanism with much precision from the demographic and circulation data, we can say for sure that the papers diverged in the premerger period and that the Journal was in many ways failing.

One might infer from our dynamic viewpoint results that the postmerger position of the Journal-Constitution in between the Journal and the Constitution is robust evidence for the convergence hypothesis. Yet this inference may be mistaken for two reasons. First, as we showed above, the Journal and Constitution catered to different subscribers. While diametrically opposed viewpoints were represented on the pages of different newspapers, they may have segmented the market such that consumption didn't in fact expose individuals to diverse viewpoints.

Second, upon deeper investigation, we uncover a deeply fractured editorial board after the merger. (Control over the weekend editorials had already presented a struggle stemming back to the $1980 \mathrm{~s}$. $)^{202}$ Figure 23 plots results from our research into the editorial board of the papers. While the same number of people from the Journal and the Constitution remained after the merger, the figure shows that three original Journal members, Meyers, Dodd, and Oliver, left within two years. As one reader remarked, "Oliver's departure leaves just a single Republican, Jim Wooten, on the eight-member editorial board of the South's leading newspaper." ${ }^{203}$ The senior positions were allocated such that the Constitution's editorial page editor, Cynthia Tucker, headed the joint board, with Jim Wooten taking a subordinate position but retaining his thrice-a-week

202. See Eleanor Randolph, In Atlanta, Amending The Constitution; New Editor Seeks to Revive Newspapers, WASH. POST, July 15, 1988, at C1 ("Some readers believed for several months they could see the old balance between the two editorial pages shifting toward the more liberal Constitution. But the Journal, which like most afternoon dailies has been losing circulation, always had one edge-its editorial staff put out the Sunday opinion pages. On June 26[, 1988], the Constitution took over the Sunday editorial pages with an announcement by Kovach that the Constitution had 'become the dominant voice of the two publications.' He said giving the Sunday page to the Constitution staff was 'an effort to speak editorially with a clear and consistent voice." (italicization added)).

203. Brian J. Fenton, Letter to the Editor, ATLANTA J.-ConST., Jan. 15, 2003. 
Figure 23. Editorial Board Composition for the Journal and Constitution

\section{AJC: Editorial Board}

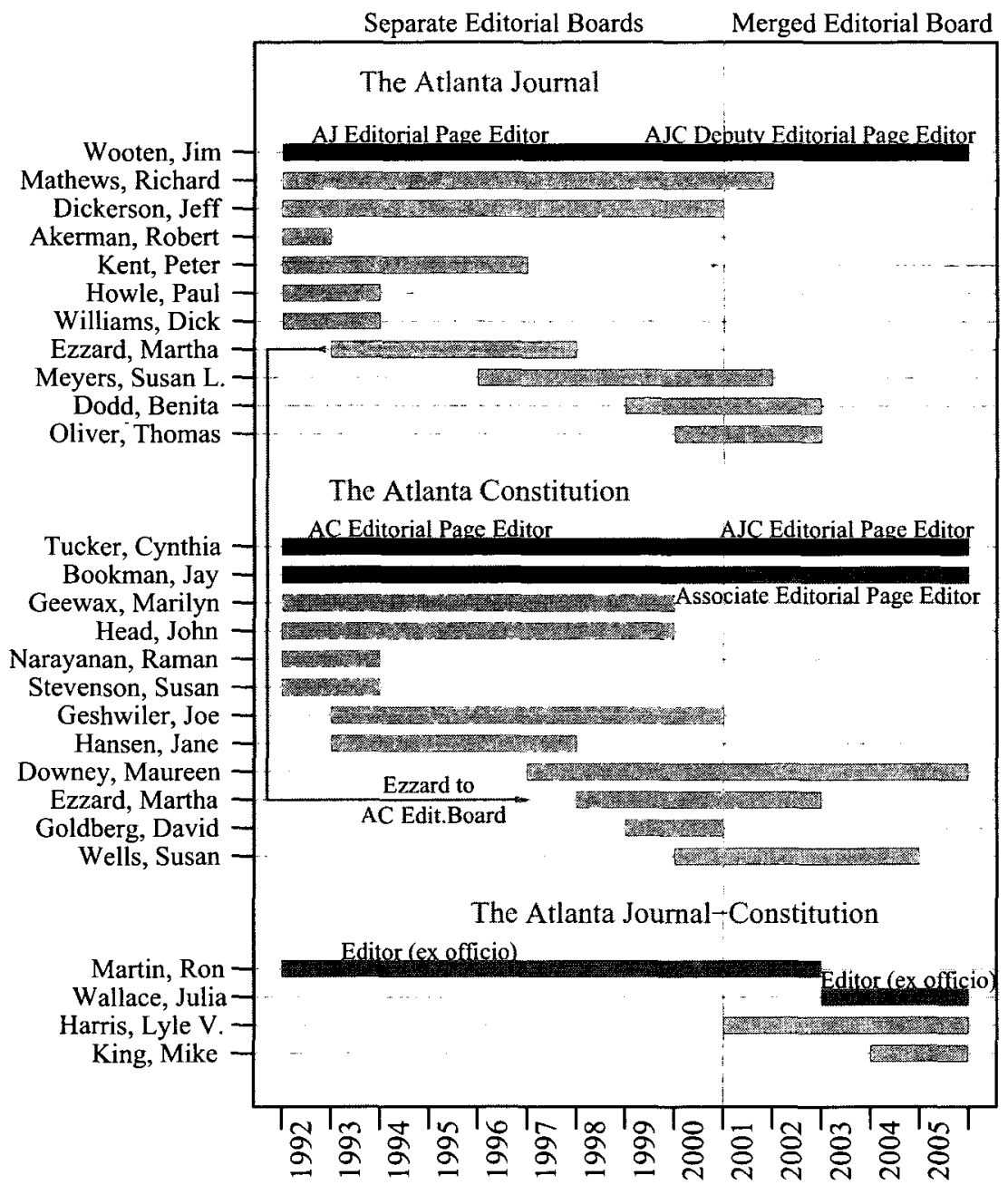

The top third of the panel depicts the Journal board, the middle the Constitution board, and the bottom those serving on the Journal-Constitution. While Bookman retains his original title of "Associate Editor" after the merger, Wooten assumes a newly created, higher, position as "Deputy Editor," effectively lowering Bookman's rank. The figure shows that the Constitution retains greater control of the merged board, with Tucker remaining on as editorial page editor, and a number of Journal editorial board members leaving shortly after the merger. 
column. ${ }^{204}$ Prior to the merger, Tucker had written only one individual column for the weekday edition of the Constitution on a Supreme Court decision. She wrote to defend the majority in Santa Fe Independent School District $v$. $D o e,{ }^{205}$ involving the question of whether student-led prayer before football games violated the Establishment Clause. The Constitution, despite Tucker's leadership, did not file an editorial, while the Journal wrote in favor of the minority. ${ }^{206}$ Tucker noted, "False prophets shall always be with us[]" and defended the majority "just in case those self-anointed prophets have persuaded you that the Supreme Court is on the side of Satan[]."207

Needless to say, the boards did not merge smoothly.

Even at the beginning, the cracks were beginning to show. In an unusual display of transparency, Tucker ominously announced the new editorial board, calling it "[a]rguably[] a [m]eeting of [m]inds" on the new pages: "We are a diverse group-urban and suburban, American-born and immigrant, soccer moms and empty nesters, liberals, conservatives and moderates. The diversity of ideology makes for lively - and occasionally lengthy-discussions around the conference table in the mornings." 208

The reference to lively and lengthy discussions no doubt referred to the difficulty of developing the newspaper's position, when previously the boards were diametrically opposed on a slew of issues. Even the lively and lengthy discussions didn't foster consensus.

Figure 6 shows that the editorials on Supreme Court decisions drop in the postmerger time period (although sample sizes are small). When it did write, the board did so tentatively. ${ }^{209}$ On the voucher case, ${ }^{210}$ it equivocated. Neither agreeing nor disagreeing with the Court, the board dwelled on the evidence of whether vouchers work (with a vague headline: "High court ruling doesn't mean vouchers will work"), what kinds of choices vouchers provide, and the neglect of public schools, never taking much of a position on each. ${ }^{211}$ Yet the editorial included a note: "For another perspective on this issue, see the next

204. Cynthia Tucker, Meet the Editorial Staff: Arguably, a Meeting of Minds, ATLANTA J.-CoNST., Dec. 30, 2001, at $1 \mathrm{~F}$ (announcing Wooten's position as associate editorial page editor and thrice-a-week column).

205. 530 U.S. 290 (2000).

206. Editorial, Sign of Hostility Toward Religion, ATLANTA J., June 21, 2000, at 14A.

207. Cynthia Tucker, Private Matter: Religion Belongs to All, Not Just Majority, ATLANTA CONST., June 21, 2000, at 14A.

208. Tucker, supra note 204, at $1 \mathrm{~F}$.

209. Cf. Kimberly Meltzer, Newspaper Editorial Boards and the Practice of Endorsing Candidates for Political Office in the United States, 8 JouRNALISM 83, 87 (2007) (discussing "impasses" over presidential endorsement in the Cleveland Plain Dealer, resulting in no endorsement).

210. Zelman v. Simmons-Harris, 536 U.S. 639 (2002).

211. Editorial, High Court Ruling Doesn't Mean Vouchers Will Work, ATLANTA J.CONST., June 28, 2002, at 19A. 
page, A20," referencing a column signed by Wooten. ${ }^{212}$ Similarly, writing about the Michigan affirmative action cases, ${ }^{213}$ the board wrote effusively about the Court's affirmation of the law school's program, ${ }^{214}$ but strangely managed to ignore entirely the companion decision striking down the undergraduate program. ${ }^{215}$ Again, the pages included a signed column to the contrary. ${ }^{216}$

The equivocal editorials contrast sharply with the premerger positions and suggest that the merged board faced considerable difficulties forging agreement on editorial positions. Individual members of the editorial board began to write for themselves and, in some cases, for the board as a whole.

Around 2006, the board formally decided to individually sign editorials. While still formally representing the consensus of the editorial board, each editorial would be signed by the author. ${ }^{217}$ In addition, just as in the voucher case, signed editorials began to make express reference to op-eds taking contrary positions on adjoining pages. ${ }^{218}$ To the best of our knowledge, the Journal-Constitution was the first major U.S. newspaper to adopt the practice of signed editorials. ${ }^{219}$

Table 2 presents a simple count of the types of pieces editorial board members have filed from 1994 to 2008 on Supreme Court opinions, collected

212. Jim Wooten, Op-Ed., Thinking Right: Dorsey, Vouchers, AtLanTa J.-Const., June 28,2002 , at $20 \mathrm{~A}$ (opining that the decision "means that no child should be kept prisoner in a non-performing public school").

213. Editorial, Court Ruling Affirms Need To Keep Affirmative Action, ATLANTA J.CONST., June 25, 2003, at 14A.

214. Grutter v. Bollinger, 539 U.S. 306 (2003).

215. Gratz v. Bollinger, 539 U.S. 244 (2003).

216. Vernadette Ramirez Broyles, Op-Ed., Ruling Won't Help Bridge Racial Gap, ATLANTA J.-CONST., June 25, 2003, at A15.

217. Angela Tuck, Wooten's Blog, Signed Editorials Encourage Lively Discussion, ATLANTA J.-CONST., June 10, 2006, at 11 A.

218. See, e.g., Maureen Downey, New Threat for Women, Atlanta J.-Const., Apr. 20, 2007, at A10 (stating "Maureen Downey, for the editorial board . . EQUAL TIME: For another perspective on this issue, see the next page, All."); Editorial, Employers Can Restrict Speech, ATLANTA J.-CoNST., June 5, 2006, at A13 ("This column is solicited to provide another viewpoint to an AJC editorial published today."); Editorial, Supreme Disapproval: Court's Ruling on Taking of Private Property Signals Need for Georgia To Protect Homeowners in State, ATLANTA J.-CONST., June 27, 2005, at A10 ("For another perspective on this issue, see the preceding page, A9").

219. See Howard Kurtz, Critiquing the Press: Live Online, WashIngtonPost.com, Apr. 9, 2007, available at 2007 WLNR 6893329 (Westlaw) ("[It] is true at virtually every newspaper in America [that the writers of the main column are not identified]; "[ $t$ ]he thinking is that the opinions are the consensus of the entire editorial board . ..."); cf. Paul Berton, Op-Ed., New Look Editorials a Sign of the Times, CALGARY SUN, Feb. 13, 2007, at 14 (announcing a shift in Canadian Sun Media newspapers toward signed editorials). The Chicago Sun-Times adopted signed editorials several years later in 2007. See Cheryl L. Reed, Our Progressive Voice of Reason and Passion Reflects City's Strength, CHI. SUNTIMES, July 15,2007 , at B6. 
Table 2. Distribution of Editorial Positions on Supreme Court Cases for All Types of Opinion Pieces in the Atlanta Journal-Constitution Papers, 1994-2008

\begin{tabular}{|c|c|c|c|}
\hline Masthead & Type & Byline & Number \\
\hline \multirow{5}{*}{$\begin{array}{r}\text { Weekday Atlanta Journal } \\
\text { (1994-2001) }\end{array}$} & Unsigned editorial & Full board & 35 \\
\hline & Op-ed & Dickerson & 1 \\
\hline & & Ezzard & 1 \\
\hline & & Matthews & 1 \\
\hline & & Wooten & 2 \\
\hline \multirow{3}{*}{$\begin{array}{r}\text { Weekday Atlanta } \\
\text { Constitution } \\
(1994-2001)\end{array}$} & Unsigned editorial & Full board & 28 \\
\hline & Op-ed & Head & 1 \\
\hline & & Tucker & 1 \\
\hline \multirow{3}{*}{$\begin{array}{r}\text { Weekend Atlanta Journal } \\
\text { Constitution } \\
(1994-2001)\end{array}$} & Unsigned editorial & Full board & 5 \\
\hline & Op-ed & Geshwiler & 2 \\
\hline & & Tucker & 2 \\
\hline \multirow{7}{*}{$\begin{array}{r}\text { Full week Atlanta Journal } \\
\text { Constitution } \\
(2001-2008)\end{array}$} & Unsigned editorial & Full board & 18 \\
\hline & Signed editorial & Downey & 1 \\
\hline & & Harris & 2 \\
\hline & Op-ed & Bookman & 1 \\
\hline & & King & 1 \\
\hline & & Tucker & 3 \\
\hline & & Wooten & 7 \\
\hline
\end{tabular}

in the same way that we collected editorials. In the premerger period, most positions were reserved for unsigned editorials, as is the predominant practice for mainstream papers. While the Journal and Constitution filed 63 editorials from 1994 to 2001, the Journal-Constitution filed only 18 from 2001 to 2008. Individual board members picked up that slack. Writing 11 op-ed pieces from 1994 to 2001 for two newspapers, board members contributed 15 signed editorials and op-eds from 2001 to 2008.

Even though the sample sizes are small, one test of the fractionalized board is to compare Tucker and Wooten writing in their individual capacity to the editorial board positions. To assess this, Figure 24 plots simple results from a static measurement model that includes viewpoint estimates for Tucker and Wooten. The static viewpoints of the Constitution, Journal, and JournalConstitution are plotted in the first three rows for reference. As these viewpoints are static, the Journal-Constitution appears much closer to the Constitution's position, which is consistent with the idea that the board was tilted toward the Constitution staff. It is clear that Wooten and Tucker correspond to the Journal and Constitution, respectively, highlighting the difficulty of consensus on the merged board. 
Figure 24. Viewpoint Estimates for Cynthia Tucker and Jim Wooten

Viewpoints for Editorials and Op-Eds

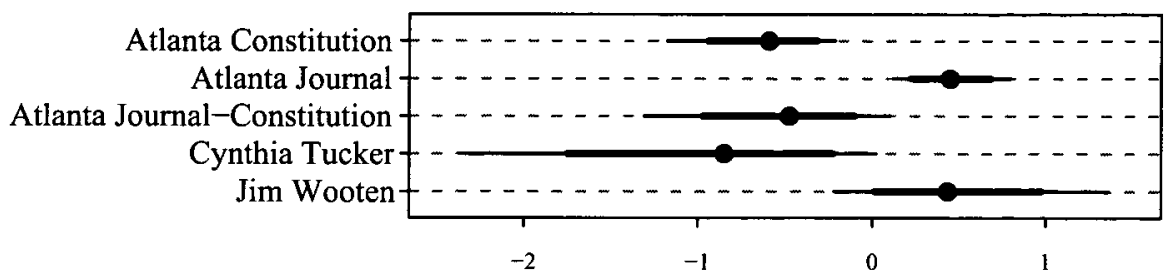

Viewpoints for the Journal, Constitution, and Journal-Constitution are plotted for reference. This panel shows that Tucker and Wooten roughly correspond to the premerger editorial boards.

The Atlanta case fundamentally challenges even the most tautological "more-voices-is-better" version of the convergence hypothesis, striking at the heart of conceptions of diversity. To the degree that the demographic patterns suggest separation between the Journal and the Constitution, as a public policy matter would we prefer a single outlet that forces many different voices to struggle for consensus or two outlets with widely diverging views? In other words, how should viewpoint diversity account for intra- or inter-outlet diversity? The right answer depends in many senses on the degree of customer separation between the outlets, and the consensus process within the outlet.

Wooten privileges inter-outlet diversity: "In Wooten's opinion, AJC endorsements were more useful when there were competing editorial voices, offered by The Atlanta Journal and The Atlanta Constitution before the boards merged in 2001."220 Further, Wooten notes, “When there is one newspaper, one voice doing that, you risk alienating large segments of voters who may not believe in the core philosophical beliefs behind our endorsements." 221 On the other hand, even after the merger one reporter noted that "[i]t's unlikely that our editorial board is going to change its political ideology.... The people who make up the board are passionate about their beliefs, both liberal and conservative. The AJC's three opinion pages offer a broad spectrum of views." 222

220. Angela Tuck, Political Endorsements More than Snap Judgments, ATLANTA J,CONST., Nov. 4, 2006, at A15.

221. Id.

222. Angela Tuck, Circulation Not a Full Measure of Newspapers' Reach, ATLANTA J.-Const., Nov. 12, 2005, at 9A. 
Figure 25. Circulation (in 10,000s) for the New York Times (left) and Boston Globe (right)
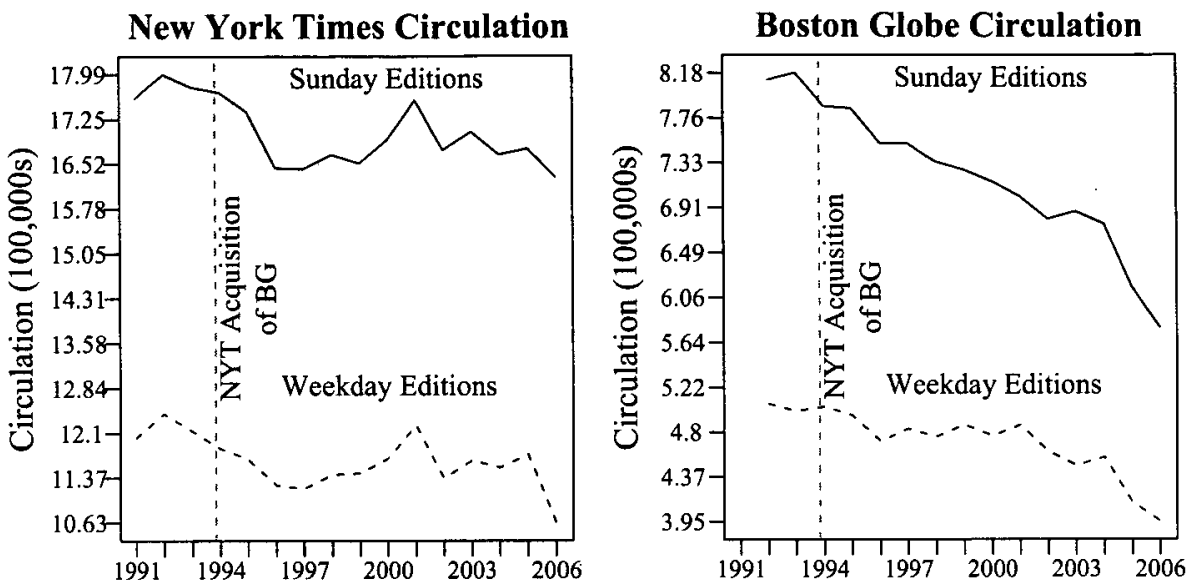

The Sunday editions are plotted in solid lines and weekday editions in dashed lines. The vertical line corresponds to the acquisition of the Globe. This figure shows that while Times subscriptions have fluctuated downwards, the drop in circulation has been much steeper for the Globe.

\section{B. New York Times-Boston Globe}

On October 1, 1993 the New York Times Company acquired the Boston Globe. ${ }^{223}$ A buyout of the Globe had been in the making for some time with Globe chairman William O. Taylor shopping for buyers during the previous few years. ${ }^{224}$ In large part, shopping had been induced by the impending expiration of the Taylor and Jordan family trusts, which held controlling interests in the Globe. ${ }^{225}$ The motives of the New York Times Company were varied: the company saw itself set to lose readership as the result of demographic shifts in New York City and looked to the Globe as an undervalued commodity that would help to diversify the Times Company's media holdings. ${ }^{226}$

223. See The Boston Globe: Company History, http://bostonglobe.com/aboutus/ about.aspx?id=7096 (last visited Nov. 14, 2008).

224. See Mark Maremont, All the News That's Fit to Buy, Bus. WK., June 21, 1993, at 40.

225. Id.; see also Glaberson, supra note 166 , at $1 \mathrm{~A}$.

226. Maremont, supra note 224, at 40; see also John H. Kennedy \& Aaron Zitner, Shareholders OK Affiliated, Times Merger, BosTON GLOBE, Sept. 29, 1993, at 43. 
Figure 26. Circulation (in 10,000s) for the Times (black) and Globe (gray) for Sunday (solid) and Weekday (dashed) Editions
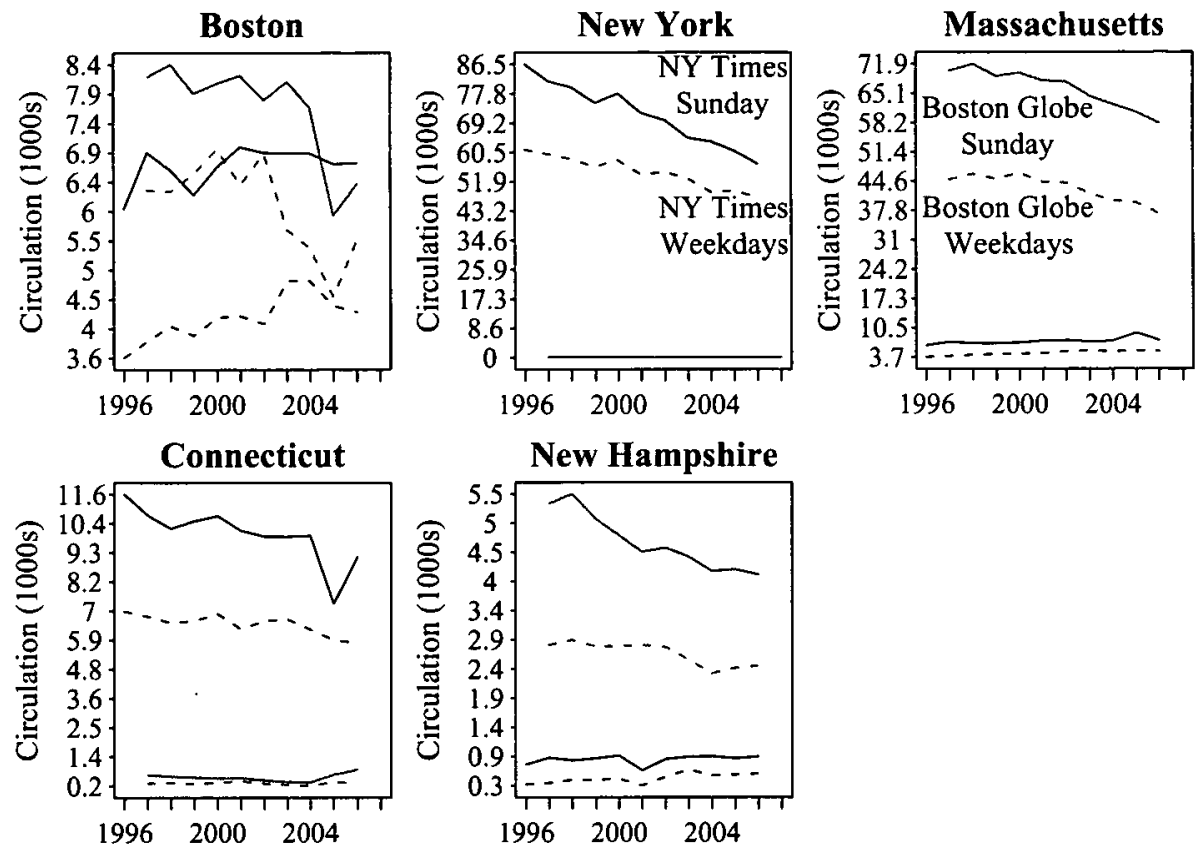

The top-left panel is for Boston, while the other four panels are statewide. (New York City is unavailable due to a reporting change.) This figure shows that in Boston, the Globe and Times compete for readership. Convergence between each of the pairs of lines suggests evidence for substitution. The right four panels show that on a statewide basis, competition between the two papers is not substantial.

A large part of the deal-at least as far as reported publicly-was a guarantee of editorial independence for the Globe, on which William Taylor, publisher of the Globe and chairman of Globe's parent Affiliated Publications, insisted. 227 The Globe reported that it would retain "complete editorial independence under its current management team for at least five years, after which local control will be reviewed and possibly extended."228

One might think that the most promising explanation for the sharp rightward shift of the Globe immediately following the acquisition lies in the economic incentives facing the Globe, its parent company, or both. On the one

227. See Maremont, supra note 224, at 40; see also George Garneau, Shareholders $O K$ New York Times, Boston Globe Deal, EdTrOR \& PUBlisher, Oct. 2, 1993, at 21 ("Under the sale agreement, the Globe gets as much autonomy as the Times.").

228. Kennedy \& Zitner, supra note 226 , at 43. 
hand, the Globe's circulation had been dwindling before the acquisition ${ }^{229}$ and its advertising revenues had taken a similar hit. ${ }^{230} \mathrm{~A}$ shift in viewpoint might have been an effort to attract a broader audience. If this were the case, however, we would expect to see the viewpoint maintained if the strategy paid off by attracting additional subscribers. Inferring the Globe's circulation in the counterfactual of no acquisition is difficult, but Figure 25 shows that the Globe has continued to hemorrhage subscribers to the present day. On the other hand, one might think that the Globe's move to the right was orchestrated by the Times Company so that there would be a more natural market niche for the leftward-leaning Times. If so, we would expect the Globe and Times to compete in some meaningful way in the Boston and Massachusetts markets. Figure 26 presents circulation figures of the Globe and the Times in six markets. Only in the Boston market is there any evidence that the papers might serve as substitutes for a large fraction of consumers. In other markets one of the two papers clearly dominates the other in terms of circulation. While this evidence is extremely tentative, and supports diversification with respect to Boston, overall there seems to be little to support the idea that purposive diversification accounts for the viewpoint shift of the Globe.

While monopoly diversification does not appear to have been the driving force behind the Globe's shift to the right postacquisition, the most plausible reason for the rightward shift was the likely exogenous, i.e., independent, appointment of H.D.S. "David" Greenway as editorial page editor in 1994, announced in June 1993 (just prior to the acquisition). ${ }^{231}$ (If the Times acquired the Globe knowing that it would turn more conservative, that might be observationally indistinguishable from monopoly diversification.) Greenway was appointed at least in part because of rifts between the more moderate William Taylor and the-at the time-more liberal editorial board. ${ }^{232}$ When Martin Nolan left the post after a disagreement with Taylor over the paper's endorsement for the 1990 gubernatorial race, Kirk Scharfenberg took over. ${ }^{233}$ Scharfenberg passed away not long after that. ${ }^{234} \mathrm{He}$ was succeeded by Loretta

229. See Jerry Ackerman, Circulation of Boston Newspapers Shows Decline, BosToN GloBE, Oct. 25, 1994, at 41; fig.25 (plotting data from the Audit Bureau of Circulations).

230. Maremont, supra note 224, at 40.

231. See Charles Stein, H.D.S. Greenway Will Become Globe's Editorial Page Editor, Boston Globe, June 2, 1993, at 39; see also Dan Kennedy, Editorial Privilege: New Globe Publisher Richard Gilman Faces His First Big Test: Choosing Someone to Lead the Paper's Opinion Pages, BOSTON PHOENIX, Apr. 13, 2000, available at http://www.bostonphoenix.com/archive/features/00/04/13/DON_T_QUOTE_ME.html ("By moving the editorial page closer to the political center on foreign, national, and local issues, [Greenway] made the page relevant in a way that it hadn't been for some years. In particular, the Globe provided crucial support to former governor Bill Weld and to legislative leaders as they took steps to cut taxes, close a gaping budget deficit, and improve the business climate.").

232. Kennedy, supra note 231 .

233. Id.

234. Id. 
McLaughlin who was forced to step down soon afterwards because of the Globe's mandatory retirement policy. ${ }^{235}$ At this point, Greenway was brought in and he promptly began staking out more conservative positions than had previously been espoused by the Globe's editorial page. ${ }^{236}$ Indeed, upon his retirement, he openly acknowledged trying "to be a little more fiscally conservative than the page had been in the past."237 Greenway was forced to retire when he reached the Globe's mandatory retirement age of 65 in 2000, a policy in place prior to the acquisition. ${ }^{238}$ Figure 27 depicts the career trajectories of members of the Globe editorial board during our observation period.

To understand the dynamics of the Times and for comparability, we provide an analogous figure for the Times in Figure 28. Unlike the Globe, which experienced clustered turnover around the time of the acquisition, the Times's editorial board has experienced more gradual turnover, in large part because of its much larger size. For much of the period that the Times shifted to the left, Howell Raines served as the editor. As described by Gail Collins, "One of the things Howell did was open up the page to the voices of the board members, so there's that opportunity to do regular editorial writing and also to write in my own voice." ${ }^{239}$ This democratization may explain how the gradual turnover of the general membership could be directly translated into editorial viewpoints.

Although limited, our examination of the Globe acquisition seems to caution against an interpretation of the divergence of the two papers as evidence for monopoly diversification. If the editorial independence guarantee was a cover, which seems hard to believe, it's possible that the Times exerted editorial pressure in a number of ways we have not observed. ${ }^{240}$ Overall, the shift between the papers appears best explained by plausibly exogenous shifts (i.e., death and mandatory retirement) on the editorial board.

235. Id.

236. Id.

237. Richard Kindleberger, Renee Loth Named Globe's Editorial Page Editor to Succeed H.D.S. Greenway on May 15, Boston GlOBE, May 5, 2000, at C1.

238. Id.

239. James Barron, Gail Collins Chosen to Head the Times's Editorial Board, N.Y. Times, June 22, 2001, at A14.

240. For example, the Times fired Ben Taylor, William Taylor's cousin, as publisher of the Globe in 1999, replacing him with Richard Gilman. See Kathryn S. Wenner, Globe Gets a New Publisher, AM. J. REv., Sept. 1999, at 91. The move was widely seen as tightening the Times's control of the Globe. See Mark Lisheron, Taking Command, AM. J. REV., Apr. 2002, at 34 ("When the Times Co. replaced the much loved Taylor with Gilman six years later, editors and reporters felt as though they were losing a patron and a friend."). Although it suggests a potential mechanism of control, no similar evidence exists for the acquisition period. 
Figure 27. Editorial Board Membership of the Globe

\section{BG: Editorial Board}

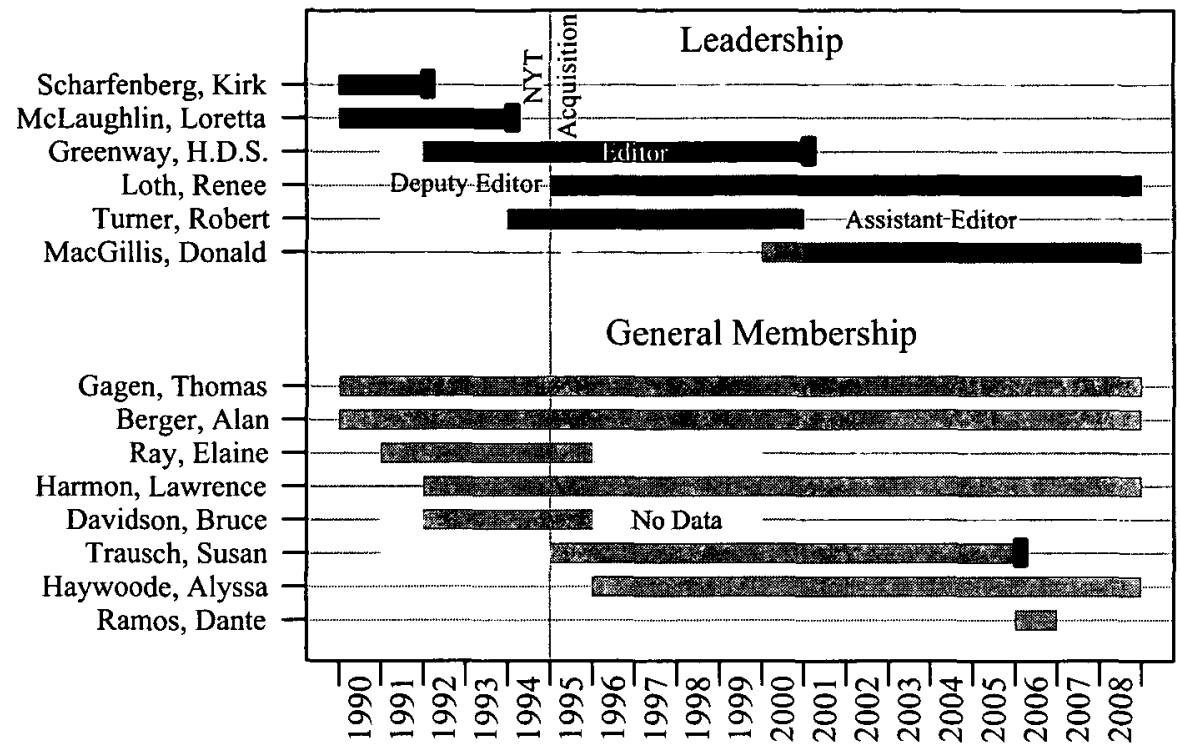

The leadership turned over rapidly right around the time of acquisition, due to the death and mandatory retirement (marked with thick black end caps) of

Scharfenberg and McLaughlin.

\section{CONCLUSION: POLICY IMPLICATIONS}

At the most general level, our Article demonstrates the promise of statistical methodology in addressing unique problems faced by empirical legal studies. ${ }^{241}$ Capitalizing on and adapting methods first developed in psychometrics allows us to unlock one the central puzzles in communications law. The development of a subfield in empirical legal methodology would similarly unlock longstanding puzzles in other areas of the law, and may be a particularly fruitful avenue to aid regulatory decision making.

Our results challenge one of the basic empirical assumptions of federal media ownership regulations. Neither convergence nor divergence inexorably follows from consolidation. We thereby sketch several policy implications of

241. See Daniel E. Ho, Affirmative Action's Affirmative Actions: A Reply to Sander, 114 YALE L.J. 2011, 2016 (2005) (noting that "[t]ools for analysis have been developed across academic fields" to facilitate empirical evaluation "with more credible and theoretically consistent assumptions"). 
Figure 28. Editorial Board Membership for the Times

NYT: Editorial Board

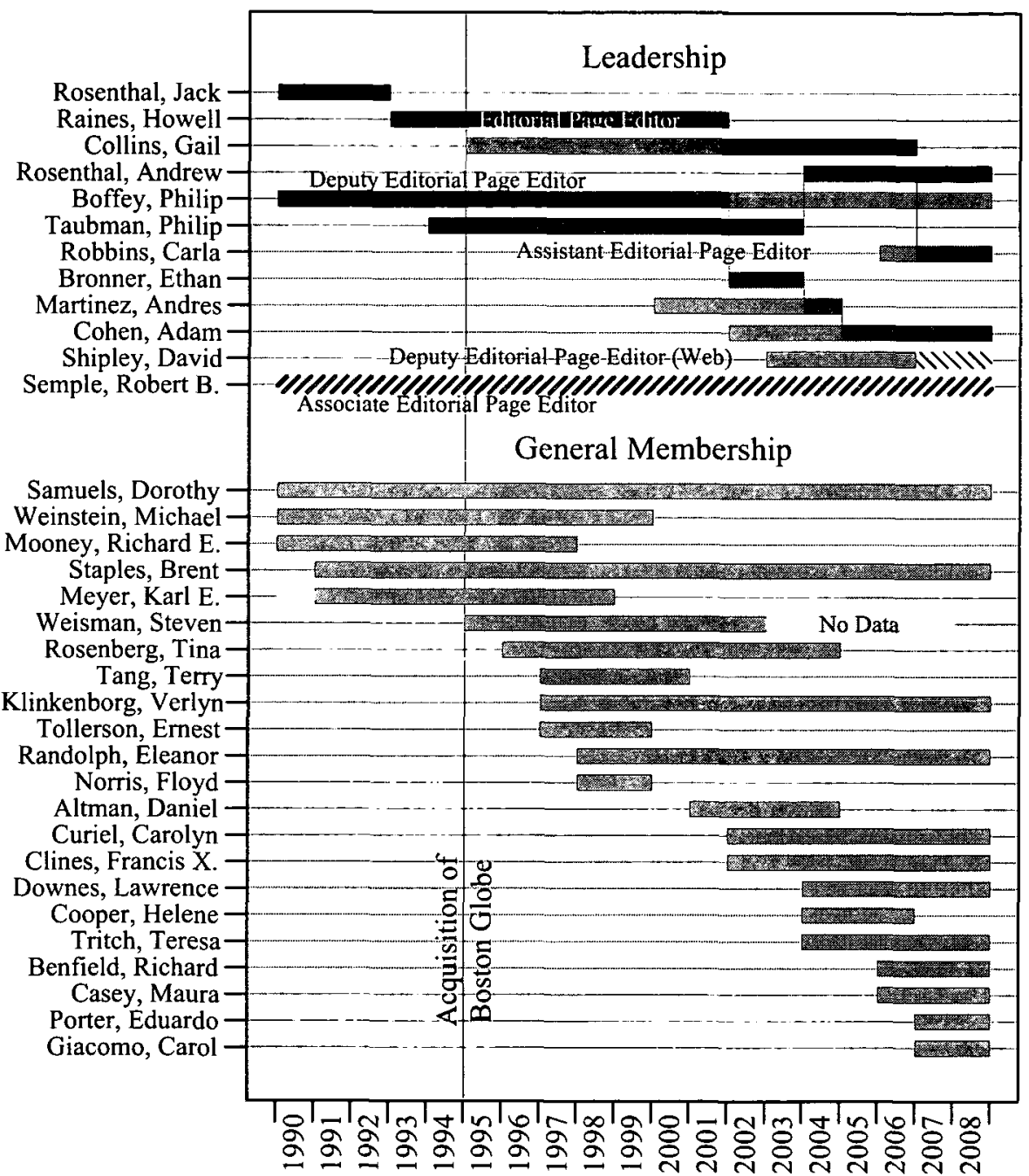

This figure depicts relatively gradual turnover, potentially accounting for the

Times's gradual and relatively constant shift to the left from 1990-2004.

our work. Unlike some approaches, we draw out these policy implications not in spite of the difficulties of drawing robust empirical inferences, but precisely because of them.

First, the prevailing interpretation of the 1996 Telecommunications Act may have set up the Commission to fail in fulfilling its mandate for empirical justification. As outlined in Part I, the biennial review provision of the Act has been read to mandate empirical justification for the Commission's ownership 
regulations as furthering the public interest. At the same time, the courts have read the 1996 Act to mean that the Commission must deregulate if it cannot provide such evidence. In the wake of the Act, the Commission initially adopted a type of precautionary approach in its biennial review. Before proposing changes, it sought to assess the impact of the 1996 Act's reforms, such as the raising of the national television audience cap to $35 \%$. The courts, however, interpreted the statute to force the Commission's hand, finding that "[t]he Commission's wait-and-see approach cannot be squared with its statutory mandate promptly... to 'repeal or modify' any rule that is not 'necessary in the public interest.",242

Yet repealing the rules would exacerbate the already profound difficulties of empirical justification about the effects of a rule. If anything, our Article demonstrates the inherent difficulties of assessing the effects of consolidation on viewpoint diversity. Wholesale changes make it impossible to attribute effects to particular policy levers. We therefore argue that the joint mandates for (a) empirical justification of the rules as serving the public interest, and (b) repeal or modification in the absence of evidence weigh in favor of incremental modification under the Act. Moderate reform would both facilitate empirical justification and meet the 1996 Act's "modification" mandate. Otherwise, the call for empirical justification may ring hollow.

One of the ironies here may be that the more erratically the Commission acts in terms of modifying its regulations, the more it facilitates the empirical justification for its rules. If the Commission were to flip a coin to approve each waiver, reliable evaluation of the waiver rules may become eminently feasible. We of course don't suggest that the Commission randomly modify its rules, but program evaluation and field experiments in collaboration with research groups may prove particularly instructive for developing methods to ground the Commission's public-interest findings. Mexico, for example, has engaged in a large-scale field experiment in universal health care. ${ }^{243}$ While health care is ultimately mandated for the entire country, as a practical matter it has to be rolled out in more limited ways. This inherent resource constraint provides room for policymakers to design reliable field experiments to assess the operation of universal health care. Similarly, reform may be joined with reliable policy evaluation in the communications context (e.g., randomizing cable broadband access to test for the effects of a universal broadband policy on exposure to different viewpoints; or data collection on pre- and postacquisition consumption behavior).

Second, our results point to the complexity of consolidation, and thereby prospectively inform the Commission's policy towards outlet combinations.

242. Fox Television Stations, Inc. v. FCC (Fox I), 280 F.3d 1027, 1042 (D.C. Cir.), modified on reh'g, 293 F.3d 537 (D.C. Cir. 2002).

243. See Gary King et al., A 'Politically Robust' Experimental Design for Public Policy Evaluation, with Application to the Mexican Universal Health Insurance Program, 26 J. POL'Y ANALYSIS \& MGMT. 479 (2007). 
Contrary to extant accounts, we detect stability, convergence, and divergence, representing considerable heterogeneity across five case studies. Most existing studies of the effects of consolidation tend to assume constancy of effects, and may therefore be prone to draw inaccurate conclusions. Taking into account the heterogeneity of effects will prove vital to reliable assessment of the convergence hypothesis. The complexity of our results informs several crucial practical criteria for the Commission to consider in developing its waiver policy for outlet combinations. First, our research points to the potentially critical role of editorial-independence policies. In its analysis of editorial independence the Commission should place particular weight on editorial policies and guarantees, such as those between the Times and the Globe. ${ }^{244}$ Consolidation may be significantly less likely to lead to convergence if critical features of editorial independence exist. Second, our analysis shows that editorial viewpoints track closely the personalities, leadership, and organizational structure of the editorial board. The Commission should therefore focus on personnel and structural reorganizations involved in waiver applications. This would place on firmer ground previous approaches of analyzing whether proposed waivers serve the public interest. ${ }^{245}$ Our work also points to more complicated dynamics, such as (a) a critical distinction between outlet mergers and acquisitions - the former at the very least tautologically eliminating one voice (notwithstanding the explosion of voices we see with individually signed editorials in the Atlanta Journal-Constitution), and (b) the potential role of employment terms (e.g., the Globe's mandatory retirement policy) in preventing entrenchment and promoting intertemporal diversity of viewpoints.

To conclude, in this Article we have placed the empirical study of viewpoint diversity and the convergence hypothesis on firm empirical footing, answering the call of recent shifts in media law. At the same time, we have shown the fragility of empirical research in viewpoint diversity and the increasing tension between the empirical turn in the law and the objectives of existing ownership regulations. One of the promises of our measurement approach is that it inductively defines what we mean by viewpoint diversity. It concretizes questions of what exactly the Commission means when it focuses on so-called "local diversity." For example, is an editorial supporting a local political candidate-but unopposed by any other editorial because the newspaper is the only one operating in the district-evidence of local diversity? How much do we value editorializing versus diversity in news reporting? On

244. See Quadrennial Review, supra note 12, I 71 (describing features leading to independent editorial decisions for cross-owned television-broadcast entities).

245. See, e.g., In re Shareholders of Tribune Co., 22 F.C.C.R. 21,266, 21,277-78 (2007) (granting permanent waiver to Chicago Tribune-WGN television-WGN radio combination, based on "the myriad public interest benefits that have resulted" and the conclusion that "any detriment to diversity caused by the common ownership is negligible given the nature of the market"). 
remand from the Third Circuit, the Commission has retained a fairly pluralistic approach to measurements: "[T]he record does not reveal any 'silver bullet' formula .... [but] in future adjudicative proceedings... parties are free to point to any metric of their choosing ...."246 Although no silver bullet, we've offered one such metric that critically informs the country's media policy.

246. Quadrennial Review, supra note 12, \73. 


\section{APPENDIX}

\section{A. Editorial Data Collection}

To collect every editorial on the Supreme Court, we started with the judicial vote matrices of 495 cases from the 1994-2004 Terms and 691 cases from 1988-1993 Terms, which contain case citations, votes of the Justices (affirming or reversing the lower court), and the Term. We randomly ordered the cases to abate any systematic coding differences from research assistants. For each case, we searched within a ten-to-fourteen day window after a decision was handed down to verify whether an editorial was written. We coded an editorial as " 1 " if the newspaper agreed with the position of majority on the merits of the case, as " 0 " if the newspaper agreed with the position of the minority on the merits, and as "missing" if no position on the merits was discernible from the editorial or if no editorial was written. Editorials taking positions on multiple cases were included, as long as the positions were sufficiently clear. With a team of over ten research assistants, the process took roughly eight months to complete.

\section{B. Editorial Board Data Collection}

\section{Atlanta Journal-Constitution}

We collected the names and titles of current editorial board members of the Atlanta Journal-Constitution from its masthead, which is printed on the opinion page of the Sunday edition, and occasionally presented in the weekday opinion sections. Membership back to 2002 was verified in this manner via microfilm. The Journal and Constitution did not follow the same masthead convention, and Maureen Downey, a current editorial board member of the JournalConstitution (and previously of the Constitution), provided additional names of members in an interview. To verify terms of service, we searched each editorial board member in Lexis. Bylines of the search results provided additional editorial board member names. Lexis stores editorial bylines in largely nonuniform ways, such that these searches would sometimes return entire editorial board listings, which helped research by providing a snapshot of the editorial board at that moment in time.

\section{Boston Globe}

Current names and titles of Boston Globe editorial board members were obtained from the Boston Globe website. Biographic information published on 
each editorial board member was used to estimate the editorial board composition over time. As in the case of the Atlanta Journal-Constitution, each current member's name was searched through Lexis's archive of previous Globe articles. The searches revealed multiple editorial board appointment announcements, ${ }^{247}$ which facilitated tracking the ranks of the board members and locating names of past board members. Finally, Internet searches for all member names were conducted, yielding analyses, ${ }^{248} \mathrm{CVs}$, and other biographic information that provided service dates for many board members.

\section{New York Times}

Names and titles of current New York Times editorial board members were obtained from the Times's website. Biographic information presented there was used to project these members back in time. Searching Lexis's archive of Times articles using these board members' names revealed announcements of leadership changes as well as some member appointments. ${ }^{249}$ Additional library and online searches for biographical information were used to eliminate uncertainty about service dates.

\section{Dynamic Item-Response Theoretic Model}

In this Subpart we describe the statistical model used to estimate newspaper viewpoints. Let $t=1, \ldots, T$ index Terms of the Court. $K$ denotes the set of all cases before the Court and $K_{t}$ denotes the set of cases decided in Term $t$. Similarly, let $J$ and $N$ denote the set of Justices and newspapers respectively with $J_{k}$ and $N_{k}$ representing the set of Justices who participated in case $k$ and the set of newspapers writing editorials on case $k$ respectively.

247. See Jerry Ackerman, Turner Is New Deputy Editorial Page Editor, BosToN Globe, July 11, 2000, at E7; Globe Appoints 2 to Editorial Pages, Boston Globe, Nov. 16, 1993, at 45; Globe Names Deputy Editor, BostoN GLOBE, Nov. 28, 1990, at 29; Mark Jurkowitz, Op-Ed., Whose Opinion Is It, Anyway?, Boston GloBE, Mar. 6, 1995, at 11; Kindleberger, supra note 237, at $\mathrm{Cl}$; Brian McGrory, They Made Us Think and Cry, BosToN GLOBE, Dec. 23, 2005, at B1; Stein, supra note 231, at 39.

248. See, e.g., Kennedy, supra note 231.

249. See Barron, supra note 239, at 14; David Carr, The Times Names a New Chief of Its Bureau in Washington, N.Y. TIMES, Aug. 7, 2003, at A21; Editorial Page of Times Gets a New Deputy, N.Y. Times, Aug. 8, 2003, at A15; The Times Appoints Three Editors to Major Posts, N.Y. TImes, Sept. 12, 1992, at 19; Times Names Deputy Editor for Editorials, N.Y. TIMEs, Aug. 2, 2001, at A17; Two Appointed Deputy Editors for Editorial Page of the Times, N.Y. Times, Dec. 20, 2006, at A20. 
The observed data consist of the votes of the Justices (denoted $Y$ ) and the editorial positions of the newspapers (denoted $\mathrm{X}$ ). An element of $\mathrm{Y}$ is coded as:

$$
y_{j k}= \begin{cases}0 & \text { if } j \text { is in the minority on case } k \\ 1 & \text { if } j \text { is in the majority on case } k \\ \text { missing } & \text { if } j \text { did not vote on case } k\end{cases}
$$

Elements of $\mathrm{X}$ are similarly coded:

$$
x_{n k}= \begin{cases}0 & \text { if } n \text { clearly agreed with the minority on case } k \\ 1 & \text { if } n \text { clearly agreed with the majority on case } k \\ \text { missing } & \text { if } n \text { did not take a clear position on case } k\end{cases}
$$

The sampling density for the model is given by:

$$
\begin{aligned}
p\left(\mathbf{Y}, \mathbf{X} \mid \alpha, \beta, \theta, \phi, \tau^{2}\right)=\prod_{t=1}^{T} \prod_{k \in K_{t}} & \left\{\prod_{j \in J_{k}} \Phi\left(-\alpha_{k}+\beta_{k} \theta_{j t}\right)^{y_{j k}}\left[1-\Phi\left(-\alpha_{k}+\beta_{k} \theta_{j t}\right)\right]^{1-y_{j k}}\right\} \times \\
& \left\{\prod_{n \in N_{k}} \Phi\left(-\alpha_{k}+\beta_{k} \phi_{n t}\right)^{x_{n k}}\left[1-\Phi\left(-\alpha_{k}+\beta_{k} \phi_{n t}\right)\right]^{1-x_{n k}}\right\} .
\end{aligned}
$$

Here $\theta_{j t}$ represents the ideological position of Justice $j$ in Term $t$ and $\phi_{n t}$ represents the viewpoint of newspaper $n$ in Term $t$. Note that because the case parameters $\left(\alpha_{k}, \beta_{k}\right)$ are constant across both the votes and the editorials on case $k$, the newspaper viewpoints are comparable to the ideological locations of the Justices. $\alpha_{k}$ controls the expected number of members of the Court who find themselves in the minority, while $\beta_{k}$ controls the extent to which observed voting patterns can be captured by the latent viewpoints.

To complete the specification of the model, we assume prior distributions for the model parameters and summarize the posterior distribution using Markov chain Monte Carlo methods. We assume that $\left(\alpha_{k}, \beta_{k}\right)$ follow independent bivariate normal distributions with mean 0 and variance 5 and 0 covariance for each $k$. We assume that a priori the ideal points and viewpoints follow random walks in time:

$$
\begin{aligned}
& \theta_{j t} \sim N\left(\theta_{j t-1}, \tau_{j}^{2}\right) \\
& \phi_{n t} \sim N\left(\phi_{n t-1}, \tau_{n}^{2}\right)
\end{aligned}
$$

Here $\tau_{j}^{2}$ and $\tau_{n}^{2}$ act as smoothing parameters in that values close to 0 result in ideal point/viewpoint sequences that are essentially constant over time, while values that approach $\infty$ imply that $\theta_{j t}$ is estimated essentially independently of 
$\theta_{j s}$ for $s \neq t$ and similarly for $\phi_{n t}$. We estimate each $\tau_{j}^{2}$ and $\tau_{n}^{2}$, assuming $a$ priori that $\tau_{j}^{2} \sim$ InverseGamma $(5,1)$ for all $j$ and $\tau_{n}^{2} \sim$ InverseGamma $(5,1)$ for all $n$. The full conditional distribution for this parameter follows directly from the conditionally Gaussian nature of the model and the semi-conjugate inverse gamma prior.

Several identification strategies are possible with this model. These include: holding constant two newspaper viewpoints, holding constant the ideal points of two Justices, putting inequality constraints on two newspaper viewpoints together with a proper prior distribution for the viewpoints, putting inequality constraints on the ideal points of two Justices together with a proper prior distribution for the ideal points, and combinations of the above. Implementing each of these approaches, we found that the results remained essentially identical. The presented are based on a model in which the prior means and variances for the 1988 Term Justice-specific ideal points are set equal to the associated posterior means from the analysis of Martin and Quinn, ${ }^{250}$ all other initial ideal points/viewpoints are assumed to be drawn from a standard normal distribution, and Justice Stevens is forced to always be to the left of 0 and Justice Scalia is forced to always be to the right of 0 . As noted above, such a prior distribution slightly biases our results toward finding homogeneous viewpoints since all newspaper viewpoints are shrunk slightly back toward 0 .

250. See Andrew D. Martin \& Kevin M. Quinn, Martin-Quinn Scores: Project Description, http://mqscores.wustl.edu/ (last visited Feb. 9, 2009). 